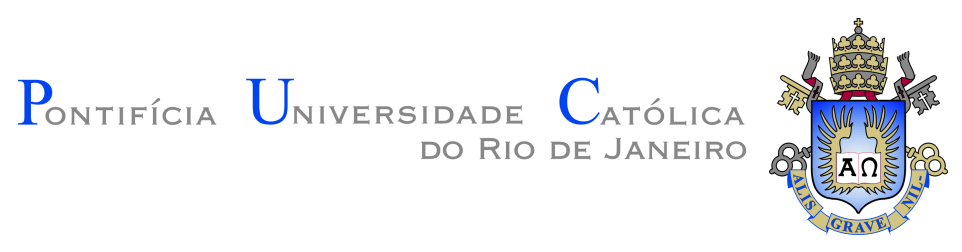

Soraya Adiva Roman Eyzaguirre

\title{
Essays on culture and early childhood
}

Tese de Doutorado

Thesis presented to the Programa de Pós-graduação em Economia of PUC-Rio in partial fulfillment of the requirements for the degree of Doutor em Economia.

Advisor: Prof. Juliano Junqueira Assunção

Rio de Janeiro

September 2017 


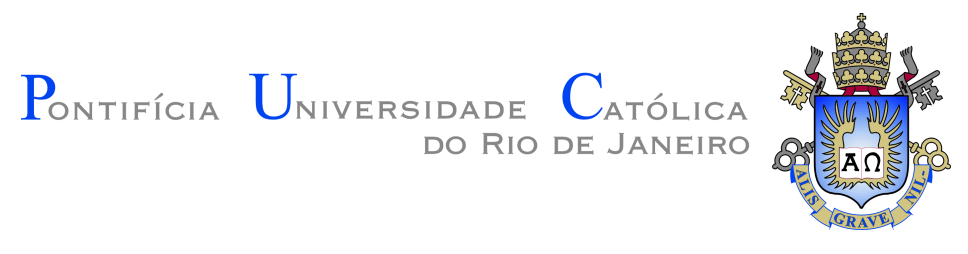

Soraya Adiva Roman Eyzaguirre

\section{Essays on culture and early childhood}

Thesis presented to the Programa de Pós-graduação em Economia of PUC-Rio in partial fulfillment of the requirements for the degree of Doutor em Economia. Approved by the undersigned Examination Committee.

Prof. Juliano Junqueira Assunção

Advisor

Departamento de Economia - PUC-Rio

Prof. Pedro Carvalho Loureiro de Souza

Departamento de Economia - PUC-Rio

Prof. Gabriel Lopes de Ulyssea

Departamento de Economia - PUC-Rio

Prof. Joana Simões de Melo Costa Instituto de Pesquisa Econômica Aplicada -

Prof. Cecilia Machado

Fundação Getulio Vargas, FGV/EPGE - Escola Brasileira de

Economia e Finanças

Prof. Augusto Cesar Pinheiro da Silva

Vice Dean of the Centro de Ciências Sociais - PUC-Rio

Rio de Janeiro, September the 4th, 2017 
All rights reserved.

\section{Soraya Adiva Roman Eyzaguirre}

Graduated in Economics at the Universidad Privada Boliviana in 2009 and obtained her M.Sc. Degree in Economics from the Universidad de Chile in 2011.

Bibliographic data

Roman Eyzaguirre, Soraya Adiva

Essays on culture and early childhood / Soraya Adiva Roman Eyzaguirre; advisor: Juliano Junqueira Assunção. Rio de janeiro: PUC-Rio, Departamento de Economia, 2017.

v., 115 f: il. color. ; $30 \mathrm{~cm}$

Tese (doutorado) - Pontifícia Universidade Católica do Rio de Janeiro, Departamento de Economia.

Inclui bibliografia

1. Economia - Teses. 2. Primeira Infancia;. 3. Aleitamento;. 4. Cultura;. 5. Desenvolvimento;. I. Junqueira Assunção, Juliano. II. Pontifícia Universidade Católica do Rio de Janeiro. Departamento de Economia. III. Título. 


\section{Acknowledgments}

I would like to express my special gratitude to my advisor, professor Juliano Assunção. Thank you for giving me space to grow as a researcher but also demanding more from me when I needed it. I would also like to thank the members of my jury, Joana Costa, Cecilia Machado, Gabriel Ulyssea and Pedro Souza. Your carefully thought comments and suggestions helped me to be more rigorous with my thesis and improve it.

A special thank you to my family. You were so supportive that I felt you lived the ups and downs of a PhD with me. Also, I would like to thank my friends and fellow students, specially Marina and Laura, for the moral support and solidarity. You include me in your lives even when I couldn't understand your language.

Finally, I would like to express my gratitude for the funding resources to the Conselho Nacional de Desenvolvimento Científico e Tecnológico (CNPq) and the Fundação Carlos Chagas Filho de Amparo à Pesquisa do Estado do Rio de Janeiro (FAPERJ). 


\section{Abstract}

Roman Eyzaguirre, Soraya Adiva; Junqueira Assunção, Juliano (Advisor). Essays on culture and early childhood. Rio de Janeiro, 2017. 115p. Tese de doutorado - Departamento de Economia, Pontifícia Universidade Católica do Rio de Janeiro.

This thesis contains three essays on culture and early childhood. The first essay studies the effect of ethnic beliefs/preferences on breastfeeding practices in Peru and Bolivia. Comparing the breastfeeding practices of rural-to-urban migrants and their descendants by ethnicity, we find that Aymara indigenous mothers breastfeed longer than non-indigenous ones. The second and third essays study the effectiveness of Chile crece Contigo - ChCC hereinafter -, a national-scale early childhood development policy implemented in Chile. This policy follows all children in the public health system from gestation until they are four years old. It has a strong prenatal component, and focuses on the early detection and amelioration of bio-psycho-social vulnerabilities in the family environment. Consistent with the policy objectives, we show that ChCC increases socio-emotional skills of children between 18 and 47 months of old, and it is more effective when the child is exposed to the policy since gestation. Furthermore, we estimate a production function of skills for cohorts exposed to ChCC before and after its expansion, and find that the increased abilities are not only associated with higher levels of parental investment but also with an increase in the average marginal product of this variable ${ }^{a}$.

${ }^{a}$ From the unpublished manuscript (1), written with Marina Aguiar Palma.

\section{Keywords}

Early Childhood; Breastfeeding; Culture; Development; 


\section{Resumo}

Roman Eyzaguirre, Soraya Adiva; Junqueira Assunção, Juliano. Ensaios em cultura e primeira infancia. Rio de Janeiro, 2017. 115p. Tese de Doutorado - Departamento de Economia, Pontifícia Universidade Católica do Rio de Janeiro.

Esta tese contém três ensaios sobre cultura e infância. O primeiro ensaio estuda o efeito das crenças/preferências étnicas sobre as práticas de amamentação no Peru e na Bolívia. Comparando as práticas de aleitamento materno de migrantes rurais para urbanos e seus descendentes por etnia, descobrimos que as mães indígenas Aymaras amamentam mais do que as que não são indígenas. Os ensaios segundo e terceiro estudam a eficácia de Chile crece Contigo - ChCC a seguir - uma política de desenvolvimento da primeira infância em escala nacional, implementada no Chile. Esta política segue todas as crianças no sistema de saúde pública desde a gestação até os cuatro anos de idade. Tem um forte componente pré-natal, e se concentra na detecção precoce e na melhoria das vulnerabilidades bio-psico-sociais no ambiente familiar. De acordo com os objetivos da política, mostramos que o ChCC aumenta as habilidades sócio-emocionais de crianças entre 18 e 47 meses de idade, e é mais eficaz quando a criança está exposta à política desde a gestação. Além disso, estimamos uma função de produção de habilidades para as coortes expostas ao ChCC antes e após de sua expansão e descobrimos que os aumentos nas habilidades não estão apenas associadas com maiores níveis de investimento parental, mas também com um aumento no produto marginal médio desta variável ${ }^{a}$

${ }^{a}$ Do manuscrito não publicado (1), escrito com Marina Aguiar Palma.

\section{Palavras-chave}

Primeira Infancia; Aleitamento; Cultura; Desenvolvimento; 


\section{Table of contents}

1 Culture and Breastfeeding duration in Peru and Bolivia 12

$\begin{array}{lll}1.1 & \text { Introduction } & 12\end{array}$

$\begin{array}{ll}1.2 \text { Cultural setting } & 16\end{array}$

$\begin{array}{ll}\text { 1.2.1 History and location of ethnic groups } & 16\end{array}$

$\begin{array}{lll}1.2 .2 & \text { Breastfeeding beliefs } & 20\end{array}$

$\begin{array}{lll}1.3 \text { Data } & 22\end{array}$

1.4 Ethnic variation and breastfeeding 25

1.4.1 Rural residents and rural-to-urban migrants 26

$\begin{array}{ll}\text { 1.4.2 Second-generation migrants } & 29\end{array}$

1.4.3 Robustness Analysis 32

1.5 Socialization mechanisms 36

$\begin{array}{lll}\text { 1.5.1 Direct vertical socialization } & 36\end{array}$

1.5.2 Ethnic Identity Formation 38

1.6 Conclusions 43

2 Is timing important in early childhood interventions? The case of "Chile crece contigo" 45

2.1 Introduction $\quad 45$

2.2 Chile Crece Contigo 47

2.3 Data 52

2.4 Empirical analysis $\quad 57$

2.4.1 The effect of the moment of entry to ChCC 58

2.4.2 Heterogeneous effects 61

$\begin{array}{lll}2.5 \text { Conclusions } & 62\end{array}$

3 A structural assessment of Chile Crece Contigo $\quad 65$

$\begin{array}{lll}3.1 & \text { Introduction } & 65\end{array}$

3.2 Chile Crece Contigo 67

3.3 Empirical strategy and Data 72

$\begin{array}{lll}\text { 3.3.1 Data } & 72\end{array}$

$\begin{array}{lll}\text { 3.3.2 Empirical strategy } & 74\end{array}$

$\begin{array}{lll}3.4 & \text { Structural modelling and estimation } & 77\end{array}$

$\begin{array}{lll}3.4 .1 & \text { The model } & 77\end{array}$

$\begin{array}{lll}3.4 .2 & \text { Estimation } & 79\end{array}$

3.4.2.1 A factor structure between measurements and latent variables $\quad 79$

3.4.3 Endogeneity of parental investment in our production function 81

3.4.3.1 Estimation Procedure $\quad 82$

3.5 Results 83

3.5.1 System of measures and latent variables 83

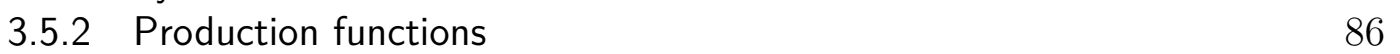

3.5.3 Model fit and simulation exercises 93

$\begin{array}{ll}3.6 \text { conclusion } & 95\end{array}$

$\begin{array}{ll}\text { Bibliography } & 97\end{array}$ 
A Chapter 2 - Additional results 108

A.1 Chile Crece Contigo 108

A.1.1 Regional variation in ChCC expansion date 108

B Chapter 3 - Additional results 112 


\section{List of figures}

Figure 1.1 Geographic Distribution of Ethnic Groups 17

Figure 1.2 Concentration of indigenous population in haciendas or Hispanic towns in 1830, Bolivia

Figure 1.3 The effect of the distance to mining centers on Aymara breastfeeding difference

Figure 1.4 The effect of Indigenous population in haciendas or towns on Aymara breastfeeding difference

Figure 2.1 Timeline of the implementation of the social protection system

Figure 2.2 Histogram of 18-47-months-old children born in the public health system by child's birth date

Figure 2.3 ChCC intention to treatment effect of child's birth date on child's socioemotional development

Figure 2.4 Intention to treatment effect of the age of entry to ChCC 63

Figure 2.5 Heterogeneity in ITT ChCC effects by child's birth date 64

Figure 3.1 Timeline of the implementation of the social protection system

Figure 3.2 Sample distribution

Figure 3.3 ChCC predicted effect along parental cognition distribution 94

Figure 3.4 Proportion of ChCC quantity effect along parental cognition distribution

Figure A.1 Number of first psycho-motor evaluations to children less than five in the public health system, by region

Figure A.2 Regional variation on the date of ChCC expansion

Figure B.1 Distribution of latent variables - Age 18-23 months

114

Figure B.2 Distribution of latent variables - Age 36-47 months 


\section{List of tables}

Table 1.1 Descriptive statistics of rural residents 24

Table 1.2 Descriptive statistics of rural-to-urban migrants 24

Table 1.3 Descriptive statistics of second-generation rural-to-urban migrants from Peru

Table 1.4 The effect of ethnicity on the breastfeeding observed duration

Table 1.5 City Effect and Breastfeeding 29

Table 1.6 Breastfeeding among second-generation migrants in Peru 31

Table 1.7 Ethnic breastfeeding differences among urban residents in -Peru (2005-2008) 33

Table 1.8 Fertility Preferences and Breastfeeding 34

Table 1.9 Grandparents' educational background and Breastfeeding 34

Table 1.10 Regression results using ethnicity self-identification 35

Table 1.11 Regression results excluding dead children from the sample 36

Table 1.12 Grandparents' cultural influence on breastfeeding 37

Table 1.13 Female peers and ethnic breastfeeding differences 38

Table 1.14 Distance to a Mining Center and ethnic breastfeeding differences

Table 1.15 Indigenous population in haciendas or towns and ethnic breastfeeding differences

Table 2.1 Coverage and expansion of Chile crece contigo

Table 2.2 Instruments and factors to determine vulnerability

Table 2.3 Outcomes of Chile crece contigo for families in the public health system

Table 2.4 Descriptive statistics of children aged 18-47 months born in the public health system by child's birth date

Table 2.5 ChCC intention to treatment effect of child's birth date on child's socioemotional development

Table 3.1 Coverage and expansion of Chile crece contigo

Table 3.2 Instruments and factors to determine vulnerability

Table 3.3 Outcomes of Chile crece contigo for families in the public health system

Table 3.4 Descriptive Statistics - Socio-demographic characteristics 74

Table 3.5 Descriptive Statistics - Potential programme outcomes $\quad 75$

Table 3.6 Percentage of information per measure of latent variables 85

Table 3.7 Mean difference of latent variable before and after ChCC 86

$\begin{array}{lll}\text { Table } 3.8 & \text { Investment functions } & 87\end{array}$

Table 3.9 External Socio-emotional skills $\quad 89$

Table 3.10 Internal Socio-emotional skills $\quad 90$

Table 3.11 Cognitive skills $\quad 91$

Table 3.12 Differences in production functions parameters 92

Table 3.13 Observed and predicted value of children abilities - Age 18-23 months 
Table 3.14 ChCC effect on children abilities with and without a change in production function

Table A.1 ChCC Statistics

Table A.2 Moment of ChCC expansion according to psycho-motor evaluation series

Table B.1 Sample size

Table B.2 2010 Descriptive Statistics - Socio-demographic characteristics

Table B.3 2012 Descriptive Statistics - Socio-demographic characteristics 


\section{Culture and Breastfeeding duration in Peru and Bolivia}

\section{1}

\section{Introduction}

Growing empirical evidence shows that culture plays a role in the determination of human behaviour. The evidence is based on the study of populations of immigrants and their descendants, who behave differently in a common economic and institutional context because of their inherited values and social beliefs (See $(2,3)$ for literature review). As recent examples we can mention the paper of Atkin on tastes and nutrition in India, and the paper of Cristopoulou et. al. on smoking behaviour in immigrants. The former attempts to quantify the effect of tastes on the family caloric intake. The latter addresses the importance of cultural dynamics on smoking, which is part of a group of economic behaviours that may be influenced by global cultural tendencies. $(4,5)$

In this paper, we build on this literature by studying the relevance of culture on breastfeeding behaviour. So far, literature shows that breastfeeding practices vary across mother's birth place, ethnicity and race, even when they face similar socioeconomic conditions. $(6,7,8,9,10,11,12)$ In addition, these practices are correlated with mother's participation in social activities (e.g. attendance to church), stigma around breastfeeding in public and gender roles beliefs, amongst others.(13, 8, 9, 11, 14, 15) Understanding whether these norms and social beliefs have a role on the adoption of adequate breastfeeding practices is important because of its positive effect on human capital, largely discussed in scientific literature (See, for example, $(18,19,20,21)$ ).

While there is extensive evidence of ethnic/racial variation in breastfeeding practices $(9,7,6,10,12)$, only some argue these differences are explained by culture ${ }^{1} .(8,11,16,17)$ Those studies usually compare immigrants versus natives outcomes, which are affected by migration shocks and selection bias. We attempt to address these issues more carefully. Thus, following Fernandez, we estimate the effect of ethnicity on the breastfeeding period of mothers from

\footnotetext{
${ }^{1}$ Consistent with the literature on cultural economics, we understand culture as the systematic differences in beliefs or preferences between ethnicities.(2)
} 
Peru and Bolivia using the within region variation of two samples: first and second generation rural-to-urban migrants.(2) Comparing migrants with each other, instead of migrants with natives, is a more robust approach because the bias on the results does not depend on the migration selection process but on the differences in this process between ethnicities. In addition, using a second generation of migrants eliminates the migration shocks and further attenuates the selection bias, as the daughters of migrants are not responsible for the decision to migrate.

We focus on three ethnic groups: Quechua, Aymara and Non-indigenous people $^{2}$. Quechua and Aymara people belong to indigenous villages from the Andean region who carry on traditions of pre-hispanic societies. On the other hand, Non-indigenous people are Bolivian and Peruvian residents that either don't have or don't acknowledge their Indigenous cultural heritage, leaning more on Hispanic traditions. Anthropological studies suggest Andean indigenous mothers tend to breastfeed longer than non-indigenous ones. Our results show this is consistently true for Aymara mothers. We find that Aymara mothers breastfeed around 10\% longer than Non-indigenous mothers in almost all the estimations.

Our empirical analysis is based on the estimation of a linear regression model of the observed breastfeeding duration on a set of ethnic dummies, socioeconomic control variables and regional fixed effects. Our data comes from the Demographic Health Survey program (rounds 2003-2004 and 2008 of Bolivia, and 2005-2008 of Peru). We can assert our results constitute evidence that culture matters for breastfeeding behaviour only under certain assumptions. First, we assume that the selection process related with the decision to migrate is not correlated with ethnicity, i.e. correlation between migration and breastfeeding is not statistically different between ethnic groups. Second, we assume unobservable variables are not correlated with ethnicity, and if they were, this correlation would not persist intergenerationally.

We cannot completely corroborate the validity of our assumptions, i.e. the effect of ethnicity on breastfeeding duration might suffer from bias. However, given the characteristics of our samples, most likely this bias leads to underestimate ethnicity's true effect, especially with the sample of secondgeneration migrants. This is because the socioeconomic gaps among ethnic groups observed in rural areas fade or even reverse for second-generation migrants, probably associated with convergence in beliefs, and thus ethnic

${ }^{2} \mathrm{An}$ ethnic group is a social group that believe to have a common history, often associated with a common homeland, founding migration or a settlement of a new territory. The ethnic group forms a cultural community, manifested in a common language, religion and/or shared customs. (22) 
differences in breastfeeding.

Even more, we estimate the ethnic differences in breastfeeding using a sample of rural residents and the compare them with the differences estimated with the sample of rural-to-urban migrants. The hypothesis test that both coefficients are equal is not rejected. This suggests that the migration selection process each ethnic group undertakes affects breastfeeding behaviour in the same way. Hence, the bias on the indigenous coefficient caused by differences in the selection process is probably small.

Although this bias is small, we still cannot fully confirm that the ethnic breastfeeding differences are explained by culture. Other unobservable variables that might persist intergenerationally could explain our results. For this reason, we perform robustness tests to rule out some alternative explanations. One possibility is that these differences represent discrepancies in fertility preferences rather than culture. Another possibility is that they are driven by systematic differences in the ancestors education instead of their culture. In addition, we test if the results are robust to an alternative definition of ethnicity. The results show that the breastfeeding differences are larger when mothers' ethnicity is defined by self-identification instead of the language learned as a child.

Furthermore, in the second generation estimation, we assume the ethnic breastfeeding differences are preserved because culture is transmitted vertically, from parents to children. To test this assumption, we estimate the model using the ethnicity of the child's grandmother and great grandparents simultaneously in order to identify the main source of the breastfeeding differences. The idea is that once we control for the great grandparents origin, the grandmother origin should become irrelevant to explain the breastfeeding differences. As expected, the results show that the effect of grandmother ethnicity goes to zero.

We also estimate two heterogeneous effects related with cultural socialization mechanisms. First, we find that the Aymara-Non-indigenous breastfeeding difference increases with the presence of an additional child-bearing-age woman in the household. Secondly, using geographic information and 1830's population statistics, we find that the interaction between Indigenous people and the Spanish colony is associated with the persistence of the breastfeeding difference. According to our results, this difference is larger in regions closer to colonial mining centres and regions where Indigenous people were more concentrated in Haciendas.

Besides the literature on culture and breastfeeding, this paper is associated to other branches of the literature. First, we contribute to the literature 
on cultural economics, which assumes cultural traits are inter-generationally transmitted.(4, 23, 5, 2, 3) Instead of taking this assumption as given, we are able to test its plausibility by using grandmother and great grandparents ethnicities, as we mentioned before.

Another growing literature in economics studies the evolution of culture and ethnic identity $(24,25,26,27,28)$. Our paper is closer to Bisin et. al.(27) They propose a theoretical framework to study the determinants of ethnic identity along two motivational process: cultural conformity and cultural distinction. In the first case, neighborhood integration reduces ethnic identity, weakening group loyalties and prejudices. In the second case, the effect of the neighborhood integration is the opposite,i.e. ethnic groups are more motivated to preserve their own heritage. Using data from ethnic minorities in the UK, Bisin et. al. find that ethnic identities are more intense in mixed than in segregated neighborhoods, which is consistent with cultural distinction.(27) Our results are also consistent with this process. But, instead of using the neighborhood ethnic composition, we use the regional variation in the interaction between Indigenous and Spanish people in colonial times and find that current Aymara-Non-indigenous breastfeeding differences are larger in regions with more Spanish-Indigenous interaction.

Recent studies are trying to understand the effect of formal institutions on culture (See Alesina et.al. (3) for a literature review). Some of these papers study the effect of an institutional shock relatively exogenous to culture, e.g. the fall of the Soviet Union, on the population's values and beliefs. Others isolate the relevance of formal institutions by looking at countries belonging to different historical empires, e.g. Becker et. al. (2011) studies the effect of the Hapsburg Austrian Empire on the trust towards the government today. Although we don't address the effect of colonial institutions formally, it is reasonable to assume that the colonial institutional setting determined the interaction between Spanish and Indigenous people, and, in that sense, it could have contributed to the formation of distinctive ethnic identities that influence mother's breastfeeding behaviour.

Finally, during the last two decades policy makers have intensively advocated for the social inclusion of indigenous people, including the access to health care. This access is not limited to the physical and economic availability of health services, but also to their cultural adequacy(29). Our results show mother's breastfeeding behaviour varies with their ethnicity, it persists for at least two generations, and it is likely explained by differences in breastfeeding beliefs. This evidence shows the importance of culture for health behaviour, and thus, the need to include these topics in the design of public policies. 
The paper is organised as follows. Section 3.2 describes the history, geographic location and breastfeeding beliefs of the three ethnic groups we study. Section 3.3 describes the data. Section 2.4 presents the regression models and main results. Section 1.5 studies socialization mechanisms for the transmission of breastfeeding beliefs, and Section 1.6, concludes.

\section{2}

\section{Cultural setting}

In this section, we describe ethnic groups' history, geographic location and breastfeeding beliefs. On the one hand, we have the Indigenous people from the Andean region who carry on the traditions of pre-hispanic societies. We consider the two largest ethnic groups of the region: the Quechua, descendants of the Inca empire, and the Aymara, descendants of the Tiwanaku Kingdom. On the other hand, we have the Non-indigenous ethnic group, Bolivians and Peruvians that either don't have or don't acknowledge their Indigenous cultural heritage, leaning more on their Hispanic traditions. Anthropological studies suggest Andean indigenous mothers tend to breastfeed longer than non-indigenous ones.

\subsection{1}

\section{History and location of ethnic groups}

The Andean region extends along South America through a 7000-kmlong mountain range that starts at Cabo de Hornos (Chile) and ends near Caracas (Venezuela). The region covers five countries: Argentina, Bolivia, Chile, Colombia, Ecuador and Peru. In general, the region is characterized by their rugged geography, which hinders accessibility, but also allows diverse ecological environments. The two largest indigenous groups of the region are Quechua and Aymara. They represent 94\% of all the Andean indigenous population and most of them live in Peru and Bolivia(30). The Aymara population lives in the Peru-Bolivian high plateau at an average altitude of 3800 meters above sea level. The soil is arid and the weather is cold, yet Aymara people rely on the cultivation of tubers, fishing and camelid raising for subsistence(30). On the other hand, the Quechua population lives in the Peruvian highlands and the inter-Andean valleys of Bolivia (1800-3000 m.a.s.l.). This group phases more heterogeneous living conditions. Those who live in the highlands face conditions similar to Aymara population, while those located in lower regions have access to a more fertile soil and warmer weather. So, they can rely more on agriculture for living(30). We can see the rural settlements of both populations in Figure 1.1. 
The origin of Quechua and Aymara ethnic groups traces back to prehispanic times, previous to the formation of the Inka State(31). The persistence of these indigenous groups can be explained by geographical, institutional and historical factors. Before the Inca empire (800-1200 CE), the two most significant civilizations of the Andean central region were the Wari- Quechua speakers-, and the Tiwanaku - Aymara speakers. When these civilizations fell, small Quechua and Aymara kingdoms emerged and expanded their territory through peaceful arrangements or war. Only 50 years before the arrival of the Spanish conquers, some of the Quechua factions consolidated its power over the Inka empire. Despite being Inka's subjects, the Aymara kingdoms preserve control over their territory by maintaining their political organization and language internally $(30,31)$.

Figure 1.1: Geographic Distribution of Ethnic Groups

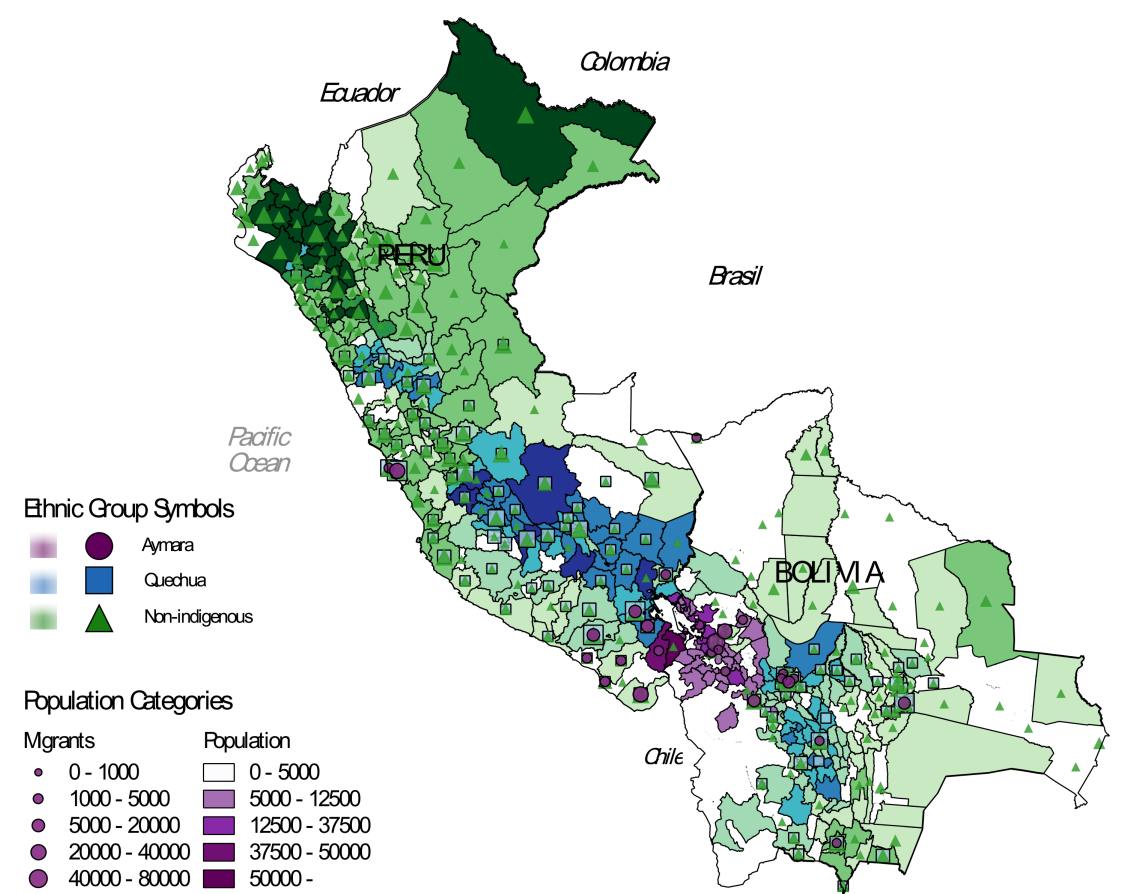

Source: Population and Housing Censuses (Peru, 1993, 2007; Bolivia, 2001, 2012)

Later in the Colonial period, the institutions contributed to the preservation of the Quechua and Aymara ethnic groups. The extractive nature of Spanish institutions conduced to the formation of a dual society, with Spanish people concentrated in cities and Indigenous people in the countryside(32). Spaniards preserve some of the Inka's administrative and economic institutions. In particular, they continued and increased the collection of taxes paid in labor force or mit' $a$ and other taxes (in food supply or money), but they 
also respected the local hierarchy by dealing only with traditional leaders, who internally decided how to pay the taxes $(32,31)$. So, because the local organization was not modified, Indigenous communities were able to preserve some of their cultural traits, even with the presence of the Catholic inquisition(33).

By the time the Spanish colony reached its maturity, when mines almost depleted, the expansion of the inter-regional economy changed Spanish investments to agriculture and livestock production. Large rural lands, named Haciendas, consolidated along the Andean region, particularly, in regions close to local markets and where the European production technology was more suitable, such as low valleys and coastal lands(32, 34). Here, geography facilitated the preservation of indigenous communities in the highlands, where Hispanic people had no suitable techniques to cultivate the soil. Yet, some Haciendas remained close to Indigenous towns ${ }^{3}$, and a considerable proportion of Indigenous people lived in the Haciendas for the mit'a or as landless free workers, named yanaconas $(32,31)^{4}$. Consequently, as Figure 1.2 shows, the distribution of indigenous population between haciendas and Hispanic towns, on one side, and indigenous communities, on the other, varied regionally. In the darker regions of Figure 1.2 most of the indigenous people lived in haciendas or Hispanic towns, while in the lighter ones most of them lived in communities.

The formation of the Non-indigenous ethnic group happened throughout the Colonial period. The social distinction of the initial ethnic groups, Spanish, Black and Indian, became unclear with the evolution of the Spanish colony. New castes emerged:criollo - person with Spanish ancestors borned in America, mestizo - person with Spanish and Indigenous ancestors, and mulato - person with Spanish and Black ancestors. These castes later mixed with each other, making harder for Spanish people to define a social position for them. However the main Spanish social hierarchy, with Spaniards at the top and indigenous people at the bottom, remained unaltered. The other castes, who usually spoke Spanish, entered to intermediate positions in the Spanish world. Because they were at least partly Spanish, they were entitled to more rights and privileges than indigenous people(32).

Although indigenous people also upraised against the Spanish crown, non-indigenous people led the independence war and the foundations of the republics of Peru and Bolivia. After the independence, they continued with the expansion to rural areas, towards the Amazon but also the Andes. In

\footnotetext{
${ }^{3}$ Indigenous towns were also known as reducciones, new locations created by the Spanish crown, that concentrated indigenous people in order to facilitate tax collection(31).

${ }^{4}$ Henderson (31) finds that between 40 to 60 percent of the indigenous population became yanaconas. These people left their communities to avoid the mita, but because of that they didn't have right to own a land.
} 
Figure 1.2: Concentration of indigenous population in haciendas or Hispanic towns in 1830, Bolivia

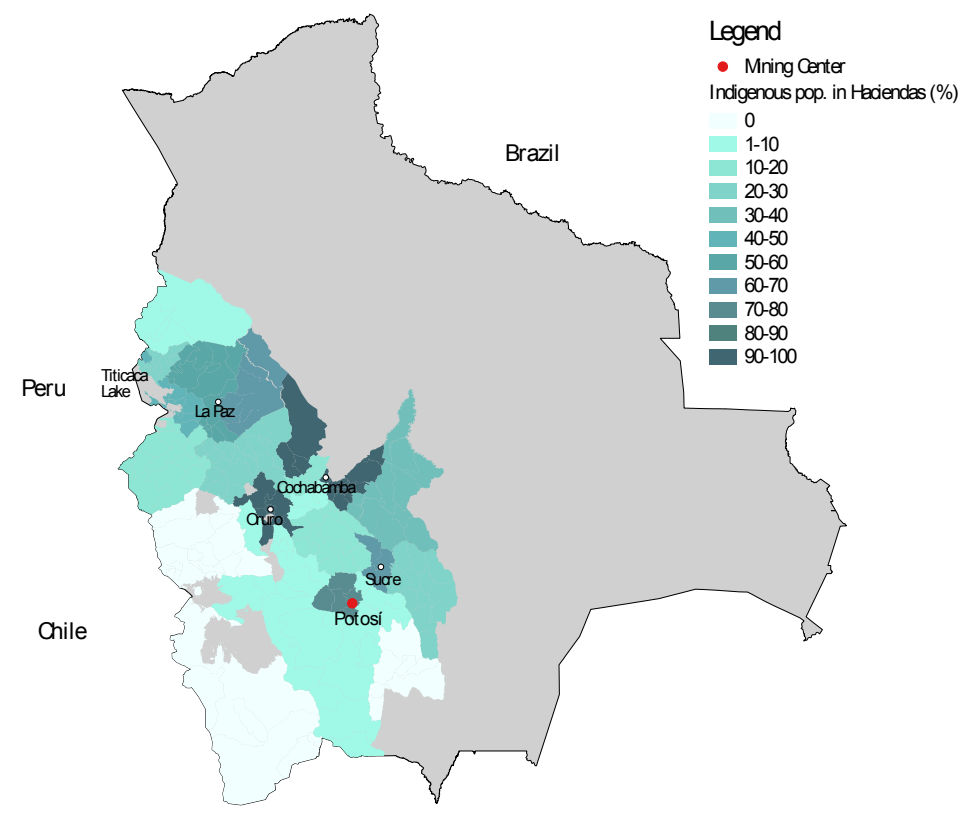

Source: (34)

both cases, the motivation was economic. The Andes region contained mineral deposits and land suitable for camelids breeding, later used by the textile industry(35). Meanwhile, the Amazon had rubber, diamonds, gold, oil and gas deposits, exploited along the post-independence history. In addition, several lands between those regions served for agricultural purposes. Today, the nonindigenous rural population live in the coastal and northeastern provinces of Peru (amazonian region), and the southeastern region of Bolivia (valleys and low plains), as we can see in Figure 1.1.

Indigenous rights over the land remained unclear until the middle of the 20th century. Thus, the organization and property rights of haciendas change marginally after the colonial period and, in some cases, the State provided land owners military support to take over indigenous lands(35). Under these circumstances, indigenous populations from Bolivia upraised several times against the State and land owners. Peru also experienced some indigenous uprising, however they were not as frequent as in Bolivia, where indigenous people, particularly Aymara population lived closer to the seat of government, La Paz. Albó (35) arguments that the constant exclusion and disregard of indigenous people contributed to the formation of the Aymara identity in the 20th century, which later led this people to demand greater political participation and economic autonomy.

Rural-to-urban migration flows in Peru and Bolivia increased only in the 
second half of the 20th century. The urbanization rate in Peru increased from $35,4 \%$ in 1940 to $75,9 \%$ in 2007, while in Bolivia, this rate increased from $26 \%$ in 1950 to $57 \%$ in $1992(36,37)$. Until the 1970 s, the main city of destination in Peru was Lima. Later, other coastal cities, such as Arequipa, became important receivers of migration flows(36). In Bolivia, the three main cities of destination were El Alto, La Paz, Cochabamba and Santa Cruz(37). All these cities contain Quechua, Aymara and Non-indigenous migrants simultaneously, which allows us to estimate ethnic differences in breastfeeding on families who live under similar conditions. However, there is a geographical pattern in the migration flows. As we can see in Figure 1.1, each ethnic group have the largest migration flows close to their place of origin in the rural area ,i.e., they tend to migrate to cities near to their native region. The effect this migration pattern has on our empirical results will be addressed in Section 2.4.

\subsection{2}

\section{Breastfeeding beliefs}

Historical and anthropological evidence suggests the breastfeeding beliefs of Andean indigenous people are different from that of Non-indigenous people. On the one hand, Non-indigenous people were mainly influenced by the Spanish culture, particularly during the colonial period, between 16th and 18th centuries. At that time, many European mothers followed the tradition of not breastfeeding themselves, frequently recurring to wet-nurses or artificial nourishment. This tradition was stronger in middle and high social classes, and in the Catholic regions(38).

A mix of religious, sexual and medical motives justified the use of wetnurses as a socially accepted tradition. The greek idea that breast-milk was a modification of the menstrual fluids together with the religious notion that menstruation was an impure, indecent event, led to the belief that breastfeeding was a private and shameful activity until the 17 th century(39). In addition, it was a common belief that the colostrum was unpurified and harmful for the child even after medical authorities started to recommend it by the 18 th century $(39,38)$. So, instead of breast-milk, infants were breastfed with sugared water or honey during their first days after birth(39). Finally, until the beginning of the 19th century, it was medically sound advice to avoid sex while breastfeeding because sex could damage the breast-milk. This belief was reinforced by the Catholic church who thought sex was only for procreation and it was immoral to do it during the breastfeeding period $(39,38)$. Therefore, either to resume sexual relations or to avoid an uncomfortable practice, nobility and high social classes preferred to employ wet-nurses. 
Although the non-breastfeeding tradition was more common in high social classes, it extended to middle and low classes too. One of the reason was that the use of wet-nurses became a sign of status. Hence, middle and low classes used them in an attempt to emulate the lifestyle of rich and noble(38). Also the clothing fashion between the 16th and 18th centuries made breastfeeding difficult, e.g., the use of tight bodices since adolescence tend to deform the nipples(39). Another reason was the use of many types of artificial nourishment too early, e.g., cow milk, goat milk, sugared water. This is one of the factors that explain the high infant mortality in Spain until the early 20th century(40). The use of animal milk dates back to the Middle Age, and it continued to be used in spite of the known disadvantages of this milk compared to breast-milk. Thorvaldsen(38) considers that in some cases, the heavy workload in non-industrial and energy-poor societies precluded mothers to breastfeed. Later, this became a normative behaviour.

On the other side, breastfeeding is important for Andean cultures, and they see it as a natural process. The importance of breastfeeding can be traced back to pre-hispanic times, where breastfeeding was part of the Andean religion. For example, Cawillaca, an Andean divinity, was known because she raised her child with only breast-milk for a year. Also, the name of the Inca temple, Poq'enkancha means "the origin of life", and comes from the words Poq'e which means colostrum and kancha which means enclosure(41). Furthermore, a tradition practiced until today, named roto chico, rutucha or haircut celebration in Spanish, was also considered a weaning party. In this party, the child was introduced as an active member of the community, receiving her definitive name and sex-specific clothes. Normally, the party was celebrated after the child was two years old. Thus, the weaning in Andean cultures was associated with child's physical and emotional growth. This is one of the factors that explain why Andean mothers prolong breastfeeding $\operatorname{today}(41)$.

Another tradition that shows the importance of breastfeeding for Andean cultures is the use of galactogogues. Spanish chroniclers stated that Andean mothers used some products to stimulate the production of breast-milk, such as soup of quinoa and $\tilde{n} u \tilde{n} u$ quehua ${ }^{5}(41)$. Anthropological studies show that still today Andean mothers, both from rural and urban areas, use the quinoa soup as a galactogue $(41,42)$.

The mother-child relationship is important for Andean cultures and helps to prolong breastfeeding. Before the age of two, the mother is almost solely responsible for raising the child. Other female family members and the husband

${ }^{5}$ The last term is translated as "worms that stimulate the breasts". 
usually help with domestic tasks and others so that the mother can stay near the baby. Even when no help is available, rural and urban mothers are used to carry the babies on their backs using an awayu while they work at home or outside $^{6}$. So, they have several opportunities to breastfeed during the day and usually breastfeed on demand $(42,45)$.

Some breastfeeding beliefs vary among Andean ethnic groups. One of the cultural differences is the use of colostrum. In Cuzco, a Quechua region, mothers don't give the colostrum to their children because they believe it is "immature milk". Meanwhile, in Puno, an Aymara region, mothers usually give the colostrum to their babies. Besides, the Aymara religion associates the colostrum with fecundity and growth(41). Probably this difference is associated with another: the moment of breastfeeding initiation. Traditionally, Andean mothers delay breastfeeding initiation. However, Aymara mothers start breastfeeding between 6 and 12 hours after birth while Quechua mothers from Cuzco start between 1 and 3 days after(41). Since recent evidence suggests one of the key factors to prolong breastfeeding is an early initiation(46), it is possible that these cultural differences explain why Aymara mothers breastfeed longer than Quechua mothers.

\section{3 \\ Data}

We use data from the Demographic Health Survey(DHS) program, the rounds 2003-2004 and 2008 of Bolivia, and 2005-2008 of Peru. These are the only years where the questions regarding the ethnic origin are the same in both countries. The survey contains information on mother-child pairings for every living birth the mother had up to five years before the interview, regardless the child is alive or dead at the moment of the interview. We exclude the multiple births and the births that happened outside the fertility range (15 to 45 years old) because they could generate atypical breastfeeding results. $(47,48,49)$ Alongside breastfeeding period and mother's ethnicity, the survey reports several socio-demographic and health variables, such as age, sex, birth weight, family composition, parents' education and occupation and family wealth index ${ }^{7}$.

Two variables are particularly important for our analyses: mother's migration status and mother's ethnicity. Ideally, we would like to have mother's place of birth, her previous and current residences, and the time in the last

${ }^{6}$ Awayu in Aymara is a rectangular colorful woolen blanket used to carry babies or things on the back(43). The word in Quechua is q'ipina(44).

${ }^{7}$ Details on sampling design and variable definitions of DHS surveys are available in https://dhsprogram.com/data/available-datasets.cfm 
place of residence since migration. However, not all the surveys from Peru and Bolivia have this information. The questions available are: the type of geographic area a mother lived in until she was 12 years old - capital city, city, town or countryside -, and mother's current place of residence. Using them, we identify a mother as a rural-to-urban migrant if she lived in a town or countryside until she was 12 years old (childhood), but currently lives in a city. Thus, mothers who currently live in a town or countryside and also did so when they were 12 years old are considered rural residents.

On the other hand, mother's ethnicity is defined by the language she learned as a child, which can be Quechua, Aymara, Spanish, Guarani and others. Spanish is the language of Non-indigenous mothers. We exclude the children whose mother isn't Quechua, Aymara or Non-indigenous. The excluded children belong to small ethnic groups, usually from the Amazonian region, that represent less than $10 \%$ of total indigenous population. Finally, we remain with 4189 under-five children whose mothers are rural-to-urban migrants, and 13341 under-five children whose mothers are rural residents.

Table 1.1 contains the mean value of breastfeeding period and socioeconomic variables by ethnicity for the sample of rural residents. As we can see, the number of months that a mother breastfeed varies by ethnic group, as well as several socio-demographic variables. We expect to observe these differences because the ethnic groups live in different geographic locations (See Figure 1.1). The data shows that indigenous mothers breastfeed longer than the other groups. Also, they are less educated, poorer and a larger percentage of them work in the agricultural sector. All these variables are usually correlated with a longer breastfeeding period in developing countries(50), something we will consider the following sections.

When ethnic groups move to urban areas, the length of the breastfeeding period and the ethnic differences in breastfeeding persist in spite of the changes in living conditions and labor markets. Table 1.2 shows that the access to water, electricity and telephone is higher in urban areas compared to rural areas, and it is even higher for Non-indigenous families. The ethnic differences in education and wealth are also greater. On the other hand, although the mother's participation in the labor market changes, the ethnic differences related with these variables reduce. While in rural areas indigenous mothers work in agriculture, normally as self-employees, in urban areas, nor the decision to work neither the job type -self-employed or others- vary with ethnicity.

The 2005-2008 Peruvian survey also collected information on mother's ancestors. Mainly, the survey asks for her parent's and grandparent's ethnicity. We use this information to identify mothers that are second-generation 
Table 1.1: Descriptive statistics of rural residents

\begin{tabular}{|c|c|c|c|c|c|}
\hline & \multirow{2}{*}{$\frac{\text { Non-indigenous }}{\text { Mean }}$} & \multicolumn{2}{|c|}{ Quechua } & \multicolumn{2}{|c|}{ Aymara } \\
\hline & & Mean & P-val & Mean & P-val \\
\hline $\ln$ (Breastfeeding) (months) & 2.3952 & 2.4458 & 0.0133 & 2.4669 & 0.0002 \\
\hline Sex of child $($ male $=1)$ & 0.5073 & 0.5126 & 0.4583 & 0.5149 & 0.7759 \\
\hline Fam. members $<5$ & 0.7106 & 0.8395 & 0.0001 & 0.8462 & 0.0243 \\
\hline Fam. members $\geq 5$ & 4.2965 & 4.1763 & 0.0743 & 4.1227 & 0.0890 \\
\hline Mother's age at birth & 25.7737 & 28.1163 & 0.0000 & 28.7803 & 0.0000 \\
\hline Birth weight (kgs) & 3.3199 & 3.2692 & 0.1037 & 3.2953 & 0.0328 \\
\hline Mother is obese & 0.1307 & 0.0825 & 0.0000 & 0.1020 & 0.0177 \\
\hline Mother's education (years) & 6.7345 & 3.8617 & 0.0000 & 5.1843 & 0.0000 \\
\hline Wealth Index & 2.0405 & 1.6898 & 0.0000 & 1.7193 & 0.0000 \\
\hline Access to water & 0.5544 & 0.5208 & 0.3791 & 0.4915 & 0.2277 \\
\hline Access to electricity & 0.5348 & 0.4256 & 0.0051 & 0.4887 & 0.5287 \\
\hline Access to telephone & 0.0275 & 0.0070 & 0.0000 & 0.0042 & 0.0000 \\
\hline Mother is not working & 0.3773 & 0.2725 & 0.0002 & 0.1559 & 0.0000 \\
\hline Mother works in agriculture & 0.3222 & 0.5515 & 0.0000 & 0.6223 & 0.0000 \\
\hline Mother works at sales & 0.1085 & 0.0833 & 0.0084 & 0.1116 & 0.6712 \\
\hline Mother is self employed & 0.7136 & 0.8641 & 0.0000 & 0.8949 & 0.0000 \\
\hline Mother works at home & 0.1896 & 0.1395 & 0.0007 & 0.1905 & 0.4839 \\
\hline Observations & 6395 & 5503 & & 1443 & \\
\hline
\end{tabular}

Table 1.2: Descriptive statistics of rural-to-urban migrants

\begin{tabular}{|c|c|c|c|c|c|}
\hline & \multirow{2}{*}{$\frac{\text { Non-indigenous }}{\text { Mean }}$} & \multicolumn{2}{|c|}{ Quechua } & \multicolumn{2}{|c|}{ Aymara } \\
\hline & & Mean & P-val & Mean & P-val \\
\hline $\ln$ (Breastfeeding) (months) & 2.3186 & 2.4027 & 0.2117 & 2.4504 & 0.0535 \\
\hline Sex of child $($ male $=1)$ & 0.5165 & 0.5324 & 0.6498 & 0.4993 & 0.8654 \\
\hline Fam. members $<5$ & 0.5797 & 0.7218 & 0.0000 & 0.7067 & 0.0258 \\
\hline Fam. members $\geq 5$ & 3.9325 & 3.6744 & 0.4748 & 3.5363 & 0.1510 \\
\hline Mother's age at birth & 26.4978 & 27.4701 & 0.0005 & 28.0385 & 0.0000 \\
\hline Birth weight (kgs) & 3.3469 & 3.3635 & 0.2455 & 3.3814 & 0.0482 \\
\hline Mother is obese & 0.2016 & 0.1627 & 0.5874 & 0.1738 & 0.6286 \\
\hline Mother's education (years) & 8.6996 & 4.7766 & 0.0000 & 5.3926 & 0.0000 \\
\hline Wealth Index & 3.4182 & 3.0748 & 0.0000 & 2.9319 & 0.0000 \\
\hline Access to water & 0.8368 & 0.7948 & 0.0093 & 0.7626 & 0.0000 \\
\hline Access to electricity & 0.9250 & 0.9506 & 0.8259 & 0.9554 & 0.0301 \\
\hline Access to telephone & 0.1784 & 0.0769 & 0.0000 & 0.0430 & 0.0000 \\
\hline Mother is not working & 0.3771 & 0.3842 & 0.3193 & 0.2889 & 0.2370 \\
\hline Mother works at sales & 0.2420 & 0.2533 & 0.5014 & 0.2815 & 0.5489 \\
\hline Mother works as domestic & 0.1277 & 0.1333 & 0.0131 & 0.1215 & 0.0350 \\
\hline Mother with skilled manual job & 0.0686 & 0.1050 & 0.3406 & 0.1881 & 0.0013 \\
\hline Mother is self employed & 0.5239 & 0.6311 & 0.0545 & 0.6417 & 0.1049 \\
\hline Mother works at home & 0.2483 & 0.2203 & 0.3046 & 0.2866 & 0.9041 \\
\hline Observations & 2310 & 1204 & & 675 & \\
\hline
\end{tabular}

Source: Bolivian DHS 2003,2008 and Peruvian DHS 2007-2008

Note: Columns (3) and (5) show the test results of the difference between Quechua and Non-indigenous groups or Aymara and Non-indigenous groups. In this test, we regress each variable on ethnic, year, season and regional dummies and estimate the p-value of the Quechua or Aymara coefficient separately, under the null hypothesis that the coefficient is zero.

migrants, i.e., mothers born and raised in the urban areas but with indigenous or non-indigenous ancestors. Table 1.3 shows the statistics of non-migrants grouped by the child's grandmother ethnicity. As we can see, the ethnic gap in several variables, such as education and wealth, close or even reverse. Yet, ethnic breastfeeding differences persist: mothers with Indigenous ancestors breastfeed longer than mothers with Non-indigenous ancestors. 
Table 1.3: Descriptive statistics of second-generation rural-to-urban migrants from Peru

\begin{tabular}{|c|c|c|c|c|c|}
\hline & \multirow{2}{*}{$\frac{\text { Non-indigenous }}{\text { Mean }}$} & \multicolumn{2}{|c|}{ Quechua } & \multicolumn{2}{|c|}{ Aymara } \\
\hline & & Mean & P-val & Mean & P-val \\
\hline $\ln$ (Breastfeeding) (months) & 2.2857 & 2.3768 & 0.0276 & 2.3900 & 0.0456 \\
\hline Sex of child $($ male $=1)$ & 0.5082 & 0.4743 & 0.0982 & 0.5846 & 0.0222 \\
\hline Fam. members $<5$ & 0.4719 & 0.4032 & 0.6347 & 0.3231 & 0.8980 \\
\hline Fam. members $\geq 5$ & 4.2842 & 4.1779 & 0.9586 & 3.7923 & 0.4685 \\
\hline Mother's age at birth & 26.4592 & 27.1324 & 0.0635 & 27.5615 & 0.7539 \\
\hline Birth weight (kgs) & 3.2855 & 3.3025 & 0.2966 & 3.3665 & 0.8393 \\
\hline Mother is obese & 0.1689 & 0.1606 & 0.4263 & 0.2857 & 0.1759 \\
\hline Mother's education (years) & 11.5887 & 11.0020 & 0.0000 & 11.6692 & 0.0138 \\
\hline wealth index & 3.9423 & 3.6779 & 0.0007 & 4.1385 & 0.0049 \\
\hline Access to water & 0.8199 & 0.8887 & 0.9973 & 0.9609 & 0.2100 \\
\hline Access to electricity & 0.9647 & 0.9901 & 0.0840 & 0.9766 & 0.4250 \\
\hline Access to telephone & 0.3919 & 0.2406 & 0.0000 & 0.2031 & 0.0000 \\
\hline Mother is not working & 0.3547 & 0.2609 & 0.3314 & 0.3385 & 0.7064 \\
\hline Mother works at sales & 0.2624 & 0.3518 & 0.0081 & 0.2846 & 0.4294 \\
\hline Mother works as domestic & 0.0658 & 0.0929 & 0.1296 & 0.0769 & 0.4927 \\
\hline Mother with skilled manual job & 0.0480 & 0.0711 & 0.4513 & 0.0462 & 0.4856 \\
\hline Mother is self employed & 0.4834 & 0.5588 & 0.0121 & 0.5116 & 0.3428 \\
\hline Mother works at home & 0.1939 & 0.2193 & 0.0976 & 0.1395 & 0.7284 \\
\hline Observations & 2755 & 506 & & 130 & \\
\hline
\end{tabular}

\section{4}

\section{Ethnic variation and breastfeeding}

In this section, we show evidence suggesting differences in breastfeeding beliefs between Quechua, Aymara and Non-indigenous mothers are relevant for the duration of the breastfeeding period. For that matter, we test the significance of ethnicity on breastfeeding period across three different samples, after controlling for a set of health, demographic and socioeconomic variables. First, we use a sample from rural areas where ethnic groups live in different geographic locations. Second, we use a sample of rural-to-urban migrants and look at the within region variation, thus comparing ethnic groups in a more similar economic and institutional environment, as literature on cultural economics normally does.(2) Third, we use a sample of second-generation migrants, who besides sharing a similar environment, are not subject to migration shocks.(2)

These tests constitute evidence that culture matters for breastfeeding behaviour under certain assumptions. First, migrants and their descendants are not a random sample. However, we assume that the selection process related with the decision to migrate is not correlated with ethnicity, i.e. correlation between migration and breastfeeding is not statistically different between ethnic groups. Second, we assume unobservable variables are not correlated with ethnicity, and if they were, this correlation would not persist 
intergenerationally.

We cannot completely corroborate the validity of our assumptions, i.e. the effect of ethnicity on breastfeeding duration might suffer from bias. However, given the characteristics of our samples, most likely this bias leads to underestimate ethnicity's true effect, especially with the sample of second-generation migrants. This is because the socioeconomic gaps among ethnic groups observed in rural areas fade or even reverse in the case of second-generation migrants, as shown in the Data section. The convergence of socioeconomic characteristics could also be associated with a convergence in beliefs, which would reduce the effect of ethnicity on breastfeeding ${ }^{8}$.

Further, the persistence of statistically significant ethnic breastfeeding differences up to second-generation migrants does not automatically imply these differences are explained by culture. Other unobservable variables that might persist intergenerationally could explain our results. For this reason, we perform robustness tests to rule out some alternative explanations, such as differences in fertility preferences and ancestor's educational background.

\subsection{1 \\ Rural residents and rural-to-urban migrants}

We estimate a linear regression model of the observed breastfeeding duration on a set of ethnic dummies and control variables. Our interest is on the coefficients of the ethnic dummies that show the differences in the breastfeeding period attributed to the ethnic origin. The control variables are known breastfeeding determinants that we can classify into two groups: healthdemographic and socioeconomic variables $(50,18,47,51)$.

We estimate three regressions. First, we estimate the regression model with a sample of rural residents, controlling for a country fixed effect. Second, we estimate the same model with a sample of rural-to-urban migrants. The idea is to test whether ethnic differences in breastfeeding among migrants are similar to those observed in rural areas, where migrants come from. Finally, we include a regional fixed effect in the migrants' estimation to test if ethnic differences in breastfeeding persist after we control for regional unobservable characteristics, i.e. institutional, geographic and economic conditions.

For each regression, we use the following two specifications:

\section{- Specification 1:}

$$
\ln B_{\text {iact }}=\alpha+\gamma I_{\text {iact }}+\mathbb{X}_{\text {iact }}^{1} \beta_{1}+\mathbb{X}_{\text {iact }}^{2} \beta_{2}+\lambda_{a}+\xi_{c}+v_{t}+\varepsilon_{\text {iact }}
$$

${ }^{8}$ Unfortunately, we can't use the same argument with first-generation migrants because the reduction of socioeconomic gaps is partial. Differences in variables related with mother's working decisions seem to be reducing, but differences in education and wealth persist. 
- Specification 2:

$$
\ln B_{\text {iact }}=\alpha+\gamma_{1} Q_{\text {iact }}+\gamma_{2} A_{\text {iact }}+\mathbb{X}_{\text {iact }}^{1} \beta_{1}+\mathbb{X}_{\text {iact }}^{2} \beta_{2}+\lambda_{a}+\xi_{c}+v_{t}+\varepsilon_{\text {iact }}
$$

where $B_{\text {iact }}$ is the number of months the child $i$ was breastfed, at age $a$, from region $c$, interviewed during trimester $t . I_{\text {iact }}, Q_{\text {iact }}, A_{\text {iact }}$ are a dummy variables that are equal to one if child's mother is Indigenous, Quechua and Aymara, respectively. The vector $\mathbb{X}_{\text {iact }}^{1}$ contains the following health-demographic variables: the age of the mother, the household composition (members under and over five years old), a dummy for obese mothers and child's birth weight. The vector $\mathbb{X}_{\text {iact }}^{2}$ contains the following variables socioeconomic variables: family wealth index, mother's education and parents' occupation. $\xi_{c}$ is a regional fixed effect; $v_{t}$ is a trimester fixed effect; $\lambda_{a}$ is an age-in-month fixed effect, and $\varepsilon_{\text {iact }}$ is an idiosyncratic error term.

As Jayachandran et. al. explain, the age-in-month fixed effect allows to compare differences in the duration of breastfeeding among children the same age.(51) In this way, we avoid incurring in bias on the estimation of $\gamma, \gamma_{1}, \gamma_{2}$ caused by the censoring in the duration of breastfeeding.

Table 1.4 shows the model's results of the rural residents' sample (columns (1) to (3)) versus the migrants' sample (columns (4) to (6)). The two samples differ in several ways. On the one hand, economic and institutional environments change between urban and rural areas and they impact the ethnic groups differently ${ }^{9}$. On the other hand, the people who decide to migrate to the city rather than stay in rural areas are potentially different and are subject to different migration costs. These costs could also vary with the ethnicity ${ }^{10}$. Despite all those differences, the model estimates show similar results for the two samples. The point estimates indicate that, after controlling for socioeconomic, demographic and health variables, indigenous mothers breastfeed $6.09 \%$ longer in rural areas, whereas they breastfeed $6.68 \%$ longer in urban areas. Both coefficients are statistically significant at 10\%. Furthermore, the hypothesis test that both coefficients are equal is not rejected ${ }^{11}$. This suggests that the migration selection process each ethnic group undertakes affects

${ }^{9}$ As shown in Section 3.2, the ethnic groups living in the rural area are in different geographic locations. Because of the climate and topographic differences, the production conditions, market access and public good provision change between the ethnic territories. Whereas, in the urban area, a fraction of the ethnic groups migrate to the same cities, thus facing a more similar economic and institutional environment.

${ }^{10} \mathrm{On}$ average, Non-indigenous migrants live further away their region of origin than Indigenous migrants. On the other hand, compared to Non-indigenous people, Indigenous people rely more frequently on relatives and family network when they migrate to the $\operatorname{city}(52)$.

${ }^{11}$ We regress both samples simultaneously, and then, we perform a $\mathrm{F}$ test on the difference of the Indigenous dummy coefficients. The P-value is 0.855 . 
breastfeeding behaviour in the same way. Thus, the bias on the indigenous coefficient caused by differences in the selection process is probably small.

Amongst migrants, the Indigenous-Non-indigenous difference in the breastfeeding period mainly comes from the Aymara ethnic group (See Table 1.4). At first, without control variables, both Quechua and Aymara coefficients are positive and statistically significant. The coefficients mildly change after controlling for demographic and health variables. However, when we include the socioeconomic variables, the Quechua coefficient falls and becomes nonsignificant while the Aymara coefficient stays significant and suffers a smaller reduction. As seen with the coefficient of the indigenous dummy, the Aymara coefficient is not statistically different to the rural residents sample ${ }^{12}$. In both cases, Aymara mothers breastfeed 11\% longer than Non-indigenous mothers.

Table 1.4: The effect of ethnicity on the breastfeeding observed duration

\begin{tabular}{|c|c|c|c|c|c|c|}
\hline & \multicolumn{3}{|c|}{ Rural Residents } & \multicolumn{3}{|c|}{ "Rural-to-urban migrants } \\
\hline & (1) & $(2)$ & $(3)$ & (4) & $(5)$ & $(6)$ \\
\hline $\begin{array}{l}\text { Specification } 1 \\
\text { Indigenous }\end{array}$ & $\begin{array}{c}0.0663^{* * *} \\
(0.0218)\end{array}$ & $\begin{array}{c}0.0967^{* * *} \\
(0.0162)\end{array}$ & $\begin{array}{c}0.0609^{* * *} \\
(0.0156)\end{array}$ & $\begin{array}{r}0.1000^{* *} \\
(0.0467)\end{array}$ & $\begin{array}{l}0.109^{* * *} \\
(0.0344)\end{array}$ & $\begin{array}{l}0.0668^{*} \\
(0.0354)\end{array}$ \\
\hline \multicolumn{7}{|l|}{ Specification 2} \\
\hline Quechua & $\begin{array}{l}0.0565^{* *} \\
(0.0227)\end{array}$ & $\begin{array}{c}0.0884^{* * *} \\
(0.0162)\end{array}$ & $\begin{array}{c}0.0521^{* * *} \\
(0.0161)\end{array}$ & $\begin{array}{l}0.0847^{*} \\
(0.0480)\end{array}$ & $\begin{array}{l}0.0924^{* *} \\
(0.0366)\end{array}$ & $\begin{array}{c}0.0465 \\
(0.0392)\end{array}$ \\
\hline Aymara & $\begin{array}{l}0.104^{* * *} \\
(0.0273)\end{array}$ & $\begin{array}{l}0.150^{* * *} \\
(0.0288)\end{array}$ & $\begin{array}{c}0.115^{* * *} \\
(0.0266)\end{array}$ & $\begin{array}{l}0.128^{* *} \\
(0.0547)\end{array}$ & $\begin{array}{l}0.157^{* * *} \\
(0.0413)\end{array}$ & $\begin{array}{r}0.119^{* * *} \\
(0.0396)\end{array}$ \\
\hline Age in moths FE & No & Yes & Yes & No & Yes & Yes \\
\hline Country FE & No & Yes & Yes & No & Yes & Yes \\
\hline Demographic vars. & No & Yes & Yes & No & Yes & Yes \\
\hline Health vars. & No & Yes & Yes & No & Yes & Yes \\
\hline Socio-economic vars. & No & No & Yes & No & No & Yes \\
\hline Observations & 13341 & 8196 & 7665 & 4183 & 3147 & 2990 \\
\hline
\end{tabular}

Next, we test if the ethnic breastfeeding differences could be explained by the features of the place of migration instead of cultural differences. To test for this possibility, we include a regional fixed effect. However, we must be careful with the interpretation of the results. As Figure 1.1 shows, migrants tends to live near to their ethnic group's native place in the rural area ${ }^{13}$. For example, more Aymara migrants are located in the metropolitan region of La Paz and the city of Tacna, relative to the other ethnic groups. This has two implications. On the one hand, it is possible that the Aymara mother's longer breastfeeding periods are explained by the characteristics of these regions (e.g., location, weather conditions, market conditions and others), and not by their culture.

\footnotetext{
${ }^{12}$ We regress both samples simultaneously, and then, we perform a $\mathrm{F}$ test on the difference of the Aymara dummy coefficients. The P-value is 0.914 .

${ }^{13}$ For each ethnic group, the migrant population symbols are near to the regions painted with the same color
} 
On the other hand, the proximity of the place of residence to rural areas can increase the contact of migrants with their places of origin, thus providing other mechanisms to preserve their culture. So, controlling for regional fixed effects reduces the bias caused by local characteristics but also could reduce the effect of culture itself. In this sense, the ethnic coefficient could be interpreted as a lower bound of the actual effect of culture.

The results of the regression model with regional fixed effects are in Table 1.5. Columns (1) and (2) show that the Aymara coefficient falls by half after we include the regional fixed effect, but it is still statistically significant at 10\%. Furthermore, once we remove the metropolitan region of La Paz, the Aymara coefficient raises again near its original value (0.1). This region has a continuous interaction with a part of the Aymara rural region. Here, the breastfeeding period is long for almost all mothers, however not all of them declare to have learned Aymara as a child, probably because of the interaction with the urban region. So, mothers classified as Non-indigenous might behave as Aymara mothers. In fact, in Table 1.10 of section 1.4.3 we show that mothers that recognize themselves as Aymara - not all learning the language as child also tend to breastfeed longer, and these results are more robust to the inclusion of regional fixed effects.

Table 1.5: City Effect and Breastfeeding

\begin{tabular}{|c|c|c|c|}
\hline & \multicolumn{2}{|c|}{ All migrants } & \multirow{2}{*}{$\frac{\text { Without M.R. of La Paz }}{(3)}$} \\
\hline & (1) & $(2)$ & \\
\hline \multicolumn{4}{|l|}{ Specification 1} \\
\hline Indigenous & $\begin{array}{l}0.0668^{*} \\
(0.0354)\end{array}$ & $\begin{array}{l}0.00864 \\
(0.0205)\end{array}$ & $\begin{array}{c}0.0204 \\
(0.0204)\end{array}$ \\
\hline \multicolumn{4}{|l|}{ Specification 2} \\
\hline Quechua & $\begin{array}{c}0.0465 \\
(0.0392)\end{array}$ & $\begin{array}{r}-0.00893 \\
(0.0259)\end{array}$ & $\begin{array}{c}0.00423 \\
(0.0229)\end{array}$ \\
\hline Aymara & $\begin{array}{c}0.119^{* * *} \\
(0.0396)\end{array}$ & $\begin{array}{l}0.0569^{*} \\
(0.0321)\end{array}$ & $\begin{array}{c}0.105^{* * *} \\
(0.0312)\end{array}$ \\
\hline $\begin{array}{l}\text { Observations } \\
R^{2}\end{array}$ & 2990 & 2990 & 2718 \\
\hline Country FE & Yes & $\mathrm{No}$ & No \\
\hline Regional FE & No & Yes & Yes \\
\hline \multicolumn{4}{|c|}{$\begin{array}{l}\text { Notes: Specification } 1 \text { contains a dummy variable that equals one if the child's } \\
\text { mother is Indigenous and zero otherwise. Specification } 2 \text { contains two dummies of } \\
\text { child's mother ethnic group, one for each indigenous group: Quechua or Aymara. } \\
\text { Controls include age and year FE, seasonal dummies, sex, family size, birth } \\
\text { weight, mother is obese, mother's age and schooling, wealth index, parent's } \\
\text { occupation. } \\
\text { Clustered standard errors in parentheses. }{ }^{*} p<0.10,{ }^{*} p<0.05,{ }^{*} * * p<0.01\end{array}$} \\
\hline
\end{tabular}

\section{4 .2}

\section{Second-generation migrants}

Now, we focus on the second generations of migrants, i.e., mothers born and raised in the urban areas but with Indigenous or Non-indigenous ancestors (parents and grandparents). Studying second-generation migrants 
is advantageous because they don't suffer from migration shocks, but they are still influenced by their ancestors' culture (53). For example, in our case, contrary to Non-indigenous people, usually Indigenous people have to learn Spanish when they migrate. Hence, labor market entry costs might be higher for them, which could lead mothers to prolong breastfeeding, regardless of their culture. The second-generation migrants don't face such costs. On the other hand, the disadvantage of this method is the fact that culture is not only transmitted through the family and without other mechanisms to learn it, e.g. at school, in the neighborhood, from friends, the second-generation migrants may choose not to follow their parent's traditions. Therefore, the cultural differences would be attenuated(53).

We use the data from the 2005-2008 Peruvian DHS, and estimate a linear regression model similar to equation (1-1) in order to test two hypothesis. First, we test if non-migrant mothers with Indigenous ancestors breastfeed longer than those with Non-Indigenous ancestors. Second, we estimate the model using the ethnicity of the child's grandmother and great grandparents simultaneously in order to identify the main source of the breastfeeding differences. The idea is that if culture is transmitted vertically, i.e. from parents to children, once we control for the great grandparents origin, the grandmother origin should become irrelevant to explain the breastfeeding differences. As in the previous section, we estimate the following two specifications:

- Specification 1:

$$
\ln B_{\text {iact }}=\alpha+\delta_{1} I_{\text {iact }}^{1}+\delta_{2} I_{\text {iact }}^{2}+\mathbb{X}_{\text {iact }}^{1} \beta_{1}+\mathbb{X}_{\text {iact }}^{2} \beta_{2}+\lambda_{a}+\xi_{c}+v_{t}+\varepsilon_{\text {iact }}
$$

- Specification 2:

$$
\begin{aligned}
\ln B_{\text {iact }}=\alpha+\delta_{1}^{Q} Q_{\text {iact }}^{1} & +\delta_{2}^{Q} Q_{\text {iact }}^{2}+\delta_{1}^{A} A_{\text {iact }}^{1}+\delta_{2}^{A} A_{\text {iact }}^{2} \\
& +\mathbb{X}_{\text {iact }}^{1} \beta_{1}+\mathbb{X}_{\text {iact }}^{2} \beta_{2}+\lambda_{a}+\xi_{c}+v_{t}+\varepsilon_{\text {iact }}
\end{aligned}
$$

where $B_{\text {iact }}, \mathbb{X}_{\text {iact }}^{1}, \mathbb{X}_{\text {iact }}^{2}, \xi_{c}, v_{t}, \lambda_{a}$ and $\varepsilon_{\text {iact }}$ are defined as in (1-1). $I_{\text {iact }}^{1}, Q_{\text {iact }}^{1}, A_{\text {iact }}^{1}$ are dummy variables that equal to one if the child's grandmother is Indigenous, Quechua or Aymara, respectively. Likewise, $I_{\text {iact }}^{2}, Q_{\text {iact }}^{2}, A_{\text {iact }}^{2}$ are dummies whose values depend on the ethnicity of child's great grandparents by mother side.

Table 1.6 shows the model results. As can be seen in columns (1) and (2), the ethnic breastfeeding differences persist and are consistent with those of the migrants sample. Mothers with Indigenous ancestors tend to breastfeed longer than those with Non-indigenous ancestors, but this difference mainly comes 
from the Aymara ethnic group. Thus, children with Aymara grandmothers are breastfed $11.8 \%$ longer, and children with Aymara great grandparents are breastfed $13.7 \%$ longer. Both coefficients are statistically significant, and they are not different from each other. Besides, although the second-generation sample is only from Peru, these coefficients are close to the ones of the migrants sample.

Column (3) of Table 1.6 shows the model results when we include the two dummies of Indigenous ancestors - child's grandmother and great grandparents. As expected, only the Aymara and Indigenous great grandparents dummies remain significant, which is evidence supporting the vertical transmission of breastfeeding beliefs.

Table 1.6: Breastfeeding among second-generation migrants in Peru

\begin{tabular}{|c|c|c|c|}
\hline & $(1)$ & $(2)$ & $(3)$ \\
\hline \multicolumn{4}{|l|}{ Specification 1} \\
\hline Indigenous grandmother & $\begin{array}{c}0.0559 \\
(0.0344)\end{array}$ & & $\begin{array}{c}-0.00771 \\
(0.0287)\end{array}$ \\
\hline Indigenous great grandparents & & $\begin{array}{c}0.0768^{*} \\
(0.0401)\end{array}$ & $\begin{array}{l}0.0816^{*} \\
(0.0463)\end{array}$ \\
\hline \multicolumn{4}{|l|}{ Specification 2} \\
\hline Quechua grandmother & $\begin{array}{c}0.0384 \\
(0.0366)\end{array}$ & & $\begin{array}{l}-0.0135 \\
(0.0322)\end{array}$ \\
\hline Aymara grandmother & $\begin{array}{l}0.118^{* *} \\
(0.0442)\end{array}$ & & $\begin{array}{l}-0.0220 \\
(0.0541)\end{array}$ \\
\hline Quechua great grandparents & & $\begin{array}{c}0.0635 \\
(0.0426)\end{array}$ & $\begin{array}{c}0.0715 \\
(0.0484)\end{array}$ \\
\hline Aymara great grandparents & & $\begin{array}{c}0.137^{* * *} \\
(0.0447)\end{array}$ & $\begin{array}{l}0.154^{* *} \\
(0.0741)\end{array}$ \\
\hline Observations & 3014 & 2942 & 2942 \\
\hline \multicolumn{4}{|c|}{$\begin{array}{l}\text { Notes: Specification } 1 \text { contains a dummy variable that equals one if the child's } \\
\text { mother is Indigenous and zero otherwise. Specification } 2 \text { contains two dummies } \\
\text { of child's mother ethnic group, one for each indigenous group: Quechua or } \\
\text { Aymara. } \\
\text { Controls include regional, age and year FE, seasonal dummies, sex, family } \\
\text { size, bith weight, mother is obese, mother's age and schooling, wealth index, } \\
\text { parent's occupation. } \\
\text { Clustered standard errors in parentheses. }{ }^{*} p<0.10,{ }^{*}{ }^{*} p<0.05,{ }^{*}{ }^{*}\end{array}$} \\
\hline
\end{tabular}

Next, we join the migrants and second-generation samples from Peru in order to estimate the following specifications:

- Specification 1:

$$
\begin{aligned}
\ln B_{\text {iact }}=\alpha+\delta_{3} I_{\text {iact }}^{3}+ & \delta_{4} M_{\text {iact }}+\delta_{5} M_{\text {iact }} \times I_{\text {iact }}^{3} \\
& +\mathbb{X}_{\text {iact }}^{1} \beta_{1}+\mathbb{X}_{\text {iact }}^{2} \beta_{2}+\lambda_{a}+\xi_{c}+v_{t}+\varepsilon_{\text {iact }}
\end{aligned}
$$

- Specification 2:

$$
\begin{aligned}
\ln B_{\text {iact }}=\alpha+\delta_{3}^{Q} Q_{\text {iact }}^{3} & +\delta_{3}^{A} A_{\text {iact }}^{3}+\delta_{4} M_{\text {iact }} \\
+\delta_{5}^{Q} & M_{\text {iact }} \times Q_{\text {iact }}^{3}+\delta_{5}^{A} M_{\text {iact }} \times A_{\text {iact }}^{3} \\
& +\mathbb{X}_{\text {iact }}^{1} \beta_{1}+\mathbb{X}_{\text {iact }}^{2} \beta_{2}+\lambda_{a}+\xi_{c}+v_{t}+\varepsilon_{\text {iact }}
\end{aligned}
$$


where $B_{\text {iact }}, \mathbb{X}_{\text {iact }}^{1}, \mathbb{X}_{\text {iact }}^{2}, \xi_{c}, v_{t}, \lambda_{a}$ and $\varepsilon_{\text {iact }}$ are defined as in (1-1). As in (1-3), $I_{\text {iact }}^{3}, Q_{\text {iact }}^{3}, A_{\text {iact }}^{3}$ are dummies whose values depend on the ethnicity of child's grandmother or great grandparents by mother side. And $M_{\text {iact }}$ is a dummy that equals one if the child's mother is a migrant and zero otherwise.

In equation (1-5), we test once again if mothers with Indigenous ancestors breastfeed longer than those with Non-indigenous ancestors. The ethnic dummy should remain significant after controlling for the migrant dummy and the interaction of these two variables. The interpretation of the interaction coefficient is ambiguous. On the one hand, it captures the effect of migration shocks that are specific to each ethnicity. On the other hand, this interaction also captures the effect of a longer exposure to the native culture. The first generation of migrants, contrary to the second generation, were raised in the rural area. So, besides their parents, their social environment, such as neighbors, friends and teachers helped on the transmission of their culture while they were growing up.

Table 1.7 shows the results of equation (1-5). Migrant mothers breastfeed longer and the effect is higher and statistically significant for Aymara mothers, which suggests that migration itself contributes to prolong breastfeeding. In spite of that, mothers with Aymara ancestors still breastfeed longer than mothers with Non-indigenous ancestors. Furthermore, these coefficients reduce slightly and are not statistically different than those of Table 1.6. The Aymara grandmother coefficient changes from 11 to 8 percent, while the Aymara great grandparents coefficient changes from 15 to 13 percent. This result implies that neither migration costs nor growing in an urban environment have a significant impact on the ethnic breastfeeding differences.

\section{4 .3}

\section{Robustness Analysis}

We present four robustness tests. First, we rule out two alternative explanations for the ethnic breastfeeding differences. One possibility is that these differences represent discrepancies in fertility preferences rather than culture. Another possibility is that they are driven by systematic differences in the ancestors education instead of their culture. Next, we test if the results are robust to an alternative definition of ethnicity, and finally, if they remain significant for the living children of the sample.

In rural areas of some developing countries, breastfeeding is also used as a traditional contraceptive method. So, instead of reflecting breastfeeding beliefs, prolonged breastfeeding periods could be a consequence of the decision to space or limit births. To test for this possibility, we follow Jayachandran 
Table 1.7: Ethnic breastfeeding differences among urban residents in -Peru (2005-2008)

\begin{tabular}{|c|c|c|}
\hline & $(1)$ & $(2)$ \\
\hline Quechua grandmother & $\begin{array}{c}0.0507 \\
(0.0308)\end{array}$ & \\
\hline Aymara grandmother & $\begin{array}{l}0.0918^{* *} \\
(0.0412)\end{array}$ & \\
\hline Quechua great grandparents & & $\begin{array}{c}0.0796^{* *} \\
(0.0380)\end{array}$ \\
\hline Aymara great grandparents & & $\begin{array}{c}0.124^{* * *} \\
(0.0408)\end{array}$ \\
\hline Quechua grandmother $\times$ Migrant mother & $\begin{array}{l}-0.0445 \\
(0.0495)\end{array}$ & \\
\hline Aymara grandmother $\times$ Migrant mother & $\begin{array}{l}0.0455^{*} \\
(0.0261)\end{array}$ & \\
\hline Quechua great grandparents $\times$ Migrant mother & & $\begin{array}{l}-0.0165 \\
(0.0390)\end{array}$ \\
\hline Aymara great grandparents $\times$ Migrant mother & & $\begin{array}{l}0.0632^{*} \\
(0.0360)\end{array}$ \\
\hline Migrant mother & $\begin{array}{c}0.0767^{* * *} \\
(0.0223)\end{array}$ & $\begin{array}{c}0.0695^{* * *} \\
(0.0220)\end{array}$ \\
\hline Observations & 4314 & 4186 \\
\hline
\end{tabular}

et. al.(51) and include the following fertility preference variables into equation (1-2) and (1-4): the difference between the ideal number of children a mother would like to have and the number she actually has, a dummy for the children born after reaching the ideal family size, the succeeding birth interval, and a dummy for the children born last. As Table 1.8 shows, although the succeeding birth interval and last birth dummy are statistically significant variables, they don't alter Aymara mothers' effect on breastfeeding, neither for the first nor the second generation of migrants (First generation results in columns (1)-(3) and Second generation results in columns (4)-(6)). These results support the idea that the breastfeeding differences are explained by variations in breastfeeding beliefs.

Mothers' ancestors come from different locations and might have potentially different stocks of human capital, which could impact mother's cognitive skills and breastfeeding decision(54). Under these circumstances, ethnic breastfeeding differences could be explained by systematic differences in grandparents education instead of culture. To test for this possibility, first we re-estimate equation (1-2) using only the migrants from 2007-2008 Peruvian DHS, which contains information of grandparents' educational level. Then, we include these variables as dummies in equation (1-2). Results are in Table 1.9. Although we didn't include regional fixed effects due to the sample size, the results are similar to those obtained with the full sample. And when we include the grandparent's education, the Aymara coefficient does not change significantly. Hence, culture is still the most likely explanation for the ethnic 
Table 1.8: Fertility Preferences and Breastfeeding

\begin{tabular}{|c|c|c|c|c|c|c|}
\hline & \multicolumn{3}{|c|}{ Migrants } & \multicolumn{3}{|c|}{ 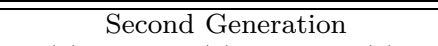 } \\
\hline & $(1)$ & $(2)$ & $(3)$ & $(4)$ & $(5)$ & $(6)$ \\
\hline Quechua & $\begin{array}{c}-0.00893 \\
(0.0259)\end{array}$ & $\begin{array}{c}-0.00801 \\
(0.0256)\end{array}$ & $\begin{array}{l}0.00130 \\
(0.0224)\end{array}$ & & & \\
\hline Aymara & $\begin{array}{l}0.0569^{*} \\
(0.0321)\end{array}$ & $\begin{array}{l}0.0573^{*} \\
(0.0314)\end{array}$ & $\begin{array}{c}0.0626^{* *} \\
(0.0261)\end{array}$ & & & \\
\hline Grandmother is Quechua & & & & $\begin{array}{c}0.0384 \\
(0.0366)\end{array}$ & $\begin{array}{c}0.0393 \\
(0.0370)\end{array}$ & $\begin{array}{c}0.0358 \\
(0.0376)\end{array}$ \\
\hline Grandmother is Aymara & & & & $\begin{array}{l}0.118^{* *} \\
(0.0442)\end{array}$ & $\begin{array}{l}0.118^{* *} \\
(0.0441)\end{array}$ & $\begin{array}{c}0.124^{* *} \\
(0.0519)\end{array}$ \\
\hline Distance to ideal family size & & $\begin{array}{c}0.00211 \\
(0.00575)\end{array}$ & $\begin{array}{c}0.000632 \\
(0.00572)\end{array}$ & & $\begin{array}{l}-0.00875 \\
(0.00869)\end{array}$ & $\begin{array}{c}-0.0103 \\
(0.00829)\end{array}$ \\
\hline Child is born after ideal family size & & $\begin{array}{c}0.0263 \\
(0.0267)\end{array}$ & $\begin{array}{c}0.0000942 \\
(0.0286)\end{array}$ & & $\begin{array}{c}0.0254 \\
(0.0305)\end{array}$ & $\begin{array}{c}0.0130 \\
(0.0286)\end{array}$ \\
\hline Succeeding birth interval & & & $\begin{array}{c}0.0149^{* * *} \\
(0.00276)\end{array}$ & & & $\begin{array}{c}0.0165^{* * *} \\
(0.00238)\end{array}$ \\
\hline Last birth & & & $\begin{array}{c}0.632^{* * *} \\
(0.0799)\end{array}$ & & & $\begin{array}{c}0.707^{* * *} \\
(0.0967)\end{array}$ \\
\hline Observations & 2990 & 2990 & 2990 & 3014 & 3014 & 3014 \\
\hline
\end{tabular}

breastfeeding differences.

Table 1.9: Grandparents' educational background and Breastfeeding

\begin{tabular}{lccc}
\hline \hline \multicolumn{1}{c}{$(1)$} & $(2)$ & $(3)$ \\
\hline Quechua & $0.0736^{*}$ & $0.0730^{*}$ & 0.0647 \\
& $(0.0411)$ & $(0.0389)$ & $(0.0389)$ \\
Aymara & $0.115^{* *}$ & $0.113^{* *}$ & $0.132^{* *}$ \\
& $(0.0432)$ & $(0.0510)$ & $(0.0548)$ \\
\hline Grandmother's education & YES & YES \\
Grandfather's education & & 865 \\
\hline Observations & 905 & 844 & \\
\hline \hline & Notes: Table only contains estimates of Specification 2. \\
Controls include age and year FE, seasonal dummies, sex, family size, \\
birth weight, mother is obese, mother's age and schooling, wealth index, \\
parent's occupation. \\
Clustered standard errors in parentheses. ${ }^{*} p<0.10,{ }^{*} * p<0.05,{ }^{*} * *$ \\
$p<0.01$
\end{tabular}

Until now, we have identified the mother's ethnicity using the language she learned as a child. Another way to do this is by self-identification, i.e., to ask the mother to which ethnic group she belongs to. So, we estimate equations (1-1) and(1-2) again, using this alternative classification to test if results change. As Tables 1.10 and 1.5 show, breastfeeding differences are qualitatively similar but are larger in magnitude when we use the self-identification instead of the language learned as a child. The breastfeeding difference between Aymara and Non-indigenous mothers doubles using self-identification instead of the language learned as a child. Seemingly, the Quechua coefficient is positive and statistically significant when we use self-identification, whereas it is not statistically different from zero when we use the language learned as a child. Probably, these results are because the cultural differences are more marked 
among mothers who identify themselves with a certain ethnic group than mothers who only speak their parents' language. ${ }^{14}$

Table 1.10: Regression results using ethnicity self-identification

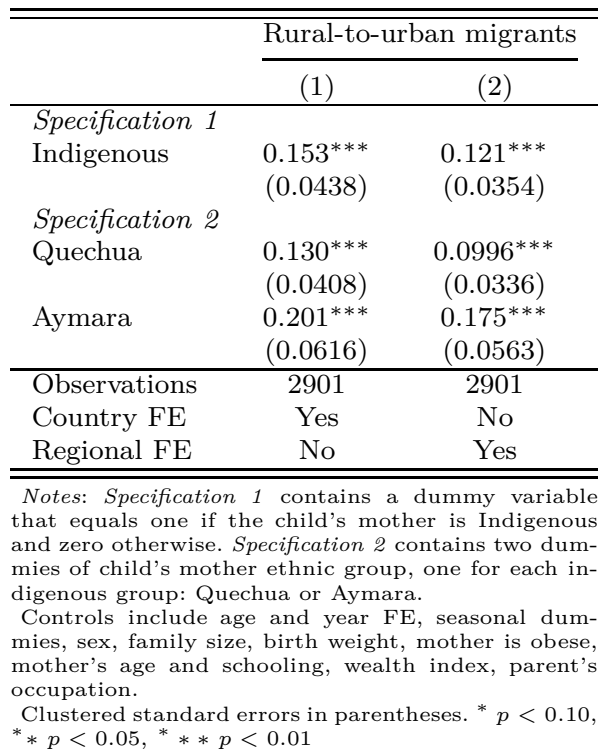

As we explained in Section 3.3, the data set we use contain information on all the living births up to five years before the interview. However, some of the children were dead at that moment, which could shorten the breastfeeding period. So, we test if our results change when we restrict the sample to the living children. Columns (1) to (3) of Table 1.11 show the estimates of equation (1-2), whereas columns (4) and (5) show the estimates of equation (1-4). Comparing these results with Table 1.5 and 1.6, we find no significant difference between the restricted and the full sample estimates. Therefore, the inclusion of dead children does not alter the ethnic breastfeeding differences.

So far, we have found that Aymara mothers consistently breastfeed $10 \%$ longer than Non-Indigenous mothers. This difference in breastfeeding remains constant for the first and second generations of rural-to-urban migrants that live in the same region, facing similar institutional, economic and geographical conditions. In addition, it is not explained by discrepancies in fertility preferences or differences in the ancestors education.

An increase in breastfeeding period of the magnitude we observe could have positive impacts on children development. Bolivia and Peru are among the countries with the largest breastfeeding period of the world. So, in principle, an additional gain in brestfeeding under these circumstances might not be so relevant. However, the magnitude of the effect of ethnicity on breastfeeding is

${ }^{14}$ We can't classify the second-generation migrants using self-identification. That is why we focus on the classification by the language learned as a child even though ethnic breastfeeding differences are larger using self-identification. 
Table 1.11: Regression results excluding dead children from the sample

\begin{tabular}{|c|c|c|c|c|c|}
\hline & \multicolumn{3}{|c|}{ Migrants } & \multicolumn{2}{|c|}{$\overline{\text { Second Generation }}$} \\
\hline & $(1)$ & $(2)$ & $(3)$ & $(4)$ & $(5)$ \\
\hline Quechua & $\begin{array}{c}0.0437 \\
(0.0409)\end{array}$ & $\begin{array}{l}-0.0122 \\
(0.0257)\end{array}$ & $\begin{array}{c}-0.000730 \\
(0.0236)\end{array}$ & & \\
\hline Aymara & $\begin{array}{l}0.126^{* * *} \\
(0.0387)\end{array}$ & $\begin{array}{c}0.0608^{* *} \\
(0.0279)\end{array}$ & $\begin{array}{c}0.0988^{* * *} \\
(0.0319)\end{array}$ & & \\
\hline Grandmother is Quechua & & & & $\begin{array}{c}0.0408 \\
(0.0357)\end{array}$ & \\
\hline Grandmother is Aymara & & & & $\begin{array}{l}0.110^{* * *} \\
(0.0403)\end{array}$ & \\
\hline Greatgrandparents are Quechua & & & & & $\begin{array}{c}0.0636 \\
(0.0428)\end{array}$ \\
\hline Greatgrandparents are Aymara & & & & & $\begin{array}{c}0.132^{* * *} \\
(0.0428)\end{array}$ \\
\hline Observations & 2912 & 2912 & 2653 & 2977 & 2906 \\
\hline Country FE & Yes & No & No & No & No \\
\hline Regional FE & No & Yes & Yes & Yes & Yes \\
\hline Without MR of La Paz & No & No & Yes & No & No \\
\hline
\end{tabular}

still important for the children development, as the following evidence suggests. The average breastfeeding period of Non-indigenous mothers in the migrants sample is 13,6 months. So, a gap of $10 \%$ between Aymara and Non-indigenous mothers implies Aymara mothers breastfeed approximately 1,4 months longer. According to Guxens et. al. (55), an additional month of lactation in 14-monthold children increases their IQ in 0.37 points of Bayleys scale. Also, according to Victora et. al. (56), increasing breastfeeding from 6-11 months to more than a year raises adult's education in 0.26 years.

\section{5}

Socialization mechanisms

In this section, we study possible transmission mechanisms of breastfeeding beliefs. Initially, we focus on direct vertical socialization mechanisms. These mechanisms are related with the transmission of cultural traits inside the family $(57)$. Thus, we test grandparents ethnicity and female peers effects on the breastfeeding period. Then, we study how the Spanish-Indigenous interaction during colonial times could have affected ethnic differences in breastfeeding today. In particular, we test two opposing sociological theories of ethnic identity formation: conformity versus distinction(26).

\subsection{1}

\section{Direct vertical socialization}

Anthropological studies of Andean Indigenous people find that child rearing is essentially a female task, especially during the child's first year of life. 
This responsibility is not only entitled to the mother, but also daughters, aunts, cousins, mothers in law and grandmothers(45). So, contrary to other cultural traits (e.g. saving habits, political beliefs), we expect that the transmission of breastfeeding beliefs relies mostly on the female family members. We verify this hypothesis in two ways. First, we compare the child's grandfather ethnicity effect on the breastfeeding period versus the grandmother ethnicity effect. Second, we test if the ethnic breastfeeding differences change with the number of female peers living in the household.

In Section 2.4, we used the second-generation sample to show evidence of cultural transmission from mothers to daughters. Now, we test the role of fathers and compare both, using the following specification

$$
\begin{aligned}
\ln B_{\text {iact }}=\alpha+\delta_{1}^{Q} Q_{\text {iact }}^{1}+\delta_{2}^{Q} Q_{\text {iact }}^{2}+\delta_{1}^{A} A_{\text {iact }}^{1}+\delta_{2}^{A} A_{\text {iact }}^{2} & \\
& +\mathbb{X}_{\text {iact }}^{1} \beta_{1}+\mathbb{X}_{\text {iact }}^{2} \beta_{2}+\lambda_{a}+\xi_{c}+v_{t}+\varepsilon_{\text {iact }}
\end{aligned}
$$

where $B_{\text {iact }}, \mathbb{X}_{\text {iact }}^{1}, \mathbb{X}_{\text {iact }}^{2}, \xi_{c}, v_{t}, \lambda_{a}$ and $\varepsilon_{\text {iact }}$ are defined as in (1-1). $Q_{\text {iact }}^{1}, A_{\text {iact }}^{1}$ are dummy variables that equal to one if the child's grandfather is Quechua or Aymara, respectively. Similarly, $Q_{\text {iact }}^{2}, A_{\text {iact }}^{2}$ are dummies whose values depend on the ethnicity of child's grandmother.

The model estimates are in Table 1.12, and they show that having an Aymara grandfather increases the breastfeeding duration in $9 \%$. However, as expected, this effect reduces to zero after we control for the grandmother ethnicity, which implies the grandfather ethnicity has no effect on how long a mother breastfeeds.

Table 1.12: Grandparents' cultural influence on breastfeeding

\begin{tabular}{lcc}
\hline \hline & $(1)$ & $(2)$ \\
\hline Quechua grandfather & 0.0389 & 0.0115 \\
& $(0.0368)$ & $(0.0416)$ \\
Aymara grandfather & $0.0910^{*}$ & -0.00807 \\
& $(0.0473)$ & $(0.0535)$ \\
Quechua grandmother & & 0.0289 \\
& & $(0.0429)$ \\
Aymara grandmother & & $0.124^{* *}$ \\
& & $(0.0484)$ \\
\hline Observations & 3000 & 2992 \\
$R^{2}$ & 0.483 & 0.483 \\
\hline \hline
\end{tabular}

Note: Controls include regional, age and year $\mathrm{FE}$, seasonal dummies, sex, family size, birth weight, mother is obese, mother's age and schooling, wealth index, parent's occupation.

Clustered standard errors in parentheses. ${ }^{*} p<0.10$ ${ }^{*} * p<0.05,{ }^{*} * * p<0.01$.

Next, we use the migrants sample to test the effect of female peers inside the household with the following specification 


$$
\begin{array}{r}
\ln B_{\text {iact }}=\alpha+\eta_{1}^{Q} Q_{\text {iact }}+\eta_{1}^{A} A_{\text {iact }}+\eta_{2} N_{\text {iact }}+\eta_{3}^{Q} N_{\text {iact }} \times Q_{\text {iact }}+\eta_{3}^{A} N_{\text {iact }} \times A_{\text {iact }} \\
+\mathbb{X}_{\text {iact }}^{1} \beta_{1}+\mathbb{X}_{\text {iact }}^{2} \beta_{2}+\lambda_{a}+\xi_{c}+v_{t}+\varepsilon_{\text {iact }}
\end{array}
$$

where $B_{\text {iact }}, Q_{\text {iact }}, A_{\text {iact }}, \mathbb{X}_{\text {iact }}^{1}, \mathbb{X}_{\text {iact }}^{2}, \xi_{c}, v_{t}, \lambda_{a}$ and $\varepsilon_{\text {iact }}$ are defined as in (1-2) and $N_{\text {iact }}$ is the number of women of child-bearing age (15-49) in the household (excluding the mother).

In line with the anthropological evidence, we expect $\eta_{3}^{Q}, \eta_{3}^{A}$ to be positive and significant. This is true for Aymara mothers, as shown in Table 1.13. The results show that among Aymara mothers, an additional women in the household increases the breastfeeding period in $14 \%$.

Table 1.13: Female peers and ethnic breastfeeding differences

\begin{tabular}{lc}
\hline \hline & $(1)$ \\
\hline Quechua $\times$ Number of women 15-45 in the family & -0.0642 \\
& $(0.0599)$ \\
Aymara $\times$ Number of women 15-45 in the family & $0.149 * * *$ \\
& $(0.0548)$ \\
Quechua & 0.00486 \\
& $(0.0271)$ \\
Aymara & 0.0275 \\
& $(0.0296)$ \\
Number of women 15-45 in the family & -0.0158 \\
& $(0.0276)$ \\
\hline Observations & 2990 \\
$R^{2}$ & 0.577 \\
\hline \hline Note: Controls include regional, age and year FE, seasonal dummies, sex, \\
family size, birth weight, mother is obese, mother's age and schooling, \\
wealth index, parent's occupation. \\
Clustered standard errors in parentheses. ${ }^{*} p<0.10,{ }^{*} * p<0.05,{ }^{*} * *$ \\
$p<0.01$.
\end{tabular}

Furthermore, these results rule out genetics as an alternative explanation of the ethnic breastfeeding differences. Recent studies found that some genetic factors can influence the lactation physiology, and the ability to produce breast milk, thus altering the breastfeeding period.(58) So, it is plausible that genetic disparities between ethnic groups explain the breastfeeding differences. However, if this was true, the ethnic breastfeeding differences should not change with the number of women of child-bearing age in the household, something that is not supported by Table 1.13 estimates. Therefore, once again, the results reinforce the cultural hypothesis.

\section{5 .2}

\section{Ethnic Identity Formation}

We use the regional variation of the Spanish-Indigenous interaction during colonial times to study the effect of this interaction on the formation of the current breastfeeding cultural traits. As we explained in Section 3.2, 
the geographic and institutional setting in colonial times caused the SpanishIndigenous interaction to vary between regions, which could have generated different regional cultural traits. However, there are different theories in which the former could impact the latter. Sociologists have two opposing views on ethnic identity formation:

1. Cultural conformity: Social contacts between ethnic groups help weaken group loyalties and prejudices, hence leading to a more culturally homogeneous society.

2. Cultural distinction: Various cognitive and psychological mechanisms, from group solidarity to prejudice and negative stereotypes with respect to other groups, are deemed responsible in achieving a positive distinctiveness $(26,27)$.

Under cultural conformity, the Spanish-Indigenous interaction would have led to a higher integration of the ethnic groups, which would have increased the proximity of their culture through time, hence reducing the breastfeeding differences today. While, on the other hand, under cultural distinction, the Spanish-Indigenous interaction would have contributed to the persistence of divergent cultural traces, increasing breastfeeding differences today.

We define two different regional-level variables that measure the SpanishIndigenous interaction so as to test which sociological theory applies to our case using the migrants sample. First, we measure the Spanish-Indigenous interaction at region $c$ as the minimum distance from this region to Potosi, Huancavelica and Pasco, which were the main mining centers during colonial times. The idea is that these economic centers and surroundings concentrated more Spanish and Indigenous people compared to other regions, so the greater the distance the smaller the interaction between them. Then, we estimate

$$
\begin{aligned}
\ln B_{\text {iadct }}=\alpha+\theta_{1}^{Q} Q_{\text {iadct }}+ & \theta_{1}^{A} A_{\text {iadct }}+\theta_{2} S_{d c}+\theta_{3}^{Q} S_{d c} \times Q_{\text {iadct }}+\theta_{3}^{A} S_{d c} \times A_{\text {iadct }} \\
& +\mathbb{X}_{\text {iadct }}^{1} \beta_{1}+\mathbb{X}_{\text {iadct }}^{2} \beta_{2}+\lambda_{a}+\xi_{d}+v_{t}+\varepsilon_{\text {iadct }}
\end{aligned}
$$

where $B_{\text {iadct }}, Q_{\text {iadct }}, A_{\text {iadct }}, \mathbb{X}_{\text {iadct }}^{1}, \mathbb{X}_{\text {iadct }}^{2}, v_{t}, \lambda_{a}$ and $\varepsilon_{\text {iadct }}$ are defined as in (1-2), the subscript $d$ means department, $\xi_{d}$ is a department fixed effect, and $S_{c d}$ is the distance to a mining center.

The coefficient of the product between the Indigenous dummy and the distance to a mining center, $\theta_{3}^{Q}, \theta_{3}^{A}$, tells us the sociological theory that applies 
to our case. Thus, if it was positive and significant, it would mean the SpanishIndigenous interaction decreased the current breastfeeding differences. Hence, the results would be in line with cultural conformity. On the contrary, if $\theta_{3}^{Q}, \theta_{3}^{A}$ were negative and significant, the results would be in line with cultural distinction.

In order for our coefficients to be interpretable, we need to assume that the place of origin of the migrant's family is in the same region as her current place of residence. Also, we have to assume that the migrant's family historically remained in the same place. This is because we use a sample of migrants only and we estimate the distance between the migrant's current place of residence and the mining centers, instead of her family's place of origin. However, our assumption seems to be plausible when we look at Figure 1.1, which shows that a considerable amount of migrants live near to their ethnic group's native regions in the rural area, as we mentioned before.

Table 1.14 shows the estimates of equation 1-9. The results of the Aymara and Non-indigenous ethnic groups are consistent with cultural distinction. As we can see, the coefficient of the product between the Aymara dummy and the distance to a mining center is negative and significant. The model predicts Aymara mothers at the mining centers breastfeed $25.9 \%$ more than Non-indigenous mothers while this difference falls to $4.45 \%$ in regions four thousand kilometers away from the mining centers and becomes non-significant for longer distances (see Figure 1.3).

Table 1.14: Distance to a Mining Center and ethnic breastfeeding differences

\begin{tabular}{|c|c|}
\hline & $(1)$ \\
\hline Quechua $\times$ Min. distance to $\mathrm{MC}$ & $\begin{array}{c}0.0236 \\
(0.147)\end{array}$ \\
\hline Aymara $\times$ Min. distance to $\mathrm{MC}$ & $\begin{array}{c}-0.543^{* *} \\
(0.227)\end{array}$ \\
\hline Quechua & $\begin{array}{r}-0.00700 \\
(0.0367)\end{array}$ \\
\hline Aymara & $\begin{array}{c}0.262^{* * *} \\
(0.0870)\end{array}$ \\
\hline Min. distance to $\mathrm{MC}$ & $\begin{array}{c}0.150 \\
(0.168) \\
\end{array}$ \\
\hline $\begin{array}{l}\text { Observations } \\
R^{2} \\
\end{array}$ & \\
\hline \multicolumn{2}{|c|}{$\begin{array}{l}\text { Note: MS stands for Mining Center. } \\
\text { Controls include regional, age and year FE, seasonal } \\
\text { dummies, sex, family size, birth weight, mother is obese, } \\
\text { mother's age and schooling, wealth index, parent's oc- } \\
\text { cupation. } \\
\text { Clustered standard errors in parentheses. }{ }^{*} p<0.10 \text {, } \\
*^{*} p<0.05,{ }^{*} * * p<0.01 \text {. }\end{array}$} \\
\hline
\end{tabular}

Using Grieshaber's demographic data of Bolivia in the 1830s (end of the colonial period, beginning of the republic) (34), we create a second alternative to measure the Spanish-Indigenous interaction: the percentage of Indigenous population located in haciendas or towns, $P_{c d}$. This variable is defined as 
Figure 1.3: The effect of the distance to mining centers on Aymara breastfeeding difference

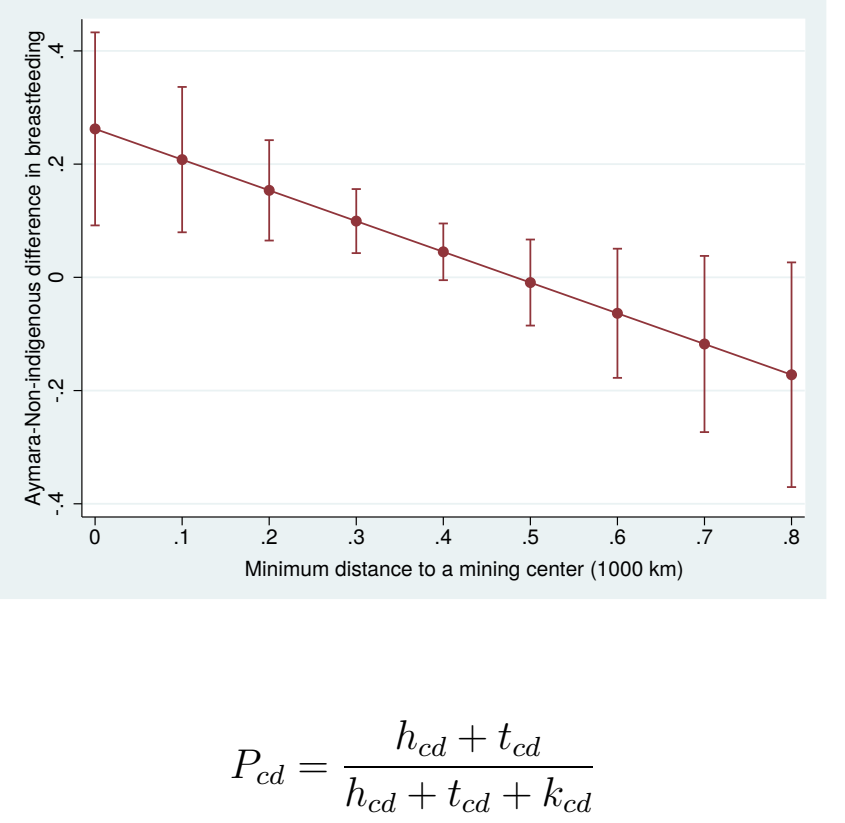

where $h_{c d}$ is the number of Indigenous people at province $c$, that lived in haciendas; $t_{c d}$ is the number of Indigenous people that lived in towns, and $k_{c d}$ is the number of Indigenous people that lived in communities. Since Spanish people didn't live in communities, we expect the interaction with Indigenous people to be higher in provinces where $P_{c d}$ is higher too.

Next, we estimate equation (1-9) again, but we replace $S_{c d}$ with $P_{c d}$. In this case, the coefficient of the product between the Indigenous dummy and the percentage of Indigenous population in haciendas or towns, $\theta_{3}^{Q}, \theta_{3}^{A}$, has a different interpretation. If $\theta_{3}^{Q}, \theta_{3}^{A}$ were positive and significant, it would mean the Spanish-Indigenous interaction increased the current breastfeeding differences. So, cultural distinction would be the most likely explanation. On the contrary, if $\theta_{3}^{Q}, \theta_{3}^{A}$ were negative and significant, cultural conformity is the most likely explanation.

The model estimates support our previous results. As well as Table 1.14, Table 1.15 shows that the coefficient of the product between the Aymara dummy and the percentage of Indigenous population in haciendas or towns is positive and significant, which is consistent with cultural distinction. In provinces where all the Indigenous population lived in haciendas or towns, Aymara mothers breastfeed 9.1\% longer than Non-indigenous mothers. On the other hand, in provinces where less than $70 \%$ of the Indigenous population lived in haciendas or towns, the difference in breastfeeding goes to zero and becomes statistically not significant (see Figure 1.4).

In addition to the last results, anthropological evidence is also consistent with cultural distinction. After the Spanish conquest, Indigenous people 
Table 1.15: Indigenous population in haciendas or towns and ethnic breastfeeding differences

\begin{tabular}{lc}
\hline \hline & $(1)$ \\
\hline Quechua $\times \%$ of Ind. Pop. in Hacienda/Town & 0.0555 \\
& $(0.0868)$ \\
& $0.206^{* *}$ \\
Aymara $\times \%$ of Ind. Pop. in Hacienda/Town & $(0.0783)$ \\
& -0.106 \\
Quechua & $(0.0755)$ \\
Aymara & $-0.115^{*}$ \\
& $(0.0585)$ \\
\% of Ind. Pop. in Hacienda/Town & -0.0245 \\
& $(0.0661)$ \\
\hline Observations & 1100 \\
$R^{2}$ & 0.648 \\
\hline \hline Note: Controls include regional, age and year FE, seasonal dummies, \\
sex, family size, birth weight, mother is obese, mother's age and \\
schooling, wealth index, parent's occupation. \\
Clustered standard errors in parentheses. ${ }^{*} p<0.10,{ }^{*} p<0.05$, \\
$* * p<0.01$.
\end{tabular}

Figure 1.4: The effect of Indigenous population in haciendas or towns on Aymara breastfeeding difference

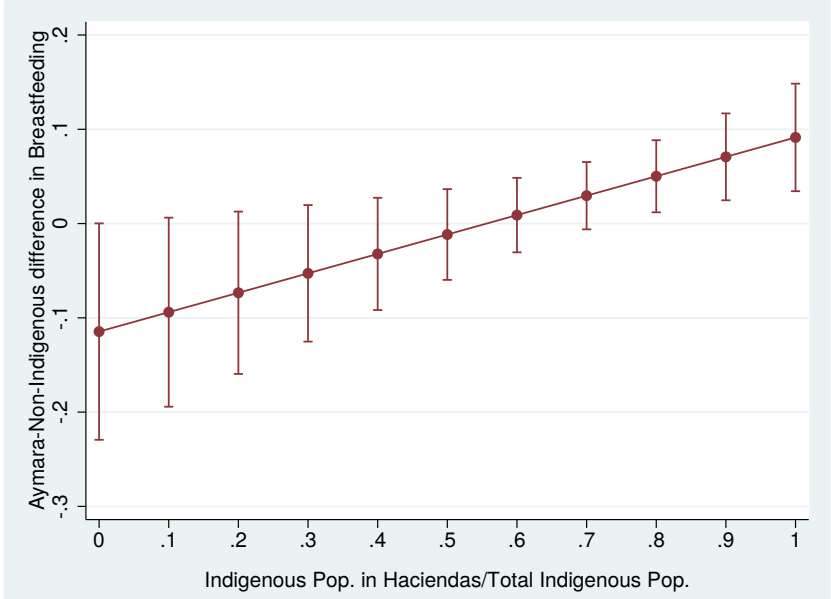

entered in a new social hierarchy. They were not entitled to the same rights as Spanish descendants and they were compelled to pay tributes and unpaid labor. The Catholic church and the state forced Indigenous people to convert to Christianity. Those who were not converted, were considered "pagans and savages". With these prejudices and negative stereotypes, Indigenous people sought refuge in local authorities and family traditions to preserve their culture, e.g. only community members took part in some religious rituals, pre-colonial features of community organization were preserved, as well as some beliefs on how to raise children and insert them in the community $(33,59,52,60)$. 


\section{6 \\ Conclusions}

In this paper, we establish that the breastfeeding period varies systematically with the mother's ethnicity, and we argue that the differences in breastfeeding between ethnic groups are likely associated with cultural differences. So, after controlling for several socioeconomic and demographic variables, and regardless the sample, we find that Aymara mothers consistently breastfeed $10 \%$ longer than Non-Indigenous mothers. In particular, this difference in breastfeeding remains constant for the first and second generations of ruralto-urban migrants that live in the same region, facing similar institutional, economic and geographical conditions. In addition, it is not explained by discrepancies in fertility preferences or differences in the ancestors education.

Some socialization mechanisms related to the transmission of culture contribute to explain the ethnic breastfeeding differences. First, we find that most likely breastfeeding beliefs are vertically transmitted, i.e. from parents to children, because the great grandparents' ethnicity affect the breastfeeding period only through the grandmother. Second, we find that the transmission of breastfeeding beliefs inside the family relies essentially on the female members, which is consistent with anthropological evidence. Thus, the grandfather's ethnicity has no effect on the breastfeeding period, once we control for the grandmother's ethnicity. But also, Aymara women who live with more female peers tend to breastfeed longer, while this doesn't happen to Non-indigenous women.

Furthermore, we find that the interaction between Spanish and Indigenous people since colonial times contributed to the persistence of ethnic breastfeeding differences. Thus, in regions with more Spanish-Indigenous interaction the difference in breastfeeding between Aymara and Non-indigenous mothers is larger today. This result is consistent with the theory of cultural distinction. In this case, probably the prejudice and negative stereotype the Spanish conquers had on Indigenous people made their interaction difficult, leading to disparate cultural traits.

Although Bolivia and Peru are among the countries with the largest breastfeeding period, the magnitude of the effect of ethnicity on breastfeeding is still important for the children development. The average breastfeeding period of Non-indigenous mothers in the migrants sample is 13,6 months. So, a gap of $10 \%$ between Aymara and Non-indigenous mothers implies Aymara mothers breastfeed approximately 1,4 months longer. According to Guxens et. al. (55), an additional month of lactation in 14-month-old children increases their IQ in 0.37 points of Bayleys scale. Also, according to Victora et. al. (56), increasing 
breastfeeding from 6-11 months to more than a year raises adult's education in 0.26 years. 


\section{2}

\section{Is timing important in early childhood interventions? The case of "Chile crece contigo"}

\section{1 \\ Introduction}

Evidence from neuroscience, biology, psychology and economics shows that investing in early childhood can reduce socioeconomic inequalities and improve human capital accumulation in a lost-lasting fashion ${ }^{1}$. But how much early does an intervention in early childhood have to go? Developmental neuroscience suggests to intervene as early as possible because of the plasticity of the brain in ages zero to three.(63) In fact, there is evidence of sensitive periods or windows of opportunity for the development of certain skills (e.g. language proficiency, social behaviour $(64,65,66))$ which start even before the child is born ${ }^{2}$. Thus, the now consolidated Barker's foetal origins hypothesis sustains that the environment we are exposed to during early development, from egg fertilisation to birth, can have short and long-term consequences on health, psycho-social behaviour and cognition.(68)

Early Childhood Development(ECD) programmes provide few and conflicting answers on the adequate timing of these interventions. The most studied ECD programmes were diverse in terms of treatment, environment and duration, direct comparisons to determine their relative effectiveness is difficult $(62,67)$. Also, there are few rigorously evaluated interventions which start during the antenatal period, being the Nurse-Family Partnership the best-known example.(69) Most of these interventions are small-scaled and conducted in developed countries (See for example, $(70,71)$ ).

In this paper, we study Chile's national early childhood policy, called Chile Crece Contigo- ChCC hereinafter. This policy follows all children in the

\footnotetext{
${ }^{1}$ Widely known examples of Early Childhood Development(ECD) programmes targeted to vulnerable populations, such as Perry School Pre-school, Abecedarian and Nurse-Family Partnership, have shown promising results, with some impacts in human capital lasting until adulthood (See $(61,62)$ for literature review).

${ }^{2}$ For example, the sensitive period of phonology is from the sixth month of foetal life through the first year. Also, the early environment can directly affect the expression of genes which control the development of the brain and nervous system (See (67) for additional examples)
} 
public health system (70\% of total children population) from gestation until they are four years old. It has a strong pre-natal component, and focuses on the early detection and amelioration of bio-psycho-social risks in vulnerable families. ChCC actions are similar to other ECD programmes. However the scale is wider, both in terms of the reach of the policy and the involvement of other government sectors, besides health. More importantly, ChCC reaches different age groups simultaneously, which allows us to explore whether the moment a child is exposed to the policy is relevant for its effectiveness. In specific, we would like to know if being exposed to ChCC early in life, e.g. gestation, entails an additional gain in child's socioemotional development respect to being exposed later.

ChCC was designed between 2006 and 2007, implemented in a small proportion of the population in the second semester of 2007, and expanded to the whole country in 2008. Because of its rapid expansion, we are not able to identify a control group to estimate the policy effect. Instead, we exploit the variation in child's birth date respect to ChCC expansion date. We use a sample of children between 18 and 47 months old born in the public health system, interviewed in 2010 and 2012 Longitudinal Early Childhood Survey of Chile. All children inside the public system are eligible for ChCC benefits and what would determine the most likely moment they entered ChCC is their birth date. Children born after ChCC expansion are more likely to receive its benefits at the beginning of gestation compared to those born before. Thus, the later they were born the earlier they might be exposed to ChCC.

We estimate a linear regression model of child's socioemotional development on child's birth date, expressed in trimesters, a set of control variables, regional and time fixed effects. The trimester coefficients can have a causal interpretation if we assume that unobservable time shocks do not vary systematically with trimesters of birth. Under this hypothesis, the coefficients are intention to treatment effects as not all ChCC services for children in the public system have full coverage.

Although we can't fully assert the validity of the identification hypothesis, we include several time fixed effects to at least control for some unobservable shocks. In particular, we include age-in-months, year of interview, year of conception fixed effects, and regional trends. Regression estimates show that participating in ChCC since gestation generates additional gains in child's socioemotional development respect to being exposed to the policy later, even for the most saturated model. These results are consistent with Doyle et.al's antenatal investment hypothesis. The hypothesis states that antenatal investment carries higher returns than postnatal investment, which makes 
gestation a sensitive period for investments in early childhood.(67)

We measure child's socioemotional development through externalising and internalising behaviour scores. The higher the score, the lower the probability of having externalising and internalising behaviour disorders. On one hand, internalising behaviour problems are indicative of over-inhibition, guiltconflict, self-deprivation and turning against the self. On the other hand, externalising behaviour problems signal anti-social behaviour, aggressiveness, excitement-hostility, self-indulgence and turning against others. (81) ChCC effects on the two dimensions of child behaviour respect to the moment of exposure to the policy reduce gradually. They start at nearly 1 standard deviation above the mean - for children who potentially received ChCC benefits since gestation - and fall to nearly 0.1 standard deviation - for children benefit from ChCC one year and a trimester later.

In addition, we find the gains on internalising behaviour are mainly explained by a reduction of self-absorption and depression/anxiety syndromes in the child. Whereas, the gains on externalising behaviour are associated with reductions in child's aggressiveness. Finally, we explore the heterogeneity of ChCC effects and find that they are concentrated in children whose mothers are less educated and emotionally more unstable. These results show ChCC targets vulnerable families, as would be expected according to the policy design.

Our analyses builds on previous impact evaluations of ChCC. Bedregal (72) and Asesorías para el Desarrollo (73) conduct two separate short-term impact analysis of ChCC. The former base their results on a before/after cohort analysis and the latter exploit regional cross-section variation, comparing districts with different implementation status in 2007. Both find positive impacts on child's psychomotor development, the latter only in districts with high quality implementation. These results are consistent with our findings. Further, we contribute to these evaluations by showing the relevance of the timing of exposure for ChCC effectiveness.

The paper is organised as follows. The next section, describes ChCC in more detail. The third section details the data. The fourth section is dedicated to the empirical strategy and results. The final section concludes.

\section{2}

\section{Chile Crece Contigo ${ }^{3}$}

Chile Crece Contigo is Chile's social protection system for children. This national policy aims at reducing existing inequalities in the development of

\footnotetext{
${ }^{3}$ Section extracted from the unpublished manuscript (1), written with Marina Aguiar
} Palma. 
Chapter 2. Is timing important in early childhood interventions? The case of "Chile crece contigo"

Table 2.1: Coverage and expansion of Chile crece contigo

\begin{tabular}{|c|c|c|c|c|c|c|c|}
\hline & 2006 & 2007 & 2008 & 2009 & 2010 & $\overline{2011}$ & $\overline{2012}$ \\
\hline \multicolumn{8}{|c|}{ Chilean demographics in number of habitants } \\
\hline Live births & 231,383 & 240,569 & 246,581 & 252,240 & 250,643 & 247,358 & 243,635 \\
\hline \multicolumn{8}{|l|}{ Children by age in months } \\
\hline$<12$ & 230,900 & 235,457 & 242,535 & 248,363 & 250,453 & 248,203 & 244,493 \\
\hline $12-23$ & 230,667 & 231,072 & 235,687 & 242,775 & 248,628 & 250,790 & 248,599 \\
\hline $24-47$ & 470,108 & 464,090 & 462,670 & 467,807 & 479,556 & 492,626 & 500,837 \\
\hline \multicolumn{8}{|c|}{ Percentage of population in the public health system } \\
\hline Live births & 70.4 & 68.7 & 69.2 & 68.1 & 68.5 & 66.3 & 64.7 \\
\hline Pregnancies per live birth & 76.0 & 81.5 & 82.2 & 79.6 & 78.9 & 79.4 & 77.0 \\
\hline \multicolumn{8}{|l|}{ Children by age in months } \\
\hline$<12$ & 70.5 & 69.3 & 69.6 & 70.9 & 69.2 & 69.4 & 69.4 \\
\hline $12-23$ & 72.4 & 72.7 & 73.9 & 74.2 & 74.6 & 73.6 & 72.3 \\
\hline $24-47$ & 69.2 & 68.7 & 69.7 & 70.4 & 70.7 & 70.3 & 69.2 \\
\hline \multicolumn{8}{|c|}{ Percentage of population who benefited from Chile crece contigo } \\
\hline Live births & 0.0 & 16.7 & 69.2 & 68.1 & 68.5 & 66.3 & 64.7 \\
\hline Pregnancies per live birth & 0.0 & 19.8 & 82.2 & 79.6 & 78.9 & 79.4 & 77.0 \\
\hline \multicolumn{8}{|l|}{ Children by age in months } \\
\hline$<12$ & 0.0 & 0.0 & 69.6 & 70.9 & 69.2 & 69.4 & 69.4 \\
\hline $12-23$ & 0.0 & 0.0 & 73.9 & 74.2 & 74.6 & 73.6 & 72.3 \\
\hline $24-47$ & 0.0 & 0.0 & 0.0 & 70.4 & 70.7 & 70.3 & 69.2 \\
\hline
\end{tabular}

early childhood, from gestation until the entry to the educational system at its transitional level (pre-school).(74) The main idea of the policy is to improve child's cognitive and non-cognitive skills through actions that enhance the family environment, parenting skills and parental investment. Although some of ChCC services are available for the entire population ${ }^{4}$, the policy focuses on families that use the public health system and who are classified as having bio-psycho-social vulnerabilities.

The design and implementation of ChCC happened between 2007 and 2009. The central components of the policy are the Bio-psycho-social Development Support Programme (PADBP in Spanish) and the Basic Community Networks, which were designed until June 2007. The policy was implemented in 159 pilot districts on that date and expanded to the whole country in 2008. The pilot districts implemented only the actions for pregnant women, attending only $19 \%$ of 2007 's live births, which represented $24 \%$ of live births in the public health system. The expansion of the policy in 2008 was rapid. In fact, all pregnancies, live births and children under 2 years old registered in the public health system received ChCC benefits. Finally, in 2009, the policy expanded its services to children under 4 years old in the public health system.(75) As shown in Table 3.1, these children represent nearly $70 \%$ of all Chilean children under 4 years old.

Further, during the period of implementation, the policy suffered additional adjustments, which expanded its services and improved its monitoring(See timeline on Figure 2.1). Thus, ChCC started with: monitoring of

\footnotetext{
${ }^{4}$ Among these services are radio promotional campaigns related to early childhood development, a website and toll-free line for information and support on childcare
} 
mother's health and child's development, home visits, education on parenting and children development, free didactic materials, stimulation sessions, and preferential access to public social programmes. Most of these actions belong to the PADBP, and are executed by health facilities and basic community networks ${ }^{5}$. ChCC added the distribution of nutritional supplements for pregnant women through the National Programme of Complementary Food (PNAC in Spanish) in 2008, and a package of free clothes and other child rearing materials to all babies born in the public health system in 2009 (New Born Healthcare Programme - PARN in Spanish). Later, in September of that year, the National Congress approved the Law 20379, that regulates ChCC benefits, its monitoring and evaluation. Finally, other minor measures were implemented between 2009 and 2010, such as the distribution of free stimulation packages, changes in the content of the prenatal workshops, promotion of breastfeeding to midwives, new home visits manuals, and a new methodology for parenting workshops -"nobody is perfect" (Nadie es perfecto in Spanish).(75, 76)

Figure 2.1: Timeline of the implementation of the social protection system

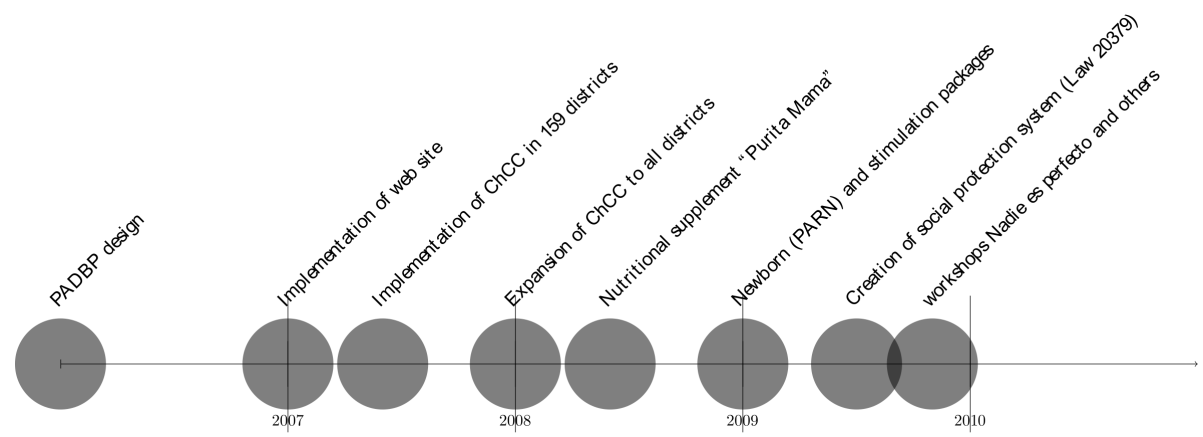

ChCC actions vary according to the vulnerability of each child and her family. Initially, ChCC offers a basic package destined to all mothers and children under five in the public health system ${ }^{6}$. But it also has several combinations of complementary packages which activate depending on specific child and family vulnerabilities. On the one hand, the basic package contains: (i) regular health controls to assess potential family vulnerabilities, mother's mental health and child's development risks, delays and deficits, (ii) free rearing

${ }^{5}$ The PADBP is carried out by the Ministry of Health. Its main task is to monitor and give personalized support to children in the pubic health system. Once a child or pregnant woman is identified and diagnosed, the PADBP either defines actions executed by the health staff e.g. home visits, specialists consults, stimulation sessions, or activates targeted benefits that require the involvement of other sectors, such as education and social services. On the other hand, the Basic Community Network is a district-level coordination unit which joins relevant institutional actors for the provision of goods and services directed to the children, e.g. family health centre directors, public nurseries directors, municipal social services unit. They gather to define a yearly plan with inter-sectoral goals based on the needs of district children and pregnant women. $(75,76)$

${ }^{6}$ Recently, ChCC expanded to children up to 9 years old.(77) 
and didactic materials for children development, (iii) nutritional supplements for mothers, and (iv) education on pregnancy topics and parenting during consults or group sessions at health facilities ${ }^{7}$.(76) A child with normal development and no family vulnerabilities has monthly controls from gestation to the fourth month of life. The next controls are at the sixth, eighth, twelfth and eighteenth month of life. After that, the controls become annual.(77)

On the other hand, the complementary packages consist of home visits, access to technical assistance at health facilities, free access to nurseries and daycares and preferential access to other social programmes. The home visits consist of therapeutic/educational sessions for parents and children conducted in the house by a health professional and a paramedic technician ${ }^{8}$. The purpose of the sessions is to address the vulnerabilities identified during health controls. Vulnerability is determined by a group of test, which evaluates the following factors: family environment, maternal mental health, maternal attachment, and child developmental delays ${ }^{9}$. Table 2.2 offers details on these tests. If we are evaluating factors related with family environment, it is enough to identify one of them, e.g. suspicion of domestic violence, to do a home visit. Otherwise, the decision to do a home visit depends on mother or child not reaching certain thresholds of psychometric tests. According to ChCC statistics, in 2012, near $40 \%$ of pregnant women had at least one risk associated with their family environment and $6 \%$ of children presented risks or deficits in development ${ }^{10}$.

The remaining ChCC benefits are regulated by the Intersectoral Social Protection System law (law № 20379). According to this law, all vulnerable pregnant women should access to Chile Solidario ${ }^{11}$. In addition, $60 \%$ of the socioeconomically most vulnerable families are entitled to access to technical aids for children with disabilities, and free access to daycares and nurseries. Likewise, $40 \%$ of the socioeconomically most vulnerable families have preferen-

${ }^{7}$ Parenting workshops consist of six group meetings where parents and workshop facilitator discuss rearing experiences, learn from each other, and receive orientations respect to specific child development issues. Among the usual discussion topics are: how to comfort a crying child, answer effectively to tantrums, foster language, security, independence, etc.

${ }^{8}$ Duration, frequency of home visits and the health professional in charge depend on the situation of each family. Each home visit lasts between 60 to 90 minutes, and the whole process can last between four months to two years. The professionals attending the home visits usually are nurses, midwives, doctors, social workers, psychologists, occupational therapists, educators and nutritionists.(78)

${ }^{9}$ Contingent on these vulnerabilities, the health professional gives support, encouragement and information to overcome family problems; helps to build safe relationship between parents and children; models parent-children interactive games for children stimulation or gives specific reinforcements for children with development delays, among others. In addition, home visits allow the early detection of other potential risks.(78)

${ }^{10}$ See these statistics in table A.1

${ }^{11}$ Chile Solidario is part of Chile's social protection system and grants monetary and non-monetary aids to families without socioeconomic support. 
Table 2.2: Instruments and factors to determine vulnerability

\begin{tabular}{|c|c|}
\hline Instrument & Description \\
\hline $\begin{array}{lrr}\text { Psico-social brief } & \text { as- } \\
\text { sessment } & \text { (EPSA } & \text { in } \\
\text { Spanish) } & & \end{array}$ & $\begin{array}{l}\text { Questionnaire for pregnant women to identify the following psycho- } \\
\text { social risks: } 1 \text {. Suspect of maternal/paternal depression } 2 \text {. Suspect } \\
\text { of domestic violence } 3 \text {. Insufficient family support, social isolation } 4 \text {. } \\
\text { Drugs and alcohol abuse } 5 \text {. Conflicts with motherhood } 6 \text {. Teenage } \\
\text { mother } 7 \text {. Less than primary education } 8 \text {. First pre-natal control after } \\
20 \text { weeks of gestation. If at least one of the risk is present, the women } \\
\text { is considered vulnerable. }\end{array}$ \\
\hline $\begin{array}{l}\text { Edinburgh postnatal } \\
\text { depression scale }\end{array}$ & $\begin{array}{l}\text { Answered by the mother during the first year of life of the child. It } \\
\text { consists of ten short statements. Mother chooses which of the four } \\
\text { possible answers - always, sometimes, rarely, never - is the one that } \\
\text { most closely resembles the way she felt in the week before. A score } \\
\text { higher than } 10 \text { indicates possible depression. }\end{array}$ \\
\hline Mass-Campbell scale & $\begin{array}{l}\text { plied in the first year of life. It measures mother } \\
\text { ing stress based on } 6 \text { parameters: gazing, affecti } \\
\text { ag, touching infant, clinging maternal holding, a }\end{array}$ \\
\hline $\begin{array}{l}\text { Brief psycho-motor de- } \\
\text { velopment test }\end{array}$ & $\begin{array}{l}\text { Applied to children under } 2 \text { years old. It } \\
\text { four actions/characteristics that predict th } \\
\text { age. Each predictor corresponds with one are } \\
\text { coordination, social and language. If a child }\end{array}$ \\
\hline Evaluation $\mathrm{S}$ & s test, \\
\hline $\begin{array}{l}\text { Psycho-motor } \\
\text { opment } \quad(\text { EE } \\
\text { Spanish) }\end{array}$ & $\begin{array}{l}\text { but more extensive. It contains } 75 \text { items, divided in the four areas } \\
\text { of development mentioned before. The final score is standardised and } \\
\text { then, children are classified into three groups: normal development, } \\
\text { at risk, delayed development. }\end{array}$ \\
\hline $\begin{array}{l}\text { Psycho-motor Devel- } \\
\text { opment test (TEPSI in } \\
\text { Spanish) }\end{array}$ & $\begin{array}{l}\text { lied to children between } 2 \text { to } 5 \text { years old. Similar } \\
\text { he previous test. Evaluates three development areas }\end{array}$ \\
\hline $\begin{array}{l}\text { Ministry of health nor- } \\
\text { mative }\end{array}$ & $\begin{array}{l}\text { Other factors considered during health controls are: signs of child } \\
\text { abuse, other parents' mental disorders, low adherence to health con- } \\
\text { trols, undernourishment and risk of death. }\end{array}$ \\
\hline Social Protection Card & $\begin{array}{l}\text { ssigns a score based on the revenue-g } \\
\text { nbers adjusted by the level of econom } \\
\text { acity is calculated based on school yea } \\
\text { on and variables of the economic envi } \\
\text { tt rate and district or regional charac }\end{array}$ \\
\hline
\end{tabular}

Source: $(75,77,79)$

tial access to other social programmes such as remedial education, employment insertion, improvement of housing and living conditions, mental health care, judicial assistance, prevention of child abuse, etc. (74) Families are granted access to these benefits through the social protection card, that determines to which percentile a family belongs to. This instrument is explained in Table 2.2. The specific course of action for each family is determined locally by the basic community network, which connects the families with other social programmes. $(75,73)$ There is no stantardized procedure to do that. So far, in 2012, the most common benefits among families in the public health system were public subsidies for pregnant women(60\%), other Chile Solidario benefits (26\%), access to nurseries and daycares (near 30\%), mental health care (11\%), and improvement of living conditions $(10 \%)^{12}$. (73)

Table 2.3 shows ChCC's potential outcomes, given its main actions. The

${ }^{12}$ This information was obtained from the study of Asesorias para el Desarrollo, which considers a sample from the $15 \%$ top and $15 \%$ bottom of the distribution of districts ranked by the degree of $\mathrm{ChCC}$ implementation. 
idea behind ChCC is that health controls, home visits and other actions should aid the improvement of the family environment and parenting skills, which later lead to increases in child's cognitive and non-cognitive skills. ChCC actions during pregnancy contribute to a higher involvement of family members in child rearing, particularly the father of the child. They could also improve mother-child bonding and mother's socio-emotional skills, e.g. reduce maternal post-partum depression. Further, ChCC actions after child's birth build on outcomes from pregnancy period actions. Family interrelationships and maternal attachment are expected to improve. The latter, together with mother's nutritional supplements and information at health controls, should enhance breastfeeding practices. In addition, ChCC actions help on the development of a safe parents-child relationship, and provide parents with tools to deal with child behaviour problems, which should reduce child abandonment or abuse. Finally, stimulation sessions for the child at health facilities and games/routines/exercises applied by parents at home should develop children's cognitive and non-cognitive skills.

Table 2.3: Outcomes of Chile crece contigo for families in the public health system

\begin{tabular}{ll}
\hline \hline \multicolumn{2}{c}{ Intermediate outcomes } \\
\hline Pregnant women & \multicolumn{1}{c}{ Children under 5 years old } \\
\hline i) more involvement of the father or & i)increase in mother-child bonding, \\
close family members during prena- & improvement of breastfeeding prac- \\
tal care and childbirth, ii) reduction & tices, ii) improvement of parenting \\
of post-partum depression rates, iii) & skills to deal with child behavioural \\
improvement of mother's nutritional & problems, iii) reduction of child \\
status & abandonment rates and child abuse, \\
& iv) increase of parent-child activities \\
& to stimulate psycho-motor develop- \\
& ment, v) increase in the adoption of \\
& healthy habits to improve physical \\
& development, vi) increase in the use \\
& of public nurseries and day cares. \\
\hline
\end{tabular}

Final outcomes

\begin{tabular}{l}
\hline i) improvement of child's physical development, ii) improve- \\
ment of child's cognitive and non-cognitive skills, iii) reduc- \\
tion of the gap on infant development between vulnerable \\
and non-vulnerable families, iv) long term improvements in \\
human capital
\end{tabular}

Source: Own elaboration based on $(75,76)$

\section{3}

Data

We use the 2010 and 2012 Longitudinal Early Childhood Survey of Chile (ELPI in Spanish). This survey is representative at national and regional level, and contains multiple measures of children and parents cognitive skills, socio- 
emotional skills, parental investments, and socio-demographic variables. The first round of ELPI surveyed a sample of nearly 15000 children who were less than 5 years old in 2010. These children were followed in the 2012 ELPI, and approximately 3000 new children were included in order to characterise younger cohorts. $(80)$

We restrict our analysis to children between 18 and 47 months of age born in the public health system. The children of that age bracket share a common set of socio-emotional development measurements, which is the focus of this paper. In addition, everyone of them could have been exposed to ChCC because they were born in the public system and were at most two years old in January of 2008, when the policy expanded nationally ${ }^{13}$. Yet, the exact moment at which each child was potentially exposed varies across the sample.

Figure 2.2 plots the histogram of the sample by child's birth date. The birth date is centred in January 2008 (zero in the histogram) and it is expressed in trimesters. A negative value indicates that by 2008 the child was not born yet, and a positive value is equivalent to the child's age. The blue bars are for children interviewed in 2010 and born between 2006 and 2009, while red bars are for children interviewed in 2012 and, as such, born between 2008 and 2011. As we can see, $32.8 \%$ of the sample probably benefited from ChCC since the beginning of gestation because they were conceived after 2008 (trimesters - 4 to -14). Likewise, $24.3 \%$ of the sample probably benefited from ChCC at some point of gestation because they were conceived during the last three trimesters of 2007(trimesters -3 to -1 ) and the remaining $42.9 \%$ might have benefited after birth because they were born in the beginning of 2007 or earlier(trimester 0 and more).

The test we use to measure children's socioemotional development is the Child Behaviour Check List (CBCL). The CBCL assesses child's behaviour and socioemotional competences as reported by their parents. It identifies seven syndromes associated with known mental disorders: Emotional Reactivity, Anxiety / Depression, Somatic Complaints, Self-absorption, Sleep Problems, Attentional Problems and Aggressive conduct. The higher the score in each category, the worse are child's socioemotional competences. Further, these syndromes can be classified in two broader scales: Internalising and Externalising behaviour. The first four are associated to the former, and the last two, to the latter. (80) On one hand, internalising behaviour problems are indicative of over-inhibition, guilt-conflict, self-deprivation and turning against the self. On

\footnotetext{
${ }^{13}$ The documents that describe the policy implementation are not clear about the exact date when the policy expanded nationally. Using tools from time series analysis, we find that January 2008 is the most likely date of ChCC expansion, since there is a structural break on that date in $75 \%$ of Chile's regions. The details are in the section A.1.1 of the appendix
} 
Figure 2.2: Histogram of 18-47-months-old children born in the public health system by child's birth date

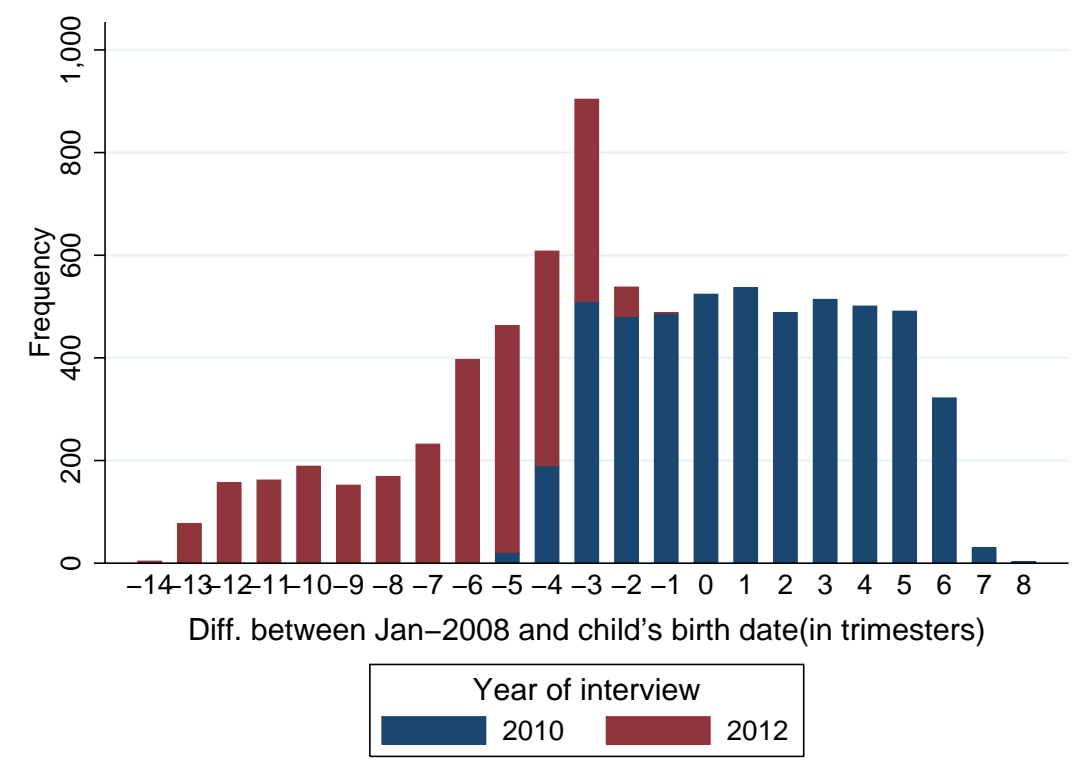

Source: ELPI 2010, 2012.

Note: A negative age implies child was not in 2008 born yet, i.e. she still in uterus or not conceived yet when ChCC expanded.

We only include observations with information on all socio-economic variables in Table 2.4.

the other hand, externalising behaviour problems signal anti-social behaviour, aggressiveness, excitement-hostility, self-indulgence and turning against others. (81) As mentioned in the introduction, an early onset of these problems lead to later behaviour problems, social skill deficits and academic difficulties. (82)

The variables we use for parental skills are: mother mental health index during pregnancy, main carer's intelligence quotient(IQ), main carer's anthropometric measures, and parents' education. The mental health index is the sum of mental health problems a mother had during pregnancy, e.g. anxiety, depression, bipolar disorder. The IQ is measured by two sub-scales of Wechsler Adults Intelligence Scale (WAIS), working memory and vocabulary ${ }^{14}$. (80) Anthropometric measures are height and body mass index (BMI).

The negative of externalising and internalising behaviour indexes are standardised using age-specific means and standard deviations of the group born after the date ChCC expanded. In that way, groups exposed sooner and later are comparable. Similarly, parental skills variables are standardised using age-specific means and standard deviations. To reduce the sensitivity to outliers and small sample sizes within age categories, we compute the

${ }^{14}$ The working memory scale assesses digit retention, which allows to infer cognitive adaptation flexibility. The vocabulary scale assesses the capacity of receiving, storing and using new information, which is associated with classification and conceptualization capacities. (80) 
age conditional means and standard deviations using a kernel-weighted local polinomial smoothing method, as in Attanasio et.al. (96, 97)

Table 2.4 shows the average value of child socioemotional development, parental skills and socio-demographic variables, by child's birth date. As we can see, child behaviour improves for children exposed earlier in life to ChCC. The score of externalising and internalising behaviour is near 0.5 standard deviations above the mean among children born in trimester -7 or less. These scores gradually fall as the trimester of birth increases, i.e. for children exposed to $\mathrm{ChCC}$ when they are older. By trimester 6 and more externalising and internalising behaviour score are near 0.1 standard deviations below the mean. In addition, magnitude and trend of externalising and internalising behaviour scores are similar.

Table 2.4 also shows several socio-demographic and parental skills variables present no systematic differences by child's birth date. This is the case of main carer's working memory and height, child's sex, and family composition. On the contrary, main carer's vocabulary score, BMI, mother's mental health problems index, and child's birth weight present significant differences by child's birth date. But, none of them increase or decrease consistently across child's birth date, as children's socioemotional development variables do. Finally, mother's age, parents' education and family income differ systematically by child's birth date in a way that correlates with children's socioemotional development patterns. Nonetheless, all these variables would likely increase over time. In fact, if evaluated at the same point in time, parents' education and family income show no systematic difference by child's birth date. 
Table 2.4: Descriptive statistics of children aged 18-47 months born in the public health system by child's birth date

\begin{tabular}{|c|c|c|c|c|c|c|c|c|c|c|c|c|c|c|c|}
\hline & \multicolumn{15}{|c|}{ Diff. between Jan-2008 and child's birth date(in trimesters) } \\
\hline & $\leq-7$ & -6 & -5 & -4 & -3 & -2 & -1 & 0 & 1 & 2 & 3 & 4 & 5 & $\geq 6$ & P-val \\
\hline \multicolumn{16}{|l|}{ Child development: } \\
\hline (-)Internal behaviour z- & 0.47 & 0.27 & 0.26 & 0.23 & 0.14 & 0.02 & 0.05 & -0.00 & 0.02 & 0.01 & 0.00 & 0.00 & -0.02 & -0.12 & 0.00 \\
\hline (-)External behaviour z-score & 0.45 & 0.30 & 0.33 & 0.27 & 0.17 & 0.02 & -0.00 & -0.02 & 0.08 & -0.05 & -0.01 & -0.00 & -0.06 & -0.07 & 0.00 \\
\hline \multirow{2}{*}{\multicolumn{16}{|c|}{$\begin{array}{l}\text { Vocabulary z-score } \\
\text { Parental skills: }\end{array}$}} \\
\hline & & & & & & & & & & & & & & & \\
\hline Mental prob. z-score & -0.08 & 0.02 & 0.11 & 0.04 & 0.07 & 0.05 & 0.03 & 0.03 & -0.07 & -0.03 & -0.01 & -0.15 & 0.12 & -0.03 & 0.00 \\
\hline Working memory z-score & -0.03 & 0.01 & 0.09 & -0.03 & 0.03 & 0.02 & 0.05 & 0.02 & -0.03 & -0.04 & -0.02 & 0.05 & -0.00 & 0.04 & 0.67 \\
\hline Vocabulary z-score & -0.21 & 0.04 & 0.16 & 0.09 & 0.12 & 0.06 & 0.12 & 0.08 & 0.08 & 0.04 & 0.01 & 0.12 & 0.09 & 0.13 & 0.00 \\
\hline Mother education & 11.23 & 10.99 & 11.05 & 10.94 & 10.90 & 10.65 & 10.70 & 10.60 & 10.55 & 10.44 & 10.51 & 10.58 & 10.61 & 10.73 & 0.00 \\
\hline Father education & 11.08 & 10.82 & 10.91 & 10.87 & 10.81 & 10.65 & 10.65 & 10.59 & 10.33 & 10.48 & 10.52 & 10.46 & 10.55 & 10.53 & 0.00 \\
\hline Height z-score & 0.00 & -0.00 & 0.06 & 0.03 & -0.01 & -0.06 & 0.00 & -0.07 & -0.06 & -0.09 & -0.02 & -0.06 & -0.01 & -0.02 & 0.54 \\
\hline BMI z-score & 0.03 & 0.14 & 0.06 & 0.05 & -0.06 & -0.10 & -0.02 & 0.02 & 0.02 & 0.02 & -0.06 & -0.06 & -0.01 & -0.04 & 0.04 \\
\hline \multicolumn{16}{|l|}{ Socio-demographic vars.: } \\
\hline Sex of the child & 0.51 & 0.53 & 0.50 & 0.49 & 0.50 & 0.52 & 0.51 & 0.52 & 0.49 & 0.51 & 0.53 & 0.49 & 0.51 & 0.51 & 0.98 \\
\hline Birth weight z-score & -0.04 & -0.06 & -0.03 & -0.03 & -0.00 & -0.08 & -0.05 & -0.07 & 0.09 & -0.04 & 0.02 & 0.09 & 0.12 & 0.02 & 0.01 \\
\hline Main caregiver's age & 28.68 & 28.73 & 29.10 & 29.26 & 28.63 & 28.16 & 28.74 & 28.70 & 29.26 & 29.27 & 30.06 & 29.88 & 29.90 & 30.53 & 0.00 \\
\hline Minors $<7$ & 1.41 & 1.35 & 1.39 & 1.39 & 1.46 & 1.41 & 1.42 & 1.41 & 1.39 & 1.40 & 1.39 & 1.40 & 1.34 & 1.39 & 0.24 \\
\hline Minors $>7$ & 0.76 & 0.70 & 0.77 & 0.75 & 0.80 & 0.78 & 0.85 & 0.79 & 0.75 & 0.82 & 0.77 & 0.86 & 0.71 & 0.82 & 0.17 \\
\hline Parents live $t$ & 0.73 & 0.69 & 0.75 & 0.73 & 0.71 & 0.72 & 0.75 & 0.73 & 0.76 & 0.74 & 0.73 & 0.75 & 0.74 & 0.72 & 0.65 \\
\hline Per capita income (logs) & 11.32 & 11.32 & 11.34 & 11.27 & 11.18 & 11.15 & 11.08 & 11.11 & 11.12 & 11.08 & 11.12 & 11.09 & 11.17 & 11.14 & 0.00 \\
\hline 2010 p.c. income $(\operatorname{logs})$ & 11.01 & 11.09 & 11.06 & 11.07 & 11.07 & 11.13 & 11.08 & 11.11 & 11.12 & 11.08 & 11.12 & 11.09 & 11.17 & 11.14 & 0.37 \\
\hline 2010 Mother education & 10.76 & 10.59 & 10.65 & 10.65 & 10.71 & 10.61 & 10.70 & 10.60 & 10.55 & 10.44 & 10.51 & 10.58 & 10.61 & 10.73 & 0.97 \\
\hline 2010 Father education & 10.36 & 10.63 & 10.59 & 10.60 & 10.67 & 10.61 & 10.64 & 10.59 & 10.33 & 10.48 & 10.52 & 10.46 & 10.55 & 10.53 & 0.92 \\
\hline Observations & 1142 & 397 & 463 & 608 & 904 & 538 & 488 & 524 & 537 & 488 & 514 & 501 & 491 & 355 & 7950 \\
\hline
\end{tabular}

Source: ELPI 2010, 2012. Note: A negative age implies child was not in 2008 born yet, i.e. she still in uterus or not conceived yet when ChcC expanded. We only 


\section{4}

\section{Empirical analysis}

We are interested in determining whether the moment a child is exposed to $\mathrm{ChCC}$ is relevant for the effectiveness of the policy. In specific, we would like to know if being exposed to ChCC early in life, e.g. gestation, entails an additional gain in child's socioemotional development respect to being exposed later. We study this effect using child's birth date. Children born after ChCC expansion are more likely to receive its benefits at the beginning of gestation compared to children born before ChCC expansion. Thus, the later they were born the earlier they might be exposed to ChCC.

In order to identify the effect of the moment of exposure to the policy, we focus only on children born in the public health system and exploit the variation in child's birth date respect to ChCC expansion date. All children inside the public system are eligible for ChCC benefits and what would determine the most likely moment they entered ChCC is their birth date. We estimate a linear regression model of child's socioemotional development on child's birth date, expressed in trimesters, a set of control variables, regional and time fixed effects. The trimester coefficients can have a causal interpretation if we assume that unobservable time shocks do not vary systematically with trimesters of birth. Under this hypothesis, the coefficients are intention to treatment effects as not all ChCC services for children in the public system have full coverage.

Time shocks could bias regression estimates. For example, economic and information shocks can impact child development through changes in government services and parental investment. Also, information on ChCC implementation suggests the policy improved over time, so younger cohorts entered $\mathrm{ChCC}$ when it was more effective. This prevents us from completely separating the effect of child's moment of exposure to ChCC from the effect of unobservable shocks. Even so, regression estimates suggest that participating in ChCC since gestation does imply additional gains in child's socioemotional development because these results remain significant after we add year of conception fixed effects and regional trends.

Finally, we analyse the heterogeneity of ChCC effects. Since the targeting of the policy depends on multiple criteria, we compare the effect of child's moment of ChCC exposure by income groups, mother's education and neurotiscism score. 
Chapter 2. Is timing important in early childhood interventions? The case of

\subsection{1}

\section{The effect of the moment of entry to ChCC}

We estimate a linear regression model where our variables of interest are trimester dummies that indicate child's birth date, and are centered around ChCC expansion date, in January of 2008. The model is estimated on children born in the public health system, and includes, a set of control variables, regional and time fixed effects. On one hand, the advantage of using this specification is that child's birth date is a relatively exogenous variable. On the other hand, this empirical strategy relies on the hypothesis that unobservable time shocks do not vary systematically with trimesters of birth, which might be challenged.

Although we can't fully assert the validity of this assumption, we include several time fixed effects to control for possible unobservable shocks. First, we include age-in-months fixed effects, so we compare differences in socioemotional development among children the same age, thus avoiding biases due to natural growth differences. Second, we include year of interview and year of conception fixed effects to partially control for shocks that happened in the year of the interview and in the year the child was in gestation. For example, economic shocks, information shocks and improvements of ChCC actions over time. Finally, we include regional trends to control for year of conception shocks specific to each region.

The linear regression model equation is as follows:

$$
\begin{aligned}
y_{\text {ircta }}=\alpha+\sum_{b=-10}^{b=5} \beta_{b} \mathbb{I}\left(B_{\text {ircta }}\right. & =b)+X_{\text {ircta }} \gamma \\
& +\lambda \mathbb{I}_{r}+\psi \mathbb{I}_{c}+\phi \mathbb{I}_{r} \times \mathbb{I}_{c}+\eta \mathbb{I}_{t}+\omega \mathbb{I}_{a}+\epsilon_{\text {ircta }}
\end{aligned}
$$

where $y_{\text {irct }}$ is a measure of child's development, $b$ is an index of birth dates, expressed in trimesters, where $b=-10$ is the tenth trimester after ChCC expansion date, $b=5$ is the sixth trimester before $\mathrm{ChCC}$ expansion date, and $b=0$ is the trimester of ChCC expansion. $B_{\text {ircta }}$ is child's birth date, which is in the same unit as $b$. We use children that were 18 months old or older in January 2008 as a base category, i.e. we exclude dummy variable $\mathbb{I}\left(B_{\text {ircta }} \geq 6\right)$ from equation (2-1). $X_{\text {irct }}$ is a vector of control variables that include parental skills and socio-economic characteristics, $\mathbb{I}_{r}, \mathbb{I}_{t}, \mathbb{I}_{c} \mathbb{I}_{a}$ are regional, year of interview, year of conception and age-in-months fixed effects, respectively, and $\epsilon_{i r c t}$ is an idiosyncratic error term.

Table 2.5 displays the estimates of equation (2-1). In column (1) we can 
see that children born after ChCC expansion have higher levels of internalising behaviour than those born before, and this difference increases the later they are born, and decreases in the opposite direction. This pattern does not change drastically after including year of conception fixed effects and regional trends (See columns (2) and (3)). Besides, the same pattern is observed for externalising behaviour scores (See columns (4) to (6)).

Table 2.5: ChCC intention to treatment effect of child's birth date on child's socioemotional development

\begin{tabular}{|c|c|c|c|c|c|c|}
\hline & \multicolumn{3}{|c|}{ Internalising behaviour } & \multicolumn{3}{|c|}{ Externalising behaviour } \\
\hline & (1) & $(2)$ & $(3)$ & $(4)$ & $(5)$ & (6) \\
\hline Trim. $\leq-10$ & $\begin{array}{c}0.968^{* *} \\
(0.397)\end{array}$ & $\begin{array}{l}0.902^{*} \\
(0.468)\end{array}$ & $\begin{array}{l}0.960^{*} \\
(0.478)\end{array}$ & $\begin{array}{l}0.816^{*} \\
(0.453)\end{array}$ & $\begin{array}{c}0.758 \\
(0.461)\end{array}$ & $\begin{array}{c}0.810 \\
(0.463)\end{array}$ \\
\hline Trim. -9 & $\begin{array}{c}1.101^{* * *} \\
(0.345)\end{array}$ & $\begin{array}{c}1.046^{* *} \\
(0.422)\end{array}$ & $\begin{array}{c}1.082^{* *} \\
(0.429)\end{array}$ & $\begin{array}{c}1.004^{* *} \\
(0.359)\end{array}$ & $\begin{array}{c}0.945^{* *} \\
(0.407)\end{array}$ & $\begin{array}{c}0.984^{* *} \\
(0.421)\end{array}$ \\
\hline Trim. -8 & $\begin{array}{c}1.036^{* * *} \\
(0.321)\end{array}$ & $\begin{array}{c}0.993^{* *} \\
(0.401)\end{array}$ & $\begin{array}{c}1.030^{* *} \\
(0.397)\end{array}$ & $\begin{array}{c}0.875^{* *} \\
(0.399)\end{array}$ & $\begin{array}{l}0.836^{*} \\
(0.398)\end{array}$ & $\begin{array}{c}0.878^{* *} \\
(0.389)\end{array}$ \\
\hline Trim. -7 & $\begin{array}{c}0.896^{* * *} \\
(0.256)\end{array}$ & $\begin{array}{c}0.934^{* *} \\
(0.339)\end{array}$ & $\begin{array}{c}0.939^{* *} \\
(0.358)\end{array}$ & $\begin{array}{c}0.901^{* *} \\
(0.352)\end{array}$ & $\begin{array}{l}0.973^{* *} \\
(0.342)\end{array}$ & $\begin{array}{c}0.956^{* *} \\
(0.351)\end{array}$ \\
\hline Trim. -6 & $\begin{array}{c}0.687^{* * *} \\
(0.230)\end{array}$ & $\begin{array}{c}0.752^{* *} \\
(0.333)\end{array}$ & $\begin{array}{l}0.763^{*} \\
(0.356)\end{array}$ & $\begin{array}{c}0.634^{* *} \\
(0.283)\end{array}$ & $\begin{array}{c}0.745^{* *} \\
(0.307)\end{array}$ & $\begin{array}{c}0.728^{* *} \\
(0.313)\end{array}$ \\
\hline Trim. -5 & $\begin{array}{c}0.564^{* *} \\
(0.241)\end{array}$ & $\begin{array}{l}0.631^{*} \\
(0.329)\end{array}$ & $\begin{array}{l}0.647^{*} \\
(0.338)\end{array}$ & $\begin{array}{l}0.551^{*} \\
(0.310)\end{array}$ & $\begin{array}{l}0.664^{*} \\
(0.335)\end{array}$ & $\begin{array}{l}0.656^{*} \\
(0.326)\end{array}$ \\
\hline Trim. -4 & $\begin{array}{c}0.517^{* *} \\
(0.209)\end{array}$ & $\begin{array}{l}0.580^{*} \\
(0.317)\end{array}$ & $\begin{array}{l}0.606^{*} \\
(0.329)\end{array}$ & $\begin{array}{c}0.477 \\
(0.278)\end{array}$ & $\begin{array}{l}0.593^{*} \\
(0.306)\end{array}$ & $\begin{array}{l}0.591^{*} \\
(0.307)\end{array}$ \\
\hline Trim. -3 & $\begin{array}{l}0.443^{*} \\
(0.209)\end{array}$ & $\begin{array}{l}0.589^{*} \\
(0.309)\end{array}$ & $\begin{array}{l}0.607^{*} \\
(0.325)\end{array}$ & $\begin{array}{c}0.420 \\
(0.238)\end{array}$ & $\begin{array}{c}0.600^{* *} \\
(0.268)\end{array}$ & $\begin{array}{c}0.601^{* *} \\
(0.268)\end{array}$ \\
\hline Trim. -2 & $\begin{array}{c}0.386 \\
(0.226)\end{array}$ & $\begin{array}{l}0.538^{*} \\
(0.304)\end{array}$ & $\begin{array}{c}0.558 \\
(0.325)\end{array}$ & $\begin{array}{c}0.306 \\
(0.240)\end{array}$ & $\begin{array}{l}0.515^{*} \\
(0.258)\end{array}$ & $\begin{array}{l}0.527^{*} \\
(0.266)\end{array}$ \\
\hline Trim. -1 & $\begin{array}{l}0.453^{*} \\
(0.226)\end{array}$ & $\begin{array}{l}0.554^{*} \\
(0.280)\end{array}$ & $\begin{array}{l}0.567^{*} \\
(0.300)\end{array}$ & $\begin{array}{c}0.293 \\
(0.242)\end{array}$ & $\begin{array}{l}0.506^{*} \\
(0.236)\end{array}$ & $\begin{array}{l}0.506^{*} \\
(0.251)\end{array}$ \\
\hline Trim. 0 & $\begin{array}{c}0.419^{* *} \\
(0.180)\end{array}$ & $\begin{array}{l}0.511^{*} \\
(0.246)\end{array}$ & $\begin{array}{l}0.495^{*} \\
(0.270)\end{array}$ & $\begin{array}{c}0.311 \\
(0.191)\end{array}$ & $\begin{array}{c}0.525^{* *} \\
(0.203)\end{array}$ & $\begin{array}{c}0.502^{* *} \\
(0.224)\end{array}$ \\
\hline Trim. +1 & $\begin{array}{c}0.458^{* * *} \\
(0.133)\end{array}$ & $\begin{array}{c}0.506^{* *} \\
(0.187)\end{array}$ & $\begin{array}{c}0.489^{* *} \\
(0.208)\end{array}$ & $\begin{array}{c}0.459^{* *} \\
(0.162)\end{array}$ & $\begin{array}{c}0.609^{* * *} \\
(0.165)\end{array}$ & $\begin{array}{c}0.593^{* * *} \\
(0.178)\end{array}$ \\
\hline Trim. +2 & $\begin{array}{c}0.431^{* * *} \\
(0.105)\end{array}$ & $\begin{array}{c}0.450^{* * *} \\
(0.115)\end{array}$ & $\begin{array}{c}0.414^{* * *} \\
(0.118)\end{array}$ & $\begin{array}{c}0.347^{* *} \\
(0.146)\end{array}$ & $\begin{array}{c}0.456^{* * *} \\
(0.126)\end{array}$ & $\begin{array}{c}0.420^{* * *} \\
(0.130)\end{array}$ \\
\hline Trim. +3 & $\begin{array}{c}0.256^{* * *} \\
(0.0790)\end{array}$ & $\begin{array}{c}0.267^{* *} \\
(0.106)\end{array}$ & $\begin{array}{l}0.230^{*} \\
(0.119)\end{array}$ & $\begin{array}{c}0.175^{*} \\
(0.0938)\end{array}$ & $\begin{array}{c}0.275^{* *} \\
(0.0935)\end{array}$ & $\begin{array}{l}0.244^{* *} \\
(0.101)\end{array}$ \\
\hline Trim. +4 & $\begin{array}{c}0.159 \\
(0.104)\end{array}$ & $\begin{array}{c}0.168 \\
(0.113)\end{array}$ & $\begin{array}{c}0.141 \\
(0.119)\end{array}$ & $\begin{array}{c}0.0673 \\
(0.0897)\end{array}$ & $\begin{array}{c}0.167^{*} \\
(0.0872)\end{array}$ & $\begin{array}{c}0.148 \\
(0.0920)\end{array}$ \\
\hline Trim. +5 & $\begin{array}{c}0.108^{*} \\
(0.0603) \\
\end{array}$ & $\begin{array}{c}0.128^{*} \\
(0.0643) \\
\end{array}$ & $\begin{array}{c}0.112 \\
(0.0653) \\
\end{array}$ & $\begin{array}{c}-0.00464 \\
(0.0811) \\
\end{array}$ & $\begin{array}{c}0.0328 \\
(0.0707) \\
\end{array}$ & $\begin{array}{c}0.0145 \\
(0.0716) \\
\end{array}$ \\
\hline Observations & 7950 & 7950 & 7950 & 7950 & 7950 & 7950 \\
\hline$R^{2}$ & 0.124 & 0.125 & 0.140 & 0.095 & 0.096 & 0.110 \\
\hline Year and regional $\mathrm{FE}$ & Yes & Yes & Yes & Yes & Yes & Yes \\
\hline Age FE & Yes & Yes & Yes & Yes & Yes & Yes \\
\hline Control vars. & Yes & Yes & Yes & Yes & Yes & Yes \\
\hline Year of conception FE & No & Yes & Yes & No & Yes & Yes \\
\hline Regional cohort trends & No & No & Yes & No & No & Yes \\
\hline
\end{tabular}

Figure 2.3 shows that the reduction in the effect of $\mathrm{ChCC}$ on internalising behaviour is gradual. It starts near 1 standard deviation above the mean for children born 10 trimesters after the expansion of $\mathrm{ChCC}$ and reaches 0.1 for children born in the sixth trimester before. The effect of ChCC on externalising behaviour shares a similar tendency. In both cases, we are not able to identify an specific phase of the policy - gestation, first year of life or others - which could be considered significantly more important than the 
others, i.e. a phase where gains in socioemotional development are distinctively higher respect to others. Overall, what the results show is that starting ChCC a trimester early generates an additional small gain in socioemotional development, independently of the specific moment the child was exposed to ChCC. Hence, the earlier a child starts the better.

These results are consistent with Doyle et.al's antenatal investment hypothesis. The hypothesis states that antenatal investment carries higher returns than postnatal investment, which makes gestation a sensitive period for investments in early childhood.(67)

Figure 2.3: ChCC intention to treatment effect of child's birth date on child's socioemotional development
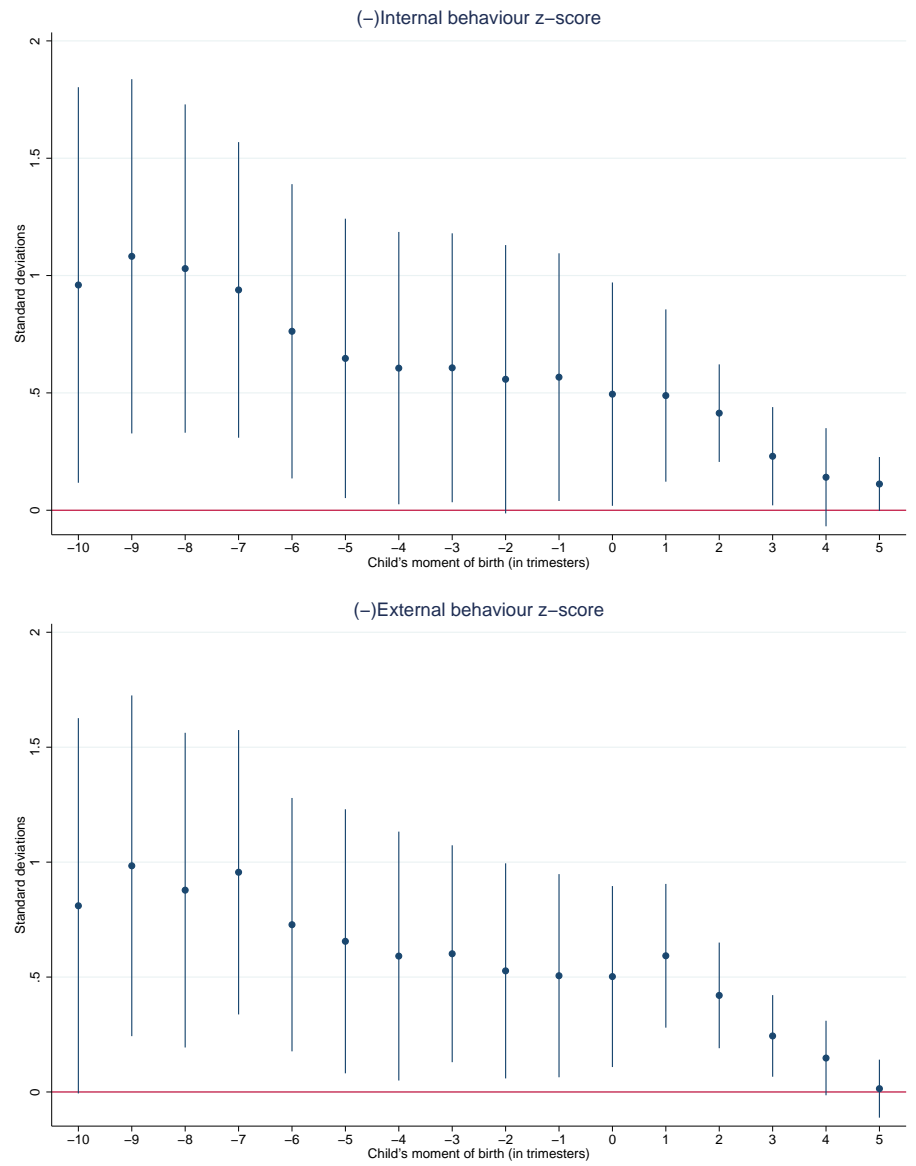

Note: A negative age implies child was not in 2008 born yet, i.e. she still in uterus or not conceived yet when ChCC expanded.

Next, we disaggregate the regression results in the components of externalising and internalising behaviour scores. The first four graphs from Figure 2.4 show the components of the internalising behaviour scores: emotional reactivity, depression/anxiety, somatic complaints and self-absorption. Whereas the last two graphs show the components of the externalising behaviour scores: attentional problems and aggressiveness. 
As we can see, the internalising behaviour components with the highest effects are anxiety/depression and self-absorption. Both of them reproduce a pattern close to the one observed for the aggregate internalising behaviour score. Manifestations of self-absorption syndromes on children are to be shy, timid, withdrawn, cling to adults, avoid eye contact, among the most important. Similarly, manifestations of anxiety/depression on children are to be sad, unhappy, refuse active games, unresponsive, withdrawn, sulk, moody and others. (83) The results indicate that children exposed earlier to ChCC don't present these syndromes as frequently as children exposed later. Although we can't identify the specific mechanisms behind the improvement in children internalising behaviour, evidence from other health studies suggest reduction of pre and post natal distress, and improvements in maternal attachment could be explaining these results. $(84,85)$

The results of externalising behaviour are mainly explained by changes in the aggressiveness component because, as shown in Figure 2.3, the other component - attentional problems - present almost none significant effect over child's birth dates. So, the early exposure to ChCC essentially led to a reduction in children aggresive behaviour. Manifestations of aggressiveness syndrome in children are difficult temper, defiance, stubbornness, punishment doesn't change behaviour, disobedience and others. (83) This type of children behaviour is usually associated with maternal depression, domestic violence and poor parenting competences. $(69,85)$ ChCC deals with these risk factors through educational sessions for parents, home visits and mental health attention, among others. However, we are not able to identify the specific mechanism.

\subsection{2}

\section{Heterogeneous effects}

As explained in the policy description section, $\mathrm{ChCC}$ is built around the concept of vulnerability of children and their families. It is thus natural to ask whether the policy had differential effects for families with varying levels of vulnerability. The process the policy follows to determine which family is vulnerable and which isn't is complex and multidimensional. So, we undertake this analysis by looking at ChCC effects over three dimensions: income, mother's education and mother's neuroticism.

Column (1) of Figure 2.5 shows ChCC effects by child's birth date, separated in children with families below the median income and children with families above it. As we can see, both series are parallel with a considerable overlap between their confidence intervals, which implies there is no statistical 
difference on ChCC effect among these two groups of children. This could be an sign that $\mathrm{ChCC}$ not necessarily is reaching vulnerable families, contrary to the policy expectations. However, it also could mean that the current family income is not strongly associated with the criteria used by ChCC to target the most vulnerable.

Columns (2) and (3) of Figure 2.5 separate ChCC effects by mother's education and main carer's neuroticism scores, respectively. Results show ChCC effects on child's externalising behaviour is concentrated in mothers that did not complete secondary education, i.e. have less than 12 years of schooling. Similarly, ChCC effects on child's internalising behaviour is concentrated in mothers with neuroticism scores above the median, i.e. emotionally less stable. Hence, evidence suggests that $\mathrm{ChCC}$ is more effective at targeting children that are vulnerable because of their mother's education and mental health.

\section{5}

\section{Conclusions}

In this paper we exploit the implementation of Chile Crece Contigo to study whether the early exposure to the policy is associated with additional gains in child's socioemotional development respect to be exposed later in life. The empirical evidence suggests this is true. Externalising and internalising child behaviour scores improve nearly 1 standard deviation above the mean for children who potentially received $\mathrm{ChCC}$ benefits since gestation and this effect reduces to nearly 0.1 standard deviation if children benefit from ChCC one year and a trimester later.

Empirical results are robust to year of conception fixed effects and regional trends. In addition, we find the improvement of internalising behaviour is mainly explained by a reduction of self-absorption and depression/anxiety syndromes in the child. Whereas, the improvement of externalising behaviour is associated with reduction in child's aggressiveness behaviour.

Finally, we explore the heterogeneity of ChCC effects and find that they are concentrated in children whose mothers are less educated and carers are emotionally more unstable. 
Figure 2.4: Intention to treatment effect of the age of entry to ChCC
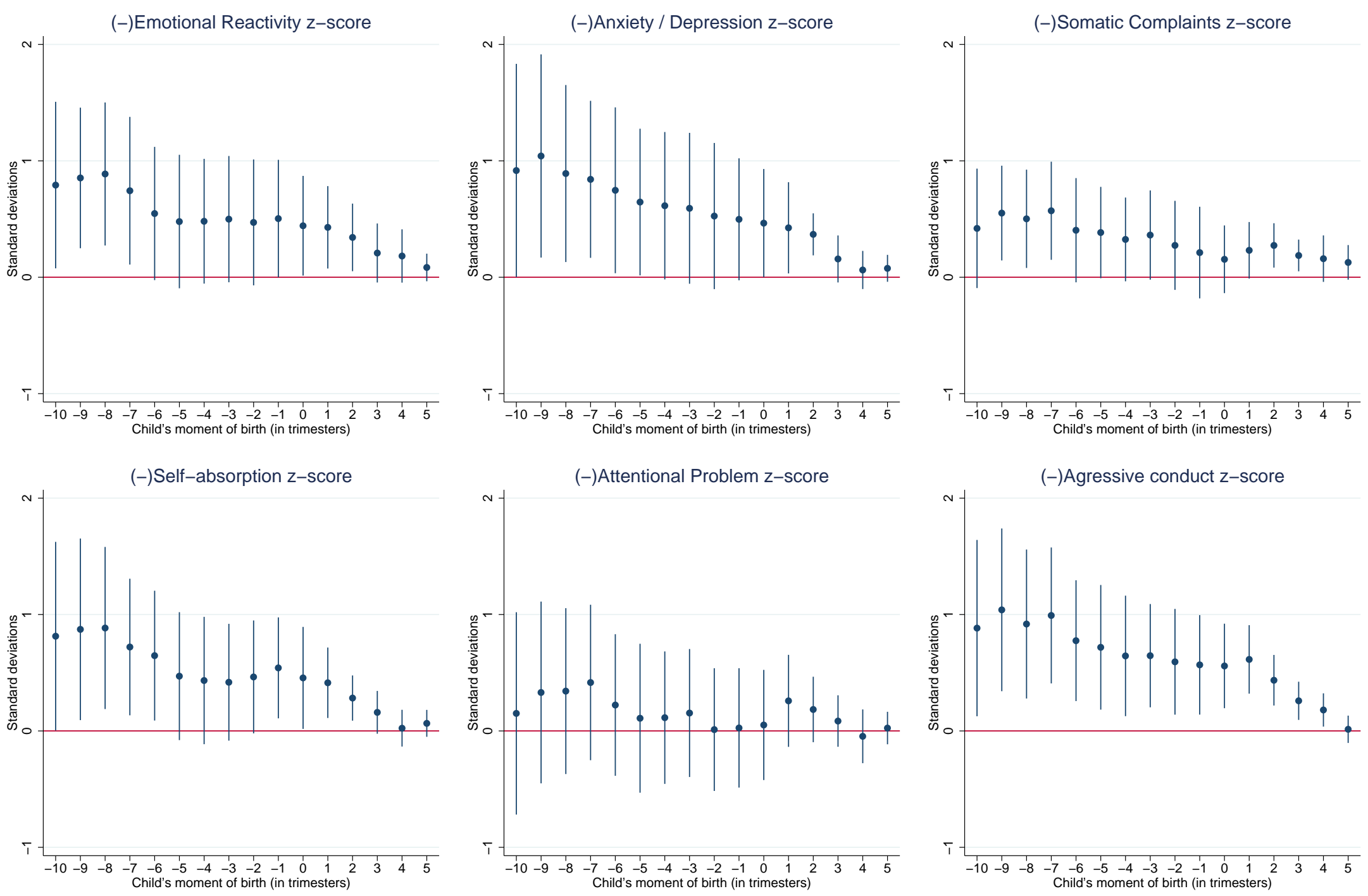
Figure 2.5: Heterogeneity in ITT ChCC effects by child's birth date

(1) Family income

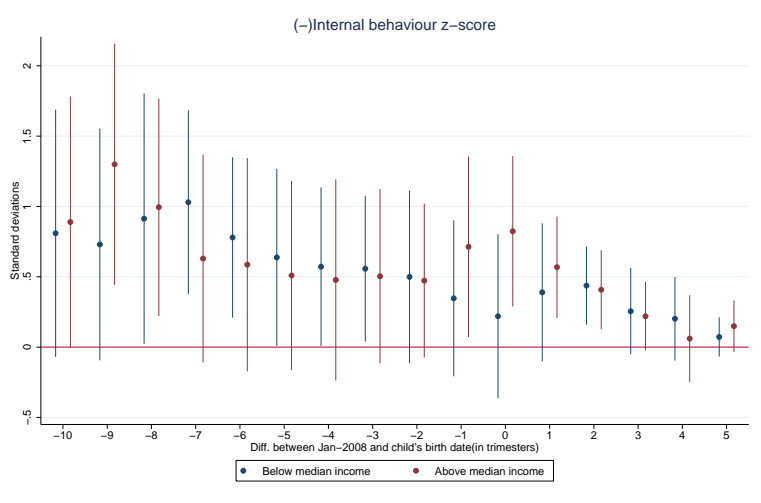

(-)External behaviour z-score

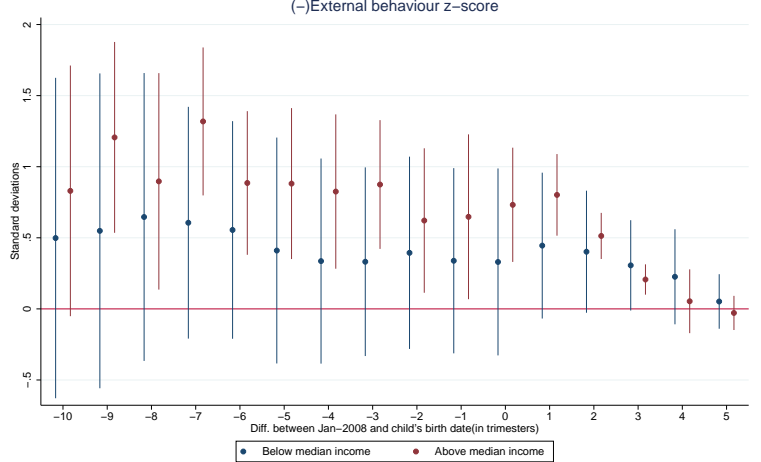

(2) Mother's education
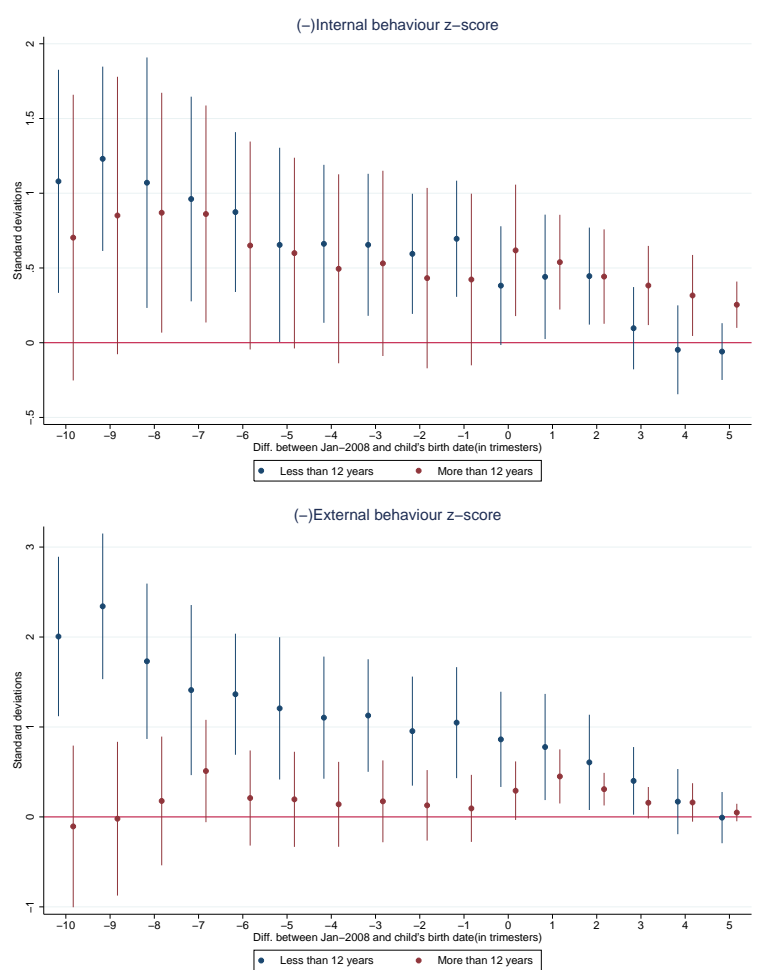

(3) Main carer's neuroticism
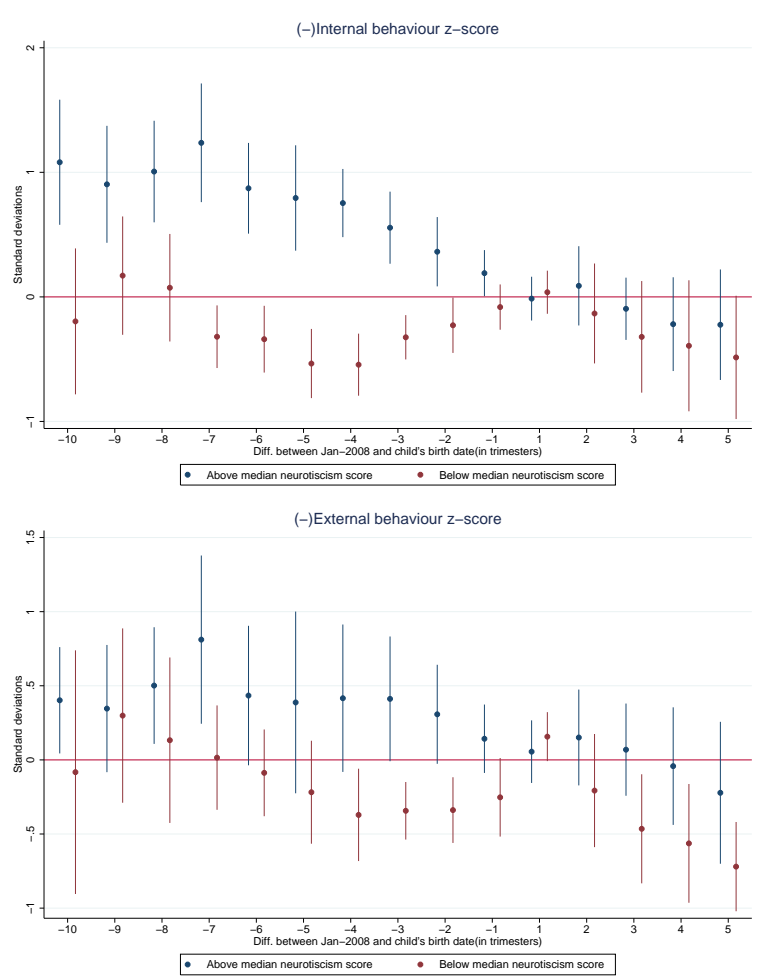

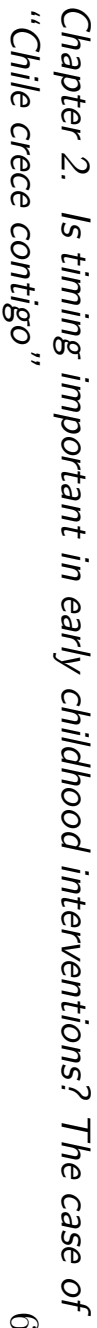

$\stackrel{8}{\perp}$ 


\section{A structural assessment of Chile Crece Contigo ${ }^{1}$}

\section{1}

\section{Introduction}

Extant literature established that well-target and well-designed Early Childhood Development (ECD) programmes affect children abilities ${ }^{2}$, with some impact lasting until adulthood. The prominent examples of such literature are: the Perry School Pre-school project implemented from 1962 to 1967 in the USA $(86,87)$, the Abecedarian project implemented between 1972 and 1977 also in USA (88), the INCAP nutritional programme which occurred in the mid 1960s in Guatemala (89), and finally the Jamaica home-visits project which happened between 1986-1987 (90). From a policy point of view however, the scaling up of such interventions remains a challenge (61). This article contributes to this literature by assessing the Chilean national early childhood policy Chile Crece Contigo.

The social protection system Chile Crece Contigo - ChCC hereinafter - is a comprehensive, intersectoral and multi-component policy aimed at reducing existing inequalities in the development of early childhood, from gestation until entry in the educational system (pre-school). The idea of the ChCC policy is to provide services, material resources and information to enhance the child's family environment and the parents participation in the child's care and education. Although some of its actions are universal, the policy focuses on families that use the public health system and who are classified as having bio-psycho-social vulnerabilities. The first point of contact between families and $\mathrm{ChCC}$ happens in the first pre-natal visit. During this visit personalised actions are devised according to the family's vulnerability level. From there on a wide range of services are offered to the family to offset such vulnerabilities with most of those happening during gestation and in the first year of the child's life.

A pillar of $\mathrm{ChCC}$ is the so called foetal origins hypothesis, the now consolidated idea that environment we are exposed to during early development,

${ }^{1}$ From the unpublished manuscript (1), written with Marina Aguiar Palma

${ }^{2}$ We, like (106) use the terms ability and skills interchangeably. 
from egg fertilisation to birth, can have short and long-term consequences on health, psycho-social behaviour and cognition (68). Examples of such literature are as follows. (91) reviews effects of maternal anxiety and stress during pregnancy on child outcomes to conclude that these lead to child conduct disorders such as ADHD, antisocial behaviour, schizophrenia. A number of contributions arise from studies of the natural experiment of the Dutch hunger winter of 1944-45, which demonstrates the effects of food deprivation during pregnancy on chronic disease, psychological health and labour market outcomes amongst others $(92,93)$.

Using data from 2010 and 2012 Longitudinal Early Childhood Survey of Chile $(E L P I)$, we construct two cohorts of children, those who were conceived before and after the official date of ChCC expansion to the entire country. Thus our evaluation considers the comparison of two non-concurrent cohorts of children. In this manner we compare children exposed to $\mathrm{ChCC}$ from conception to those exposed at later point in their life. We choose this due to the focus of $\mathrm{ChCC}$ on prenatal behaviour and environment. We investigate whether different exposure to $\mathrm{ChCC}$ are associated with differences in parental investments and child abilities. Specifically, we estimate a production function of abilities for children conceived before and after the start of ChCC separately, as in (95). The latter allows us to i) view differences in distribution of abilities between the two groups children ii) map the mechanisms through which these changes occurred iii) check whether productivity of parental investments differs between groups. We estimate these cohort differences for two age groups: 18-23 months of age and 36-47 months of age.

We find that children who were exposed to ChCC since conception have higher levels of socio-emotional abilities when compared to children exposed at later stages. We however have inconclusive result for children's cognitive abilities. The higher levels of socio-emotional abilities are explained by both increases in parental investments and productivity of parental investments, with the latter explaining $40 \%-80 \%$ of the total effect. Our results suggest that $\mathrm{ChCC}$ had differential effects between age groups. For children of 18-23 months of age vulnerable populations appear to have felt the highest benefits. While for children of 36-47 months of age we find families at the top of ability distribution appear to have benefited most from the policy. Our results are consistent with prenatal behaviour and environment affecting the level and the productivity of parental investment during early childhood.

Our analyses builds on previous evaluations of the ChCC programme. Bedegral evaluates the short-term impact of a subsection of ChCC, the Biopsycho-social Development Support Programme -PADB in Spanish(72). In 
the same manner, the evaluation considers two non-concurrent (or historical) cohorts of children: those born before the the start and consolidation of the PADB program and those born after it but uses a different dataset to ours. The results show positive impacts on global development and in the socio-personal and adaptive development. Asesorías para el Desarrollo compares four groups according to two variables, the quality of implementation, given by the Key Performance Indicator by municipality and cohort(73). They find higher levels of child cognitive development for the treatment cohort only within districts defined as having high quality implementation. Our added value lays on using structural modelling to analyse the mechanisms behind ChCC.

This article is organised as follows. The next section, two, describes ChCC and its implementation in more detail. The third section delves into our data. The fourth section is dedicated to structural modelling. The fifth section shows our estimates of productions functions and distribution of parental investments and child's abilities. We follow with some simulation exercises. The final section concludes.

\section{2 \\ Chile Crece Contigo}

Chile Crece Contigo is Chile's social protection system for children. This national policy aims at reducing existing inequalities in the development of early childhood, from gestation until the entry to the educational system at its transitional level (pre-school).(74) The main idea of the policy is to improve child's cognitive and non-cognitive skills through actions that enhance the family environment, parenting skills and parental investment. Although some of ChCC services are available for the entire population ${ }^{3}$, the policy focuses on families that use the public health system and who are classified as having bio-psycho-social vulnerabilities.

The design and implementation of ChCC happened between 2007 and 2009. The central components of the policy are the Bio-psycho-social Development Support Programme (PADBP in Spanish) and the Basic Community Networks, which were designed until June 2007. The policy was implemented in 159 pilot districts on that date and expanded to the whole country in 2008 . The pilot districts implemented only the actions for pregnant women, attending only $19 \%$ of 2007 's live births, which represented $24 \%$ of live births in the public health system. The expansion of the policy in 2008 was rapid. In fact, all pregnancies, live births and children under 2 years old registered in the public

${ }^{3}$ Among these services are radio promotional campaigns related to early childhood development, a website and toll-free line for information and support on childcare 
Table 3.1: Coverage and expansion of Chile crece contigo

\begin{tabular}{|c|c|c|c|c|c|c|c|}
\hline & 2006 & 2007 & 2008 & 2009 & 2010 & 2011 & 2012 \\
\hline \multicolumn{8}{|c|}{ Chilean demographics in number of habitants } \\
\hline Live births & 231,383 & 240,569 & 246,581 & 252,240 & 250,643 & 247,358 & 243,635 \\
\hline \multicolumn{8}{|l|}{ Children by age in months } \\
\hline$<12$ & 230,900 & 235,457 & 242,535 & 248,363 & 250,453 & 248,203 & 244,493 \\
\hline $12-23$ & 230,667 & 231,072 & 235,687 & 242,775 & 248,628 & 250,790 & 248,599 \\
\hline $24-47$ & 470,108 & 464,090 & 462,670 & 467,807 & 479,556 & 492,626 & 500,837 \\
\hline \multicolumn{8}{|c|}{ Percentage of population in the public health system } \\
\hline Live births & 70.4 & 68.7 & 69.2 & 68.1 & 68.5 & 66.3 & 64.7 \\
\hline Pregnancies per live birth & 76.0 & 81.5 & 82.2 & 79.6 & 78.9 & 79.4 & 77.0 \\
\hline \multicolumn{8}{|l|}{ Children by age in months } \\
\hline$<12$ & 70.5 & 69.3 & 69.6 & 70.9 & 69.2 & 69.4 & 69.4 \\
\hline $12-23$ & 72.4 & 72.7 & 73.9 & 74.2 & 74.6 & 73.6 & 72.3 \\
\hline $24-47$ & 69.2 & 68.7 & 69.7 & 70.4 & 70.7 & 70.3 & 69.2 \\
\hline \multicolumn{8}{|c|}{ Percentage of population who benefited from Chile crece contigo } \\
\hline Live births & 0.0 & 16.7 & 69.2 & 68.1 & 68.5 & 66.3 & 64.7 \\
\hline Pregnancies per live birth & 0.0 & 19.8 & 82.2 & 79.6 & 78.9 & 79.4 & 77.0 \\
\hline \multicolumn{8}{|l|}{ Children by age in months } \\
\hline$<12$ & 0.0 & 0.0 & 69.6 & 70.9 & 69.2 & 69.4 & 69.4 \\
\hline $12-23$ & 0.0 & 0.0 & 73.9 & 74.2 & 74.6 & 73.6 & 72.3 \\
\hline $24-47$ & 0.0 & 0.0 & 0.0 & 70.4 & 70.7 & 70.3 & 69.2 \\
\hline
\end{tabular}

Source: DEIS(2006-2012), INE(2006-2012)

health system received ChCC benefits. Finally, in 2009, the policy expanded its services to children under 4 years old in the public health system.(75) As shown in Table 3.1, these children represent nearly $70 \%$ of all Chilean children under 4 years old.

Further, during the period of implementation, the policy suffered additional adjustments, which expanded its services and improved its monitoring(See timeline on Figure 3.1). Thus, ChCC started with: monitoring of mother's health and child's development, home visits, education on parenting and children development, free didactic materials, stimulation sessions, and preferential access to public social programmes. Most of these actions belong to the PADBP, and are executed by health facilities and basic community networks ${ }^{4}$. ChCC added the distribution of nutritional supplements for pregnant women through the National Programme of Complementary Food (PNAC in Spanish) in 2008, and a package of free clothes and other child rearing materials to all babies born in the public health system in 2009 (New Born Healthcare Programme - PARN in Spanish). Later, in September of that year, the National Congress approved the Law 20379, that regulates ChCC benefits, its monitoring and evaluation. Finally, other minor measures were implemented

${ }^{4}$ The PADBP is carried out by the Ministry of Health. Its main task is to monitor and give personalized support to children in the pubic health system. Once a child or pregnant woman is identified and diagnosed, the PADBP either defines actions executed by the health staff e.g. home visits, specialists consults, stimulation sessions, or activates targeted benefits that require the involvement of other sectors, such as education and social services. On the other hand, the Basic Community Network is a district-level coordination unit which joins relevant institutional actors for the provision of goods and services directed to the children, e.g. family health centre directors, public nurseries directors, municipal social services unit. They gather to define a yearly plan with inter-sectoral goals based on the needs of district children and pregnant women. $(75,76)$ 
between 2009 and 2010, such as the distribution of free stimulation packages, changes in the content of the prenatal workshops, promotion of breastfeeding to midwives, new home visits manuals, and a new methodology for parenting workshops -"nobody is perfect" (Nadie es perfecto in Spanish).(75, 76)

Figure 3.1: Timeline of the implementation of the social protection system

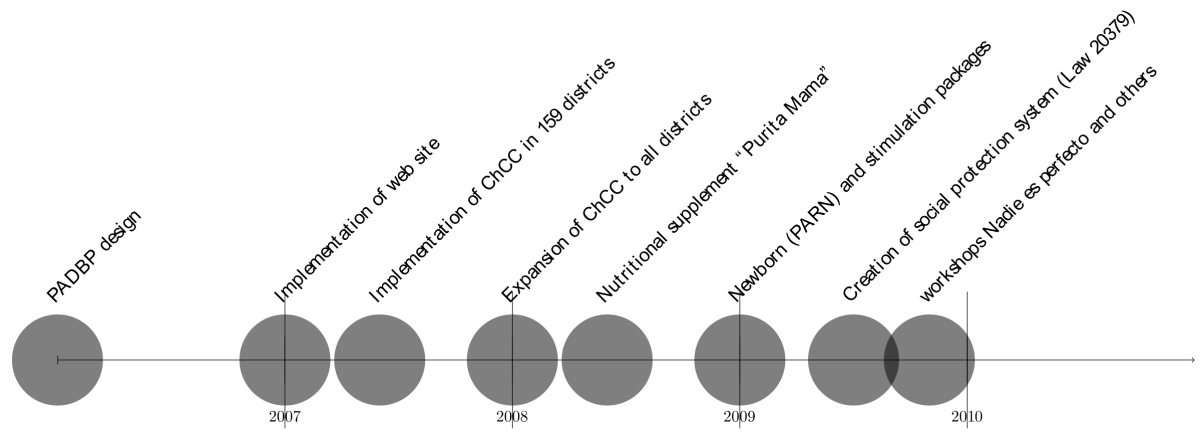

ChCC actions vary according to the vulnerability of each child and her family. Initially, ChCC offers a basic package destined to all mothers and children under five in the public health system ${ }^{5}$. But it also has several combinations of complementary packages which activate depending on specific child and family vulnerabilities. On the one hand, the basic package contains: (i) regular health controls to assess potential family vulnerabilities, mother's mental health and child's development risks, delays and deficits, (ii) free rearing and didactic materials for children development, (iii) nutritional supplements for mothers, and (iv) education on pregnancy topics and parenting during consults or group sessions at health facilities ${ }^{6}$.(76) A child with normal development and no family vulnerabilities has monthly controls from gestation to the fourth month of life. The next controls are at the sixth, eighth, twelfth and eighteenth month of life. After that, the controls become annual.(77)

On the other hand, the complementary packages consist of home visits, access to technical assistance at health facilities, free access to nurseries and daycares and preferential access to other social programmes. The home visits consist of therapeutic/educational sessions for parents and children conducted in the house by a health professional and a paramedic technician ${ }^{7}$. The purpose of the sessions is to address the vulnerabilities identified during health controls.

${ }^{5}$ Recently, ChCC expanded to children up to 9 years old.(77)

${ }^{6}$ Parenting workshops consist of six group meetings where parents and workshop facilitator discuss rearing experiences, learn from each other, and receive orientations respect to specific child development issues. Among the usual discussion topics are: how to comfort a crying child, answer effectively to tantrums, foster language, security, independence, etc.

${ }^{7}$ Duration, frequency of home visits and the health professional in charge depend on the situation of each family. Each home visit lasts between 60 to 90 minutes, and the whole process can last between four months to two years. The professionals attending the home visits usually are nurses, midwives, doctors, social workers, psychologists, occupational therapists, educators and nutritionists.(78) 
Vulnerability is determined by a group of test, which evaluates the following factors: family environment, maternal mental health, maternal attachment, and child developmental delays ${ }^{8}$. Table 3.2 offers details on these tests. If we are evaluating factors related with family environment, it is enough to identify one of them, e.g. suspicion of domestic violence, to do a home visit. Otherwise, the decision to do a home visit depends on mother or child not reaching certain thresholds of psychometric tests. According to ChCC statistics, in 2012, near $40 \%$ of pregnant women had at least one risk associated with their family environment and $6 \%$ of children presented risks or deficits in development ${ }^{9}$.

The remaining $\mathrm{ChCC}$ benefits are regulated by the Intersectoral Social Protection System law (law № 20379). According to this law, all vulnerable pregnant women should access to Chile Solidario ${ }^{10}$. In addition, $60 \%$ of the socioeconomically most vulnerable families are entitled to access to technical aids for children with disabilities, and free access to daycares and nurseries. Likewise, $40 \%$ of the socioeconomically most vulnerable families have preferential access to other social programmes such as remedial education, employment insertion, improvement of housing and living conditions, mental health care, judicial assistance, prevention of child abuse, etc. (74) Families are granted access to these benefits through the social protection card, that determines to which percentile a family belongs to. This instrument is explained in Table 3.2. The specific course of action for each family is determined locally by the basic community network, which connects the families with other social programmes. $(75,73)$ There is no stantardized procedure to do that. So far, in 2012, the most common benefits among families in the public health system were public subsidies for pregnant women(60\%), other Chile Solidario benefits $(26 \%)$, access to nurseries and daycares (near 30\%), mental health care (11\%), and improvement of living conditions $(10 \%)^{11}$. (73)

Table 3.3 shows ChCC's potential outcomes, given its main actions. The idea behind $\mathrm{ChCC}$ is that health controls, home visits and other actions should aid the improvement of the family environment and parenting skills, which later lead to increases in child's cognitive and non-cognitive skills. ChCC ac-

${ }^{8}$ Contingent on these vulnerabilities, the health professional gives support, encouragement and information to overcome family problems; helps to build safe relationship between parents and children; models parent-children interactive games for children stimulation or gives specific reinforcements for children with development delays, among others. In addition, home visits allow the early detection of other potential risks.(78)

${ }^{9}$ See these statistics in table A.1

${ }^{10}$ Chile Solidario is part of Chile's social protection system and grants monetary and non-monetary aids to families without socioeconomic support.

${ }^{11}$ This information was obtained from the study of Asesorias para el Desarrollo, which considers a sample from the $15 \%$ top and $15 \%$ bottom of the distribution of districts ranked by the degree of ChCC implementation. 
Table 3.2: Instruments and factors to determine vulnerability

\begin{tabular}{|c|c|}
\hline Instrument & $\overline{\text { Description }}$ \\
\hline $\begin{array}{lr}\text { Psico-social } & \text { brief } \\
\text { assessment } & \text { (EPSA } \\
\text { in Spanish) } & \end{array}$ & $\begin{array}{l}\text { Questionnaire for pregnant women to identify the following } \\
\text { psycho-social risks: } 1 \text {. Suspect of maternal/paternal depres- } \\
\text { sion } 2 \text {. Suspect of domestic violence } 3 \text {. Insufficient family } \\
\text { support, social isolation } 4 \text {. Drugs and alcohol abuse } 5 \text {. Con- } \\
\text { flicts with motherhood } 6 \text {. Teenage mother } 7 \text {. Less than pri- } \\
\text { mary education } 8 \text {. First pre-natal control after } 20 \text { weeks of } \\
\text { gestation . If at least one of the risk is present, the women } \\
\text { is considered vulnerable. }\end{array}$ \\
\hline $\begin{array}{l}\text { Edinburgh postna- } \\
\text { tal depression scale }\end{array}$ & $\begin{array}{l}\text { Answered by the mother during the first year of life of the } \\
\text { child. It consists of ten short statements. Mother chooses } \\
\text { which of the four possible answers - always, sometimes, } \\
\text { rarely, never - is the one that most closely resembles the } \\
\text { way she felt in the week before. A score higher than } 10 \\
\text { indicates possible depression. }\end{array}$ \\
\hline $\begin{array}{l}\text { Mass-Campbell } \\
\text { scale }\end{array}$ & $\begin{array}{l}\text { Applied in the first year of life. It measures moth } \\
\text { attachment during stress based on } 6 \text { parameters: } \\
\text { affective sharing, vocalizing, touching infant, cling } \\
\text { ternal holding, and physical proximity. These com }\end{array}$ \\
\hline $\begin{array}{l}\text { Brief psycho-motor } \\
\text { development test }\end{array}$ & $\begin{array}{l}\text { Applied to children under } 2 \text { years old. It contains an in- } \\
\text { ventory of four actions/characteristics that predict the de- } \\
\text { velopment status by age. Each predictor corresponds with } \\
\text { one area of development: motor, coordination, social and } \\
\text { language. If a child satisfies all of them, he has an adequate } \\
\text { development status. }\end{array}$ \\
\hline $\begin{array}{l}\text { Evaluation Scale of } \\
\text { Psycho-motor De- } \\
\text { velopment (EEDP } \\
\text { in Spanish) }\end{array}$ & $\begin{array}{l}\text { Applied to children under } 2 \text { years old. Similar to the previ- } \\
\text { ous test, but more extensive. It contains } 75 \text { items, divided } \\
\text { in the four areas of development mentioned before. The fi- } \\
\text { nal score is standardised and then, children are classified } \\
\text { into three groups: normal development, at risk, delayed de- } \\
\text { velopment. }\end{array}$ \\
\hline $\begin{array}{l}\text { Psycho-motor } \\
\text { Development test } \\
\text { (TEPSI in Spanish) }\end{array}$ & $\begin{array}{l}\text { Applied to children between } 2 \text { to } 5 \text { years old. Similar charac- } \\
\text { teristics to the previous test. Evaluates three development } \\
\text { areas: motor, coordination and language. }\end{array}$ \\
\hline $\begin{array}{l}\text { Ministry of health } \\
\text { normative }\end{array}$ & $\begin{array}{l}\text { Other factors considered during health controls are: signs of } \\
\text { child abuse, other parents' mental disorders, low adherence } \\
\text { to health controls, undernourishment and risk of death. }\end{array}$ \\
\hline $\begin{array}{l}\text { Social Protection } \\
\text { Card }\end{array}$ & $\begin{array}{l}\text { It assigns a score based on the revenue-generation capacity } \\
\text { of family members adjusted by the level of economic needs. } \\
\text { Revenue-generation capacity is calculated based on school } \\
\text { years, working experience, affiliation and variables of the } \\
\text { economic environment, such as unemployment rate and } \\
\text { district or regional characteristics. }\end{array}$ \\
\hline
\end{tabular}

Source: $(75,77,79)$

tions during pregnancy contribute to a higher involvement of family members in child rearing, particularly the father of the child. They could also improve mother-child bonding and mother's socio-emotional skills, e.g. reduce maternal post-partum depression. Further, ChCC actions after child's birth build on outcomes from pregnancy period actions. Family interrelationships and maternal attachment are expected to improve. The latter, together with 
mother's nutritional supplements and information at health controls, should enhance breastfeeding practices. In addition, ChCC actions help on the development of a safe parents-child relationship, and provide parents with tools to deal with child behaviour problems, which should reduce child abandonment or abuse. Finally, stimulation sessions for the child at health facilities and games/routines/exercises applied by parents at home should develop children's cognitive and non-cognitive skills.

Table 3.3: Outcomes of Chile crece contigo for families in the public health system

\begin{tabular}{ll}
\hline \hline \multicolumn{2}{c}{ Intermediate outcomes } \\
\hline Pregnant women & \multicolumn{1}{c}{ Children under 5 years old } \\
\hline i) more involvement of the father or & i)increase in mother-child bonding, \\
close family members during prena- & improvement of breastfeeding prac- \\
tal care and childbirth, ii) reduction & tices, ii) improvement of parenting \\
of post-partum depression rates, iii) & skills to deal with child behavioural \\
improvement of mother's nutritional & problems, iii) reduction of child \\
status & abandonment rates and child abuse, \\
& iv) increase of parent-child activities \\
& to stimulate psycho-motor develop- \\
& ment, v) increase in the adoption of \\
& healthy habits to improve physical \\
& development, vi) increase in the use \\
& of public nurseries and day cares. \\
\hline
\end{tabular}

i) improvement of child's physical development, ii) improvement of child's cognitive and non-cognitive skills, iii) reduction of the gap on infant development between vulnerable and non-vulnerable families, iv) long term improvements in human capital

Source: Own elaboration based on $(75,76)$

\section{3}

\section{Empirical strategy and Data}

\subsection{1}

Data

We use the 2010 and 2012 Longitudinal Early Childhood Survey of Chile. The ELPI is a detailed survey which contains multiple measures of children and parents cognitive and socio-emotional skills, parental investments, and socio-demographic variables.

The first round of ELPI surveyed a sample of nearly 15000 children who were less than 5 years old in 2010(80). These children were followed in the 2012 ELPI forming the panel section of our dataset. Moreover, during the second round, approximately 3000 new children were included in the sample in order to characterise younger cohorts. Within this group we identify cohorts 
conceived before and after the programme implementation, which is January of 2008. As explained in our programme description section, families which use the public health services are the main recipients of $\mathrm{ChCC}$, so we restricted our sample to children born in the public health system.

First we divide our sample into two subgroups these conceived before and after ChCC. Then we restrict our sample to age groups that contain comparable measurements of all variables of interest, cognitive socio-emotional skills, for both pre-ChCC and post-ChCC cohorts. This leaves us with children 18 to 23 months old, 36-47 months old ${ }^{12}{ }^{13}$. We proceed to estimate all equations separately for these two remaining age groups as they differ in terms of stage of development and in terms of actions related ChCC programme.

We are interested in determining the effect of the programme in intermediate outcomes, mainly measures of parental investment and parents' socioemotional skills, and final outcomes, i.e. measures of children development. We use the Big Five Inventory (BFI) of the main carer to approximate changes in parents' socio-emotional skills. This test contains 44 items to measure the five main personality traits: neuroticism, extroversion, kindness, responsibility and openness to experience(80). Secondly, we use a group of questions that asks about parents-child activities in the week previous to the interview to approximate parental investment ${ }^{14}$.

Finally, in order to evaluate different aspects of child development we use the Battelle Development Inventory (BDI), the Peabody Image Vocabulary test and the Child Behaviour Check List (CBCL). The BDI evaluates five developmental areas: adaptive, personal-social, communication, motor and cognitive, whereas the CBCL identifies seven potential mental problems, that characterise children internal and external behaviour: Emotional Reactivity, Anxiety / Depression, Somatic Complaints, Self-absorption, Sleep Problems, Attentional Problem and Aggressive conduct. The first five are associated to internal behaviour, and the last two, to external behaviour. All these variables have been standardised using age-specific means and standard deviations of the pre-ChCC group. In that way, cohorts and children of different ages are comparable. To reduce the sensitivity to outliers and small sample sizes within age categories, we compute the age conditional means and standard deviations using a kernel-weighted local polinomial smoothing method, as in $(96,97)$.

\footnotetext{
${ }^{12}$ We also excluded children of 30-35 months of age from our analyses as we could not secure identification of our production function parameters as our investment instrument did not display significant variation.

${ }^{13}$ See appendix for the distribution of children by year of interview and cohort.

${ }^{14} \mathrm{We}$ are not able to use theELPI HOME inventory because the version of the inventory questionnaire changes between 2010 and 2012
} 
Table 3.4 and 3.5 show descriptive statistics by age-group and cohort. As shown in table 3.4, within each age group almost all the socio-demographic characteristics between pre and post ChCC groups are similar. The exceptions are the parents education and the family per capita income, which are higher for the child conceived after the programme implementation. This is because both variables, ChCC status and family income, are likely to increase with time. In fact, if we measure them on a fixed date, these differences become non-significant (See 2010 income and education in the appendix).

Table 3.4: Descriptive Statistics - Socio-demographic characteristics

\begin{tabular}{|c|c|c|c|c|c|c|}
\hline & \multicolumn{3}{|c|}{ 12-23 months } & \multicolumn{3}{|c|}{ 36-47 months } \\
\hline & pre-ChCC & post-ChCC & P-val & pre-ChCC & post-ChCC & $\mathrm{P}$-val \\
\hline \multicolumn{7}{|l|}{ Other parents skills: } \\
\hline Working memory & 0.02 & -0.07 & 0.08 & 0.02 & -0.01 & 0.44 \\
\hline Vocabulary & 0.07 & -0.14 & 0.02 & 0.07 & 0.05 & 0.52 \\
\hline Mother education & 10.56 & 11.11 & 0.01 & 10.65 & 11.01 & 0.00 \\
\hline Father education & 10.55 & 11.09 & 0.01 & 10.62 & 10.89 & 0.00 \\
\hline Height & -0.01 & -0.04 & 0.88 & -0.01 & 0.01 & 0.69 \\
\hline Weight & -0.09 & 0.02 & 0.25 & -0.03 & 0.05 & 0.01 \\
\hline \multicolumn{7}{|l|}{ Socio-demographic vars. } \\
\hline Gestation in weeks & 0.02 & -0.01 & 0.69 & -0.00 & 0.00 & 0.94 \\
\hline Birth height & -0.06 & -0.08 & 0.73 & 0.03 & -0.05 & 0.01 \\
\hline Birth weight & 0.02 & -0.05 & 0.21 & 0.02 & -0.03 & 0.12 \\
\hline Sex of the child & 0.50 & 0.50 & 0.92 & 0.51 & 0.51 & 0.89 \\
\hline Main caregiver's age & 27.55 & 28.09 & 0.22 & 30.04 & 29.64 & 0.08 \\
\hline Minors $<7$ & 1.43 & 1.44 & 0.86 & 1.40 & 1.41 & 0.83 \\
\hline Minors $>7$ & 0.78 & 0.79 & 0.86 & 0.80 & 0.77 & 0.29 \\
\hline Parents live together & 0.62 & 0.66 & 0.41 & 0.65 & 0.64 & 0.42 \\
\hline Per capita income & 11.10 & 11.21 & 0.07 & 11.15 & 11.32 & 0.00 \\
\hline 2010 p.c. income (logs) & 11.10 & 11.06 & 0.41 & 11.12 & 11.06 & 0.01 \\
\hline 2010 Mother educ. (in years) & 10.56 & 10.62 & 0.81 & 10.57 & 10.57 & 0.98 \\
\hline 2010 Father educ. (in years) & 10.55 & 10.76 & 0.28 & 10.54 & 10.56 & 0.82 \\
\hline Observations & 904 & 906 & 1240 & 3089 & 2066 & 4626 \\
\hline
\end{tabular}

Table 3.5 shows significant positive differences in outcomes between children conceived after and before the programme implementation. Although, not all of them change. On one hand, we observe a consistent improvement across all age groups in variables that measure socio-emotional skills, and parent-child activities. On the other hand, we observe a decrease the Peabody Vocabulary test for children of 36-47 months of age. Other variables, such as main carer neuroticism index, improve for some age groups.

\subsection{2}

\section{Empirical strategy}

The evaluation of the ChCC system is a challenge. ChCC is a national scale programme that was not designed as a randomised control trial this 
Table 3.5: Descriptive Statistics - Potential programme outcomes

\begin{tabular}{|c|c|c|c|c|c|c|}
\hline & \multicolumn{3}{|c|}{ 18-23 months } & \multicolumn{3}{|c|}{ (36-47 months } \\
\hline & pre-ChCC & post-ChCC & P-val & pre-ChCC & post-ChCC & P-val \\
\hline \multicolumn{7}{|c|}{ 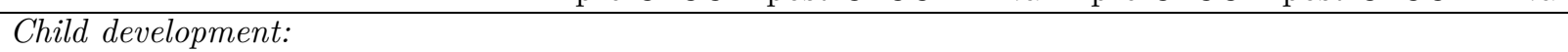 } \\
\hline Psycho-motor test & -0.00 & 0.67 & 0.00 & & & \\
\hline Vocabulary & & & & 0.00 & -0.19 & 0.00 \\
\hline (-)Internal behaviour & -0.01 & 0.43 & 0.00 & -0.00 & 0.31 & 0.00 \\
\hline (-)External behaviour & -0.00 & 0.36 & 0.00 & -0.00 & 0.35 & 0.00 \\
\hline \multicolumn{7}{|l|}{ Parental investment: } \\
\hline Reads books to the child & -0.00 & 0.12 & 0.44 & -0.00 & 0.25 & 0.00 \\
\hline Tells stories to the child & -0.00 & 0.21 & 0.02 & -0.00 & 0.28 & 0.00 \\
\hline Sings to the child & 0.00 & 0.23 & 0.00 & -0.00 & 0.28 & 0.00 \\
\hline Visits parks, museums, etc. & 0.00 & 0.14 & 0.49 & 0.00 & 0.14 & 0.00 \\
\hline Talks and draws with the child & 0.00 & 0.28 & 0.00 & -0.00 & 0.40 & 0.00 \\
\hline Child time in pre-school since birth & & & & 0.00 & 0.23 & 0.00 \\
\hline \multicolumn{7}{|l|}{ Parents' socio-emotional skills: } \\
\hline (-)Neuroticism & 0.06 & 0.18 & 0.06 & -0.00 & -0.01 & 0.95 \\
\hline Extraversion & 0.09 & 0.02 & 0.12 & 0.01 & -0.00 & 0.67 \\
\hline Kindness & 0.06 & 0.07 & 0.87 & 0.00 & -0.02 & 0.43 \\
\hline Responsibility & 0.06 & 0.00 & 0.17 & 0.03 & -0.09 & 0.00 \\
\hline Opening to Experience & 0.06 & 0.01 & 0.31 & 0.02 & -0.02 & 0.20 \\
\hline Observations & 904 & 906 & 1760 & 3089 & 2066 & 4907 \\
\hline
\end{tabular}

imposes restrictions on our ability to identify pure programme effects. We attempt to answer this issue by choosing a conservative empirical strategy.

By choosing a cut-off date of conception before and after January 2008 we are comparing individuals with different time of exposition to ChCC. We chose conception dates in place of birth dates because the policy has a strong prenatal care component. Thus individuals in the post-ChCC cohort have benefited from $\mathrm{ChCC}$ as whole while those in the pre-ChCC cohorts have still partially benefited from the policy. In figure 3.2 we see that for ages 18-23 months the pre-ChCC group is composed of individuals with conception dates which are very close to our cut-off point January 2008, meaning that those individuals were not exposed to $\mathrm{ChCC}$ during gestation or at most up until the first months of life. For individuals aged 36-47 months we have that the majority of individuals in pre-ChCC cohort we conceived around January 2006, this means these individuals began exposition to the policy around 1 year and 3 months. In both case we expect that this will generate an estimated effects of the exposure to the policy during gestation.

The implementation of ChCC happened in two stages it was first implemented in June 2007 in just under half of Chilean districts and then in January 2008 in all remaining districts. Our data does not contain information on district of residence. By choosing a cut-off date of January 2008 we include inhabitants of the pilot districts that have benefited from ChCC since conception in our "control" group. Thus our analysis is likely to suffer from attenuation 
Figure 3.2: Sample distribution
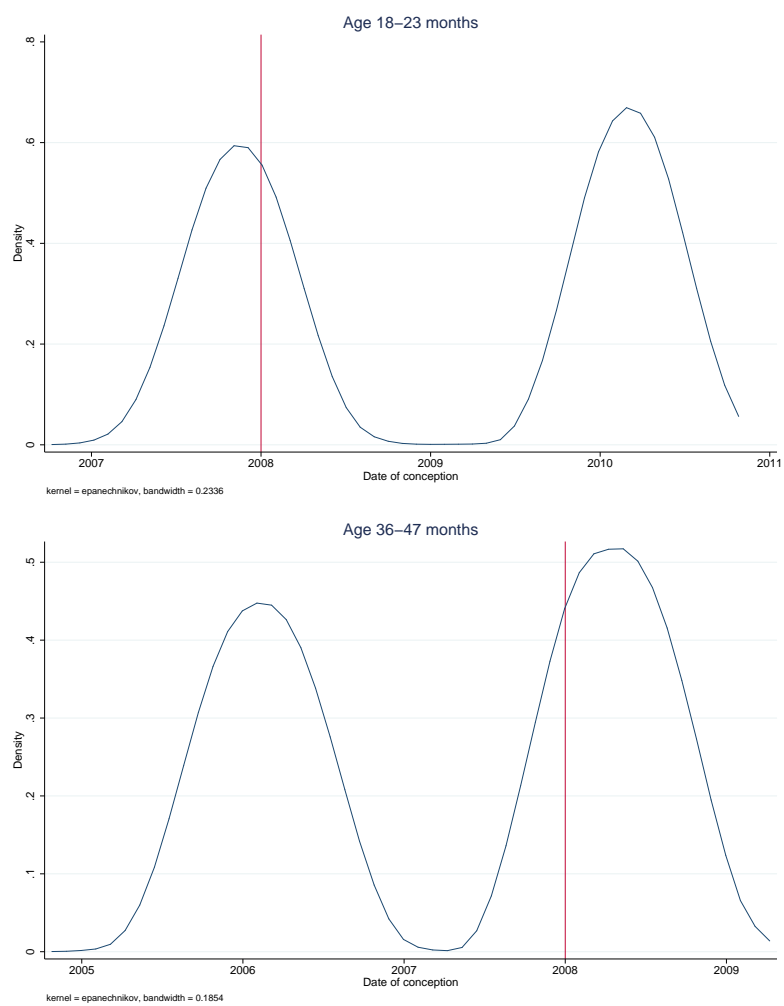

bias. Additionally, the implementation of ChCC happened first in districts with better infrastructure and maternity centre management capacities(75). Also, the availability of non-physician professionals, such as psychologists and social workers, conditioned the implementation of the policy(72). Our placement of these individuals in the pre-ChCC cohort generates further attenuation of results.

We have chosen to exclude from both pre and post-ChCC cohorts individuals who were not delivered in public health facilities. We did this as ChCC is mainly implemented through public institutions. The exclusion results in a group of individuals who are more similar in observable characteristics, such as income, family composition amongst others.

The comparison of cohorts before and after the complete implementation of the programme, as we undertake here, could face biases from differences between cohorts that are not related to ChCC. However, as we compare cohorts with a mean difference of two and half years between them, we expect these effects to be small. Finally, using the ELPI 2010 and 2012, and the early ChCC implementation starting in 2007 we have at maximum 5 years of implementation of the programme. It thus likely some of the programme's effects are only now beginning to crystallise.

The advantage of estimating a non-linear production function of child 
abilities is that organises within a defined theoretical framework the possible mechanism behind the policy's effect. Further it allows to recuperate not only point estimates of effects but distributions giving us the ability to perform contra-factual exercises to better assess the policy. Finally, our methodology uses common variances between various measurements that reflect a given latent trait. This, as it will be detailed later in the article, reduces bias due to measurement error in the data.

\section{4}

\section{Structural modelling and estimation}

This section is divided into two sub-sections. The first section details the production function we wish to estimate. The second section is devoted to its estimation, it explains the econometric problems we face and our estimation procedure.

\subsection{1}

\section{The model}

Our model is based on the seminal article of Cunha, Heckman and Schennach(95). They develop a theoretical and empirical framework where the child's abilities depend of a technology of production, parental abilities, previous period abilities and parental investments.

We define a production function for three types of abilities given by $\boldsymbol{\Theta}=$ $\left[\theta^{c}, \theta^{s}, \theta^{e}\right]$, where $\theta^{c}, \theta^{e}, \theta^{s}$ represents cognitive skills external socio-emotional skills, and internal socio emotional skills, respectively. The separation between external and internal socio-emotional skills represents an innovation in terms of existing production function literature. The field of child psychology has long distinguished between "internalising" and "externalising" disorders (103). The former reflecting the child negatively acting on the external environmental stimuli and the latter reflecting problems with the child's internal psychological environment. Examples of externalising behaviour problems are aggressiveness, attentional deficits and hyperactivity while examples of internalising behaviour include anxiety, depression and inhibition. We are particularly interested in the external component of CBCL as external behaviour problems are linked to executive functioning of the brain(100, 101). Executive function consists of four principle dimensions: i) attentional control ii) information processing iii) cognitive flexibility iv) goal setting. All contribute to determining a child's cognitive function behaviour, emotional control and social interaction. Attentional control, subdivided into processes of selective attention, selfregulation, self-monitoring and inhibition, appears to emerge in infancy and 
develop in early-childhood. The remaining three dimensions develop and mature at later stages of childhood (102). Although the ECD literature has not distinguished between "internalising" and "externalising" mental health, it has begun to measure EF as a separate skill from socio-emotional and cognitive skills $(104,105)$.

As we wish to check whether Chile Crece Contigo affected the parameters governing the production function abilities, we let the production function vary between pre and post-ChCC cohorts, denominated by the superscript $d$. The production function also varies by age group $a$. We consider the two age groups described in data section: 18-23 months and 36-48 months of age.

The production function describes the formation of child abilities in two moments of time. The initial moment is child's birth, which we denote as $t=t_{0}$. The second moment, which we denote as $t=t_{1}$, is when ELPI survey was collected, that could be one or three years after birth depending on the age group the child belongs to. We assume a CES technology in the production of abilities, where child's current ability $\boldsymbol{\Theta}_{t_{1}}$ is a result of the combination of a vector of parental cognitive, socio-emotional skills and parental health $\Omega=\left[\omega^{c}, \omega^{s}, \omega^{h}\right]$, child's initial skills $\theta_{t_{0}}$, parental investment $i_{t_{1}}$, and a factorneutral productivity parameter $A_{t_{1}}^{a, d}$. Our production functions of each of the three dimensions of child skills are depicted below in matrix notation.

$$
\boldsymbol{\Theta}_{t_{1}}=A_{t_{1}}^{a, d}\left[\gamma_{1}^{a, d}\left(i_{t_{1}}\right)^{\phi^{a, d}}+\gamma_{2}^{a, d}\left(\theta_{t_{0}}\right)^{\phi^{a, d}}+\gamma_{3}^{a, d}(\boldsymbol{\Omega})^{\phi^{a, d}}\right]^{\frac{1}{\phi^{a, d}}}
$$

where the production function parameters $\gamma_{1}^{a, d}, \gamma_{2}^{a, d}, \gamma_{3}^{a, d}, \phi^{a, d}$ are matrices of the same length as $\boldsymbol{\Theta}_{t_{1}}$, and $A_{t_{1}}^{a, d}$ is given by the following expression which depends on a set of controls $\boldsymbol{X}_{t_{1}}$ and a random shock $u_{t_{1}}^{a, d}$ :

$$
A_{t_{1}}^{a, d}=\exp \left(\delta_{1}^{a, d}+\delta_{2}^{a, d} \boldsymbol{X}_{t_{1}}+u_{t_{1}}^{a, d}\right)
$$

The advantage of this functional form is that we do not have to assume an specific degree of substitutability between the inputs of our production function. The parameter $\phi^{a, d} \in(-\infty, 1]$ determines the elasticity of substitution, that is given by $\frac{1}{1-\phi^{a, d}}$.

We adopt a logarithm version of our model as in Attanasio et al (98). The equation to be estimated is thus:

$$
\begin{aligned}
\ln \boldsymbol{\Theta}_{t_{1}}=\frac{1}{\phi^{a, d}} \ln \left[\gamma_{1}^{a, d}\left(i_{t_{1}}\right)^{\phi^{a, d}}+\gamma_{2}^{a, d}\left(\theta_{t_{0}}\right)^{\phi^{a, d}}+\gamma_{3}^{a, d}(\boldsymbol{\Omega})^{\phi^{a, d}}\right] & \\
& +\delta_{1}^{a, d}+\delta_{2}^{a, d} \boldsymbol{X}_{t_{1}}+u_{t_{1}}^{a, d}
\end{aligned}
$$




\subsection{2}

\section{Estimation}

The estimation of our non-linear production function is complex. We face two challenges: the regressors are non-observables, and parental investments may be endogenous. The variables of our function: cognitive abilities, socioemotional abilities, health and parental investments are latent traits. We do not observe them directly, but instead we have a variety of measures in our dataset that reflect these traits. Hence we need to develop a model that relates the measures in our data and our latent variables in a manner that permits non-linear relationship between our latent variables.

The second problem with the estimation of our production function is that parental investments may suffer from endogeneity. This is because when parents make their investment decisions they may take into account random shocks to the child's ability. For example, if a child falls sick her parents may invest more in her to offset this negative shock, or act in a way to reinforce it.

In the next subsections we explain our estimation procedure, which deals with the non-observability and endogeneity problems, and follows Attanasio et. al.(98). Our estimation consists of three steps. In the first step, we estimate the distribution of our measurements, separately for pre and post ChCC cohorts. We then, use the distribution of measurements to reover the distribution of latent factors. This is done again for pre and post $\mathrm{ChCC}$ cohorts. In the final step, using the distribution of latent factors we draw a synthetic dataset and apply non-linear least squares to estimate our non-linear production functions.

\subsubsection{1}

\section{A factor structure between measurements and latent variables}

The principle challenge with our estimation is the fact that our latent traits are non-observable. Hence we need to model the relationship between our measurements and our latent factors. Denote our latent factors by $\boldsymbol{\Psi}=$ $\left[\boldsymbol{\Theta}_{t_{1}}, i_{t_{1}}, \theta_{t_{0}}, \boldsymbol{\Omega}, \mathbf{X}_{t_{1}}\right]$. We assume a factor structure between latent variables and measurements, where each measurement has a component associated with the latent factor and a component which is purely noise. The intuition behind factor models, such as ours, is that the common variance between our measurements is attributed to the latent factor they all reflect, while the remaining variance is the noise. The factor structure for each measurement is related to latent variables $\boldsymbol{\Psi}$ as follows: 


$$
\begin{aligned}
M^{\boldsymbol{\Theta}_{t_{1}}, a, d} & =\beta^{\boldsymbol{\Theta}_{t_{1}}, a, d}+\lambda^{\boldsymbol{\Theta}_{t_{1}}, a, d} \ln \left(\boldsymbol{\Theta}_{t_{1}}\right)+\epsilon_{\boldsymbol{\Theta}_{t_{1}}, a, d} \\
M^{\theta_{t_{0}}, a, d} & =\beta^{\theta_{t_{0}}, a, d}+\lambda^{\theta_{t_{0}}, a, d} \ln \left(\theta_{t_{0}}\right)+\epsilon_{\theta_{t_{0}}, a, d} \\
M^{i_{t_{1}}, a, d} & =\beta^{i_{t_{1}}, a, d}+\lambda^{i_{t_{1}}, a, d} \ln \left(i_{t_{1}}\right)+\epsilon_{i_{t_{1}}, a, d} \\
M^{\boldsymbol{\Omega}, a, d} & =\beta^{\boldsymbol{\Omega}, a, d}+\lambda^{\boldsymbol{\Omega}, a, d} \ln (\boldsymbol{\Omega})+\epsilon_{\boldsymbol{\Omega}, a, d} \\
M^{\mathbf{X}_{t_{1}}, a, d} & =\mathbf{X}_{t_{1}}^{a, d}
\end{aligned}
$$

where $\quad M^{\boldsymbol{\Theta}_{t_{1}}, a, d}, M^{\theta_{t_{0}}, a, d}, M^{i_{1}, a, d}, M^{\boldsymbol{\Omega}, a, d}, M^{\mathbf{X}_{t_{1}}, a, d} \quad$ are $\quad$ vectors $\quad$ of measurements, $\beta^{\theta_{t_{1}}, a, d}, \beta^{\theta_{t_{0}}, a, d}, \beta^{i_{1}, a, d}, \beta^{\boldsymbol{\Omega}, a, d}$ are vectors of measurement means, $\quad\left[\lambda^{\theta_{t_{1}}, a, d}, \lambda^{\theta_{t_{0}}, a, d}, \lambda^{i_{t_{1}}, a, d}, \lambda^{\boldsymbol{\Omega}, a, d}\right] \equiv \Lambda$ are factor loadings and $\epsilon_{\boldsymbol{\Theta}_{t_{1}}, a, d}, \epsilon_{\theta_{t_{0}}, a, d}, \epsilon_{i_{1}, a, d}, \epsilon_{\boldsymbol{\Omega}, a, d}$ are idiosyncratic error terms. Notice that $\theta_{t_{1}}, i_{t_{1}}, \theta_{t_{0}}, \boldsymbol{\Omega}$ are measured with error whereas the control variables, $\mathbf{X}_{t_{1}}$, are measured without error.

In order to identify the parameters of the measurement system, we assume that errors are orthogonal to latent variables and normalise our system by setting the factor loading coefficient of the first measurement of each latent variable to one, as the extant literature does. Further, we assume that errors are independent amongst themselves ${ }^{15}$.

At this point, we remind the reader that we wish to recover the distribution of latent factors for control and treatment groups. It is standard to assume normal distributions for all errors and measurements, which implies that latent factors also are multivariate normally distributed. Multivariate normal distribution implies that any linear combination of its components, latent variables, is also normally distributed. This implies linear conditional means of children abilities given other latent traits, ruling out a non-linear production function. In order to add enough flexibility we assume latent factors are drawn from a mixture of two normal distributions, as done by Attanasio et al $(98)^{16}$. We also assume that the errors of the equations above are normally distributed. We thus have:

$$
\begin{gathered}
\epsilon \sim N\left(0, \Sigma^{\epsilon}\right) \\
f_{a, d}(\ln \Psi)=\tau_{a, d} f_{a, d}^{1}(\ln \Psi)+\left(1-\tau_{a, d}\right) f_{a, d}^{2}(\ln \Psi)
\end{gathered}
$$

${ }^{15}$ This assumption can be relaxed, as shown in (95). However, we do not explore this possibility on this paper.

${ }^{16}$ Attanasio et al (2015) test mixed normal distributions with more than two components but revert to the two component normal mixture. The gain from adding mixtures is small when compared to the computational burden of such choices 
where $f_{a, d}^{1}$ and $f_{a, d}^{1}$ are multivariate normal distribution and $\tau$ represents the weight of each distribution.

Given the above equations and our measurements to latent factor structure we can derive the following formula for our distribution of measurements:

$$
\begin{aligned}
f\left(\tilde{m}_{a, d}\right)=\tau_{a, d} \int g(\Lambda \ln \Psi & \left.-\tilde{m}_{a, d}\right) f_{a, d}^{1}(\ln \Psi) d \ln \Psi \\
& +\left(1-\tau_{a, d}\right) \int g\left(\Lambda \ln \Psi-\tilde{m}_{a, d}\right) f_{a, d}^{2}(\ln \Psi) d \ln \Psi
\end{aligned}
$$

where $\mathrm{g}($.$) is \epsilon \sim N\left(0, \Sigma^{\epsilon}\right), f_{a, d}^{1}(\ln \Psi)=N\left(\mu_{a, d}^{1}, \Sigma_{a, d}^{1}\right), f_{a, d}^{2}(\ln \Psi)=N\left(\mu_{a, d}^{2}, \Sigma_{a, d}^{2}\right)$

\subsection{3}

\section{Endogeneity of parental investment in our production function}

Endogeneity of parental investments result in the error term of production function no longer being independent from parental investment, that is we have $E\left(u_{t_{1}} \mid \theta_{t_{0}}, \boldsymbol{\Omega}, i_{t_{1}}, \boldsymbol{X}_{t_{1}}\right) \neq 0$. We solve this problem with the introduction of a control function for investment. We assume that the conditional expectation of the error term in equation (3-1), $u_{t_{1}}$, is linear on an endogeneity component $v_{t_{1}}$, and a true random error ${ }^{17}$. Hence, we have $E\left(u_{t_{1}} \mid \theta_{t_{0}}, \Omega, i_{t_{1}}, \boldsymbol{X}_{t_{1}}\right)=E\left(u_{t_{1}} \mid v_{t_{1}}\right)=\rho^{a, d} v_{t_{1}}$, and the error of the production function becomes:

$$
u_{t_{1}}=\rho^{a, d} v_{t_{1}}+\zeta_{i, t_{1}}
$$

We proceed to estimate the endogeneity component $v_{t_{1}}$, by constructing an equation with the determinants of the our endogenous variable, investment. We assume the equation on the determinants of investments is as follows:

$$
\ln i_{t_{1}}=\alpha_{1}^{a, d}+\alpha_{2}^{a, d} \ln \theta_{0}+\alpha_{3}^{a, d} \boldsymbol{\Omega}+\alpha_{4}^{a, d} \boldsymbol{X}_{t_{1}}+\alpha_{5}^{a, d} \ln q_{t_{1}}+v_{t_{1}}
$$

where, as standard, we assume that $E\left(v_{t_{1}} \mid \ln \theta_{t_{0}}, \ln \Omega, \boldsymbol{X}_{t_{1}}, \ln q_{t_{1}}\right)=0$. The investment equation contains all variables of the production function in addition to an instrument, $\ln q_{t_{1}}$. Our identification rests on finding a variable that affects ability only via parental investments. A natural candidate for our instruments are prices or income shocks. They are likely to affect investment through the family budget constraint, but not the production function directly. Here, we use the international monthly price of copper, which can be seen as

${ }^{17} \mathrm{We}$ also assume that both errors, $u_{t_{1}}$ and $v_{t_{1}}$, are jointly independent of the state variables $\theta_{t_{0}}, \boldsymbol{\Omega}, \boldsymbol{X}_{t_{1}}$, and that the parental investment has a one-to-one function with the endogenous error term, as in (99) 
a relevant exogenous shock on family income because of the importance of copper in Chilean economy. We use the average price over the last year of life of the child as our instrument. The relationship between copper price and investment can be either negative or positive. On one hand, as copper price rises the opportunity cost of not working becomes higher. This means parents would spend less time at home with their children. Further, higher salaries allows parents to hire alternative care for their children. On the other hand, income effect means that parents can consume more time with their children. In both cases, copper prices will affect child development through parental time investments.

Once we secure our identification, we use the investment equation to obtain an estimate of $\hat{v}_{t_{1}}^{a, d}$. This estimated error term becomes an additional variable in our production function, a variable that controls for the endogeneity of investment.

\subsubsection{1}

\section{Estimation Procedure}

We have now established our complete estimation approach. For clarity we detail each step of our estimation procedure.

In the first step, we estimate the distribution of demeaned measurements for pre and post ChCC cohorts and each age group. We assume $f\left(\tilde{m}_{a, d}\right)$ is a mixture of normal distributions given by the equation (3-2). We use an Expectation Maximisation algorithm ${ }^{18}$ to estimate the means and variancecovariance matrices of $f\left(\tilde{m}_{a, d}\right): \tilde{\mu}_{a, d}^{1}, \tilde{\Sigma}_{a, d}^{1}, \tilde{\mu}_{a, d}^{2}, \tilde{\Sigma}_{a, d}^{2}, \tilde{\tau}_{a, d}$.

In the next step, we estimate the distribution of latent variables $f_{a, d}(\ln \Psi)$, which is defined by the means and covariance-variance matrices of each mixture component, given by $\mu_{a, d}^{1}, \Sigma_{a, d}^{1}, \mu_{a, d}^{2}, \Sigma_{a, d}^{2}, \tau_{a, d}$, factor loadings matrix $\Lambda$ and the covariance matrix of the distribution of errors $\Sigma^{\epsilon}$. Note that the latter two are assumed to be the same between pre and post $\mathrm{ChCC}$ cohorts so that all differences between cohorts arise from differences in the distribution of latent variables.

The parameters of the latent variables are given by the minimum distance between the right handside of the equation and the parameters of the distribution of measurements, obtained in the earlier step, in the left handside

${ }^{18}$ This method has been widely utilised for estimating mixture of normals, as described in (107). This method consists of two steps. First, the expectation step computes the probability that each observation belongs to one of the normal distributions. Given these probabilities, we maximize the likelihood function in the second step. This two steps are repeated until convergence. 
of the system below ${ }^{19}$.

$$
\begin{gathered}
\tau_{a, d}=E\left[\tilde{\tau}_{a, d}\right] \\
\Lambda \mu_{a, d}^{1}=E\left[\tilde{\mu}_{a, d}^{1}\right] \\
\Lambda \mu_{a, d}^{2}=E\left[\tilde{\mu}_{a, d}^{2}\right] \\
\Lambda^{\prime} \Sigma_{a, d}^{1} \Lambda+\Sigma^{\epsilon}=E\left[\tilde{\Sigma}_{a, d}^{1}\right] \\
\Lambda^{\prime} \Sigma_{a, d}^{2} \Lambda+\Sigma^{\epsilon}=E\left[\tilde{\Sigma}_{a, d}^{2}\right]
\end{gathered}
$$

The final step consists of using $f_{a, d}(\ln \Psi)$ to draw a synthetic dataset of latent factors and estimate our production, equation (3-1), as if the latent variables were observable. Specifically we use OLS to estimate the determinants of investment, equation (3.4.3), and construct $\hat{v}_{t_{1}}$. Then we apply non-linear least squares with the addition of $\hat{v}_{t_{1}}$ and estimate parameters of our production function.

The standard errors are obtained using bootstrapp over all the procedure. We report confidence intervals for all our estimates. In this way, we don't need to assume a standard distribution to compute p-values for our estimates.

\section{5 \\ Results}

\subsection{1}

\section{System of measures and latent variables}

We begin by showing the measurements we chose for each of our latent variables. Our selection of measurements was guided by the literature on nonlinear production function of abilities $(95,98,97,108)$ and the availabiltiy of measurement in our dataset. We have standard measurements of child's ability at birth, child's socio-emotional abilities and parental abilities. These measurements are derived from tests widely used in literature Wechsler Adult Intelligence Scale (WAIS) test-, mental health-CBCL test- and the big five personality test. However due to data restrictions, our cognitive ability consists of just one measurement per age gruop the psycho-motor Battelle score for ages 18-23 months and the Peabody Vocabulary tests for those of 3-4 years off age. Although these test are standard in the literature, other articles do

${ }^{19}$ The only conceptual difference between our estimation and (98) is that they compute the covariance matrix between latent traits and control by equating it to the covariance matrix between the measurement of the latent trait which had its weight normalised to one and the controls. We on the other hand, minimise the distance between the covariance matrix of latent traits and controls and the covariance matrices of all measurements and controls. Our estimation is computationally more demanding but more general. 
not use a sole test score to generate the child's cognitive ability. Our parental investments variable only reflects time investments in children. The standard in literature is to also use measurements which reflect material investments. Again, our data contains few variables of that nature ${ }^{20}$.

Table 3.6 shows the percentage of information of each measurement per latent variable for children aged 18-23 months, the first two columns, and for children aged 36-48 months, the last two columns. Analysing the table we note that at large information percentages remain constant across ages and across cohorts. Further, we note that the chosen measurements appear to have high levels of common correlation. The majority of measurements show percentages of signal to noise of at least one quarter.

For abilities at birth we have weight, height, and gestation length. The two first variables are the most informative with ratios of information higher than $60 \%$. We follow with the child's socio-emotional abilities, divided into externalising and internalising scores. Attentional problems have a lower percentage of information, which ranges from $30 \%$ to $47 \%$ and aggressive conduct has information percentages that vary from $63 \%$ to $94 \%$. While the poorest measurement on internalising has a signal ratio slightly above $20 \%$, the richest measurements has ratio of over $40 \%$.

Parental cognitive abilities, consists of four measurements, mother's and father's schooling in years and the mother's WAIS test score for vocabulary and memory. The least noisy measurements are mother education and father education, the former has ratios averaging $45 \%$ and the latter just below $35 \%$. Parental socio-emotional ability is measured using each dimension of the Big five personality test taken by the main carer. We see that the personality dimension with the highest commmunality is neuroticism while the dimesions of extroversion and kindness display the lowest communalities. We note however that the dimensions of the Big five personality test have low levels of communality in general at maximum of $35 \%$. Parental health is composed of mother's height and weight, all of which have similar levels of information.

Finally, parental investment contains variables on activities undertaken with child by the father and the mother during the week before the interview. These variables are given scores of 0-2 depending on whether neither, one or both parents undertook activity in question. For children of 48-36 months we have included in parental investment a variable reflecting the time spent in

\footnotetext{
${ }^{20}$ We have attempted to use the question "Do you have more than 10 children books at home?". However with this variable our E.M algorithm converged to a degenerate distribution. This is common with dummy variables with small variances. (107)
} 
nursery or day-care since completing 36 months $^{21}$. In table, 3.6 we observe differences in information percentages between ages. For younger children the most informative variables are activities related to reading books and singing to the child. For older children the reading books is accompanied by telling stories to the child.

Table 3.6: Percentage of information per measure of latent variables

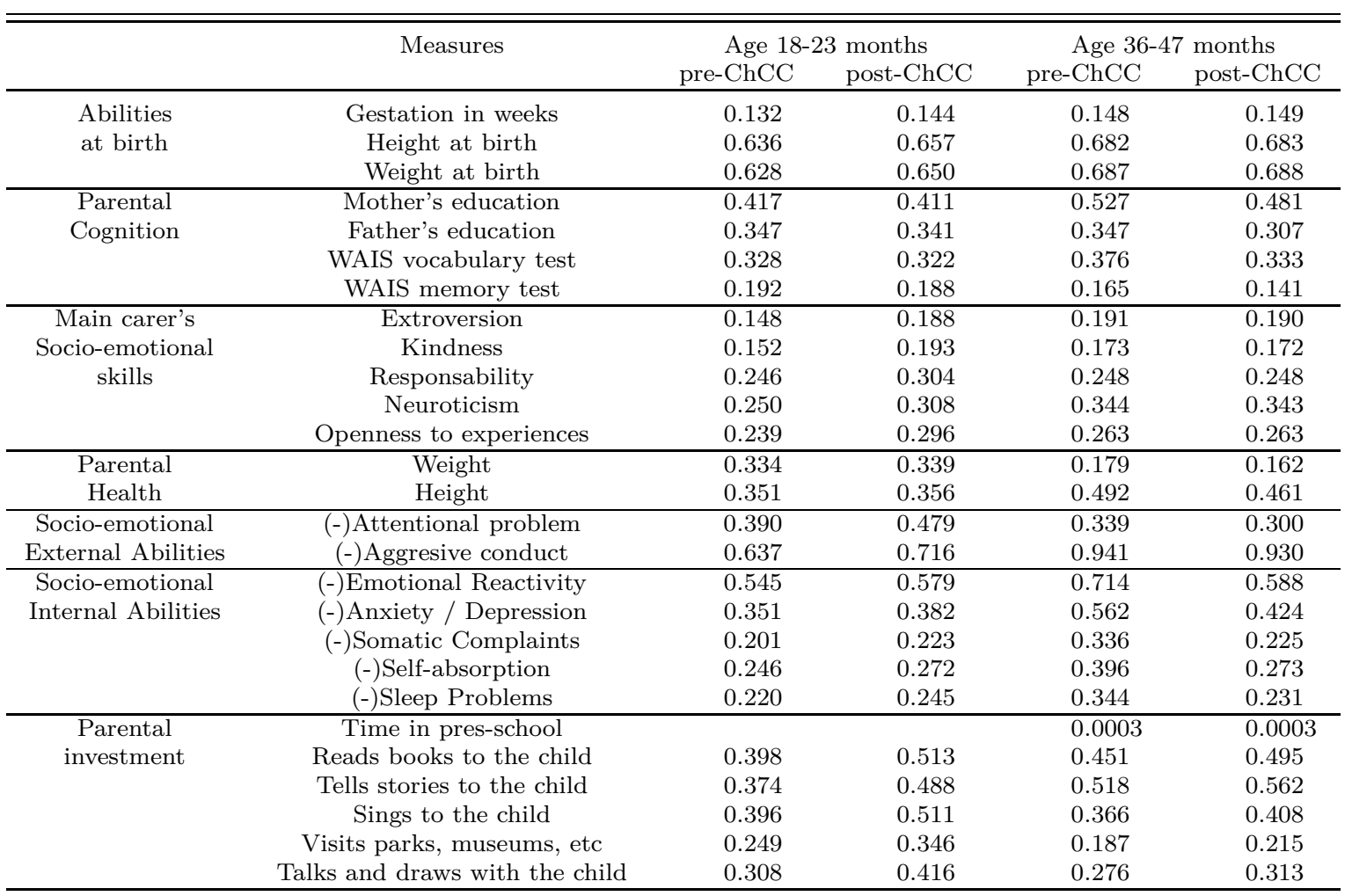

Source: Own elaboration based on EM estimation

We have established the composition of our latent variables. We can analise mean differences between pre and post ChCC cohorts. As discussed in the empirical strategy section, we have been most conservative, and thus attribute these differences to a lower bound of the effect of ChCC. For both age groups, we consistently observe that the post $\mathrm{ChCC}$ cohort has higher levels of external and internal socio-emotional skills when compared to the pre-ChCC cohort. The same is true for parental investment. On the other hand, parental socio-emotional skills remain unchanged after ChCC. For all other variables we have inconclusive results (See Table 3.7).

For cognition, our results are ambiguous. ChCC is associated with higher levels of cognitive skills for children of 18-23 months of age and lower levels of cognition for those of 36-47 months years of age. We note that the results

${ }^{21}$ We attempted to add the same variable for children aged 18 to 23 months. However, this variable was purely noise and few children attended daycare in that age. Thus, we decided to exclude it from our analysis. 
are not necessarily comparable between these two age groups as we use scores from different tests.

Table 3.7: Mean difference of latent variable before and after ChCC

\begin{tabular}{lcc}
\hline \hline & Age $18-23$ months & Age 36-47 months \\
& $(1)$ & $(2)$ \\
\hline External S.E. skills & 0.806 & 0.856 \\
& $(0.603,1.031)$ & $(0.715,0.995)$ \\
Internal S.E. skills & 0.303 & 0.252 \\
& $(0.247,0.392)$ & $(0.225,0.319)$ \\
Cognition & 0.910 & -0.310 \\
& $(0.818,1.113)$ & $(-0.443,-0.174)$ \\
Parental Investment & 0.369 & 0.368 \\
& $(0.253,0.532)$ & $(0.338,0.507)$ \\
Abilities at birth & 0.029 & -0.123 \\
& $(-0.092,0.135)$ & $(-0.186,-0.053)$ \\
Parental cognition & -0.024 & 0.042 \\
& $(-0.077,0.039)$ & $(0.013,0.069)$ \\
Parents' SE skills & -0.002 & -0.004 \\
& $(-0.076,0.078)$ & $(-0.038,0.038)$ \\
Parental health & 0.068 & 0.015 \\
& $(-0.022,0.171)$ & $(-0.084,0.092)$ \\
\hline \hline
\end{tabular}

\subsection{2}

\section{Production functions}

We can move to the estimation of the production functions. The first step in the estimation is to obtain $\hat{v}$ through modelling the determinants of investment. Table 3.8 contains the determinants of investment equation for age 18-23 months and 36-47 months. We see that the price of copper in the first year of life, first two columns, and in the third year of life, last two columns, is positively and significantly correlated with parental investment for both the cohort before and after the beginning of ChCC. The overall positive effect indicates that when parents become richer due to higher copper prices tend to spend more time with their children. Further, the confidence intervals of our coefficient estimates for before and after ChCC overlap for both ages. This suggests there is little differentiation between cohorts.

Our control variables affect the investment equation in a manner that is consistent with extant literature. Parental abilities are positively correlated with investment, especially cognitive abilities. An additional child in the household reduces parental investment, more so if this child is younger than 7 years of age. Parents who cohabit tend to invest more in their children. We however do not observe any correlations between abilities at birth and child sex with parental investment.

We begin by analysing general patterns in the production function of skills and health. First, all functions follow a Cobb-Douglas technology, which 
Table 3.8: Investment functions

\begin{tabular}{|c|c|c|c|c|}
\hline & \multicolumn{2}{|c|}{ Age $18-23$ months } & \multicolumn{2}{|c|}{ Age $36-47$ months } \\
\hline & $\begin{array}{c}\text { pre-ChCC } \\
(1) \\
\end{array}$ & $\begin{array}{c}\text { post-ChCC } \\
(2) \\
\end{array}$ & $\begin{array}{c}\text { pre-ChCC } \\
(3) \\
\end{array}$ & $\begin{array}{c}\text { post-ChCC } \\
(4) \\
\end{array}$ \\
\hline $\ln ($ Copper price $)$ & $\begin{array}{r}0.18 \\
(0.061,\end{array}$ & $\begin{array}{r}0 \\
(0.08\end{array}$ & $\begin{array}{c}0.099 \\
(0.088,0.137)\end{array}$ & $481)$ \\
\hline Abilit. & $\begin{array}{c}-0.090 \\
(-0.162,-0.019)\end{array}$ & $\begin{array}{r}-0 \\
(-0.06\end{array}$ & $\begin{array}{c}-0.017 \\
(-0.048,0.018)\end{array}$ & $\begin{array}{c}0.006 \\
(-0.029,0.048)\end{array}$ \\
\hline Parer & $\begin{array}{c}0.271 \\
(0.134,0.367)\end{array}$ & $\begin{array}{r}0 . \\
(0.089\end{array}$ & $\begin{array}{c}0.208 \\
(0.145,0.285)\end{array}$ & $\begin{array}{r}0.2 \\
(0.211\end{array}$ \\
\hline Parer & $\begin{array}{c}0.134 \\
(0.053,0.266)\end{array}$ & $\begin{array}{r}0 . \\
(-0.03\end{array}$ & $\begin{array}{c}0.038 \\
(0.002,0.090)\end{array}$ & $\begin{array}{c}-0.071 \\
(-0.149,-0.013)\end{array}$ \\
\hline Parent & $\begin{array}{c}0.241 \\
(0.143,0.385)\end{array}$ & $\begin{array}{r}0 . \\
(-0.02\end{array}$ & $\begin{array}{c}0.120 \\
(0.080,0.180)\end{array}$ & $\begin{array}{c}0.061 \\
(-0.005,0.124)\end{array}$ \\
\hline Parer & $\begin{array}{r}0.2 \\
(0.174,\end{array}$ & $\begin{array}{r}0.3 \\
(0.255\end{array}$ & $\begin{array}{c}0.192 \\
(0.180,0.241)\end{array}$ & $\begin{array}{r}0.2 \\
(0.210\end{array}$ \\
\hline Chi & $\begin{array}{c}-0.021 \\
(-0.072,0.024)\end{array}$ & $\begin{array}{c}-0.105 \\
(-0.168,-0.029)\end{array}$ & $\begin{array}{c}-0.008 \\
(-0.031,0.010)\end{array}$ & $\begin{array}{c}-0.0004 \\
(-0.023,0.027)\end{array}$ \\
\hline Mino & $\begin{array}{c}-0.087 \\
(-0.130,-0.032)\end{array}$ & $\begin{array}{c}0.017 \\
(-0.039,0.076)\end{array}$ & $\begin{array}{c}-0.020 \\
(-0.042,-0.003)\end{array}$ & $\begin{array}{c}-0.014 \\
(-0.053,0.013)\end{array}$ \\
\hline Minors $<18$ at home & $\begin{array}{c}0.017 \\
(-0.040,0.078)\end{array}$ & $\begin{array}{c}-0.005 \\
(-0.092,0.066)\end{array}$ & $\begin{array}{c}-0.035 \\
(-0.059,-0.018)\end{array}$ & $\begin{array}{c}-0.041 \\
(-0.071,-0.012)\end{array}$ \\
\hline Mother's Age & $\begin{array}{c}-0.067 \\
(-0.110,-0.020)\end{array}$ & $\begin{array}{c}-0.080 \\
(-0.131,-0.026)\end{array}$ & $\begin{array}{c}-0.021 \\
(-0.043,-0.005)\end{array}$ & $\begin{array}{c}-0.007 \\
(-0.040,0.020)\end{array}$ \\
\hline
\end{tabular}

Note: $90 \%$ bootstrapped confidence interval in parenthesis. 100 replications.

means that the inputs of the function are complements. This is evident as the substitution parameters confidence intervals contain zeros in all cases, as shown in tables 3.9 to 3.11. Secondly, the investment residuals are significant and negative in all cases but for the production of cognition of age 36-47 months in the pre-ChCC cohort. We interpret this as evidence that parents compensate shocks to the children's skills. Our results are consistent across the literature on non-linear production functions of child abilities $(95,98,97,108)$. In general, the share of parental investment is positive, significant and it increases after ChCC implementation. We see a positive and significant association between abilities at birth for health and cognition only. Finally, we observe that the inputs with the highest shares are parental investment and the dimension of parental ability that reflects the child's ability output.

Table 3.9 contains the estimated parameters of the external socioemotional skills production function for ages 18-23 months and 36-47 months. Results show that parental investment and parental socio-emotional skills are the only two statistically significant inputs for the production of socioemotional skills. As mentioned before, the share of parental investment raises for the post-ChCC cohorts. The relative change of this share is higher for children aged 37 to 48 months. Thus, the share of parental investment increases 
by $45 \%$ for the age group of $18-23$ months, whereas it increases by $84 \%$ for the older age group. In order to compensate the rise of this share, the share of parental socio-emotional skills falls. Nonetheless, it remains positive and significant for both age groups.

Parental investment, cognition and socio-emotional skills are the three highest shares of the production function of internal socio-emotional skills, as we can see in table 3.10. Contrary to external socio-emotional skills results, the relative increase of the investment share after ChCC implementation is higher for the younger age group, whose share rises by $71 \%, 50$ percent points higher than the increase of the older age group. The increase in the investment share is followed by a reduction in the shares of parental cognition and socioemotional skills. The former becomes non-significant for age 18-23 months, while the latter remains positive and significant for both age groups, like in the external socio-emotional production function.

Table 3.11 offers the parameters of our production function of cognitive abilities for ages 18-23 months and 36-48 months. For age 18-36 months we have that for both those conceived before and after January 2008 parental investment has highest coefficient of share. In the cohort before ChCC, we have that parental investment has the highest share followed by parental cognition, socio-emotional skills, abilities at birth and health which is not significant. For the ChCC cohort, we have a case where the coefficient on investment is higher than one, and all other coefficients are either zero or negative. For age 36-48 months we have that parental cognition is the dominant input for both cohorts. Specifically, for the pre-ChCC cohort, only parental cognition and abilities at birth have non-zero coefficients. In the case of the post-ChCC cohort the variables which have significant impacts are parental investments and parental cognition. 
Table 3.9: External Socio-emotional skills

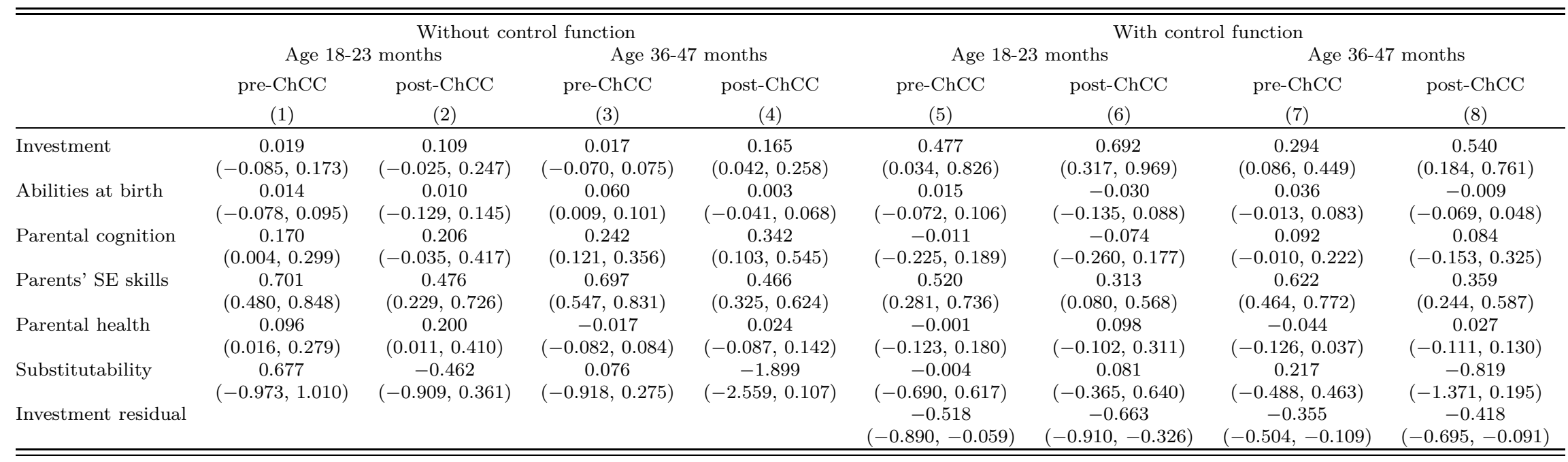

Note: $90 \%$ bootstrapped confidence interval in parenthesis. 100 replications. 
Table 3.10: Internal Socio-emotional skills

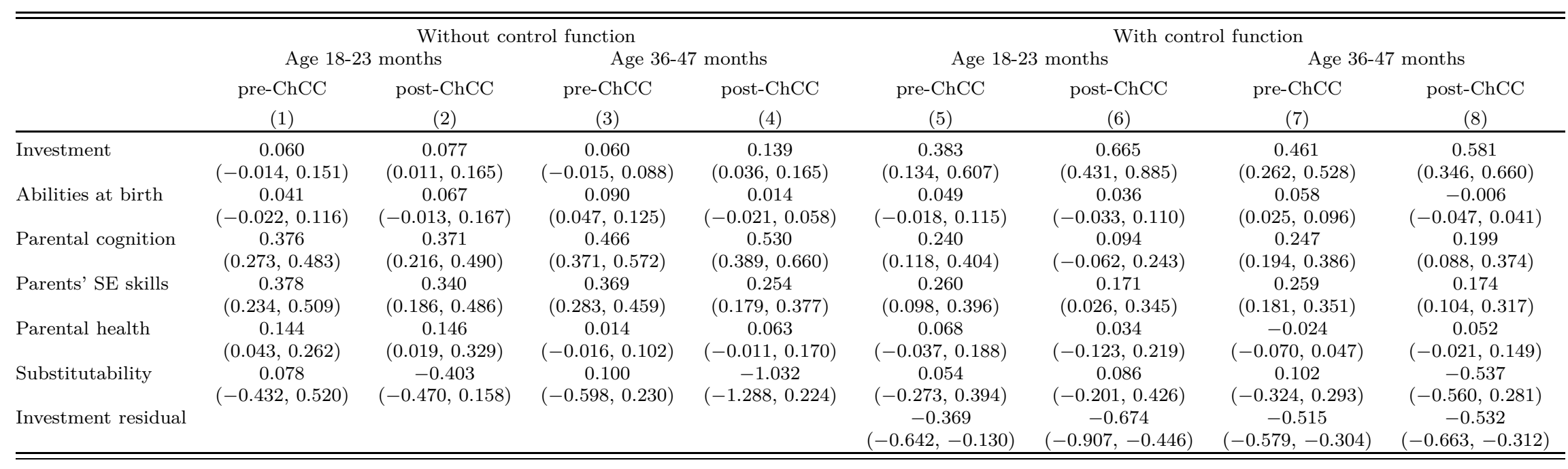

Note: $90 \%$ bootstrapped confidence interval in parenthesis. 100 replications. 
Table 3.11: Cognitive skills

\begin{tabular}{|c|c|c|c|c|c|c|c|c|}
\hline & \multicolumn{4}{|c|}{ Without control function } & \multicolumn{4}{|c|}{ With control function } \\
\hline & \multicolumn{2}{|c|}{ Age $18-23$ months } & \multicolumn{2}{|c|}{ Age 36-47 months } & \multicolumn{2}{|c|}{ Age $18-23$ months } & \multicolumn{2}{|c|}{ Age $36-47$ months } \\
\hline & $\begin{array}{c}\text { pre-ChCC } \\
(1) \\
\end{array}$ & $\begin{array}{c}\text { post-ChCC } \\
(2) \\
\end{array}$ & $\begin{array}{c}\text { pre-ChCC } \\
(3) \\
\end{array}$ & $\begin{array}{c}\text { post-ChCC } \\
(4) \\
\end{array}$ & $\begin{array}{c}\text { pre-ChCC } \\
(5) \\
\end{array}$ & $\begin{array}{c}\text { post-ChCC } \\
(6) \\
\end{array}$ & $\begin{array}{c}\text { pre-ChCC } \\
(7) \\
\end{array}$ & $\begin{array}{c}\text { post-ChCC } \\
(8) \\
\end{array}$ \\
\hline Investment & $\begin{array}{c}0.074 \\
(-0.034,0.204)\end{array}$ & $\begin{array}{c}0.185 \\
(0.109,0.248)\end{array}$ & $\begin{array}{c}0.049 \\
(-0.019,0.109)\end{array}$ & $\begin{array}{c}0.181 \\
(0.080,0.243)\end{array}$ & $\begin{array}{c}0.302 \\
(-0.013,0.641)\end{array}$ & $\begin{array}{c}1.550 \\
(1.146,1.959)\end{array}$ & $\begin{array}{c}-0.122 \\
(-0.299,0.030)\end{array}$ & $\begin{array}{c}0.284 \\
(0.098,0.420)\end{array}$ \\
\hline Abilities at birth & $\begin{array}{c}0.096 \\
(-0.002,0.181)\end{array}$ & $\begin{array}{c}0.131 \\
(0.028,0.196)\end{array}$ & $\begin{array}{c}0.065 \\
(0.018,0.121)\end{array}$ & $\begin{array}{c}0.034 \\
(-0.043,0.117)\end{array}$ & $\begin{array}{c}0.104 \\
(0.009,0.189)\end{array}$ & $\begin{array}{c}0.037 \\
(-0.099,0.134)\end{array}$ & $\begin{array}{c}0.074 \\
(0.026,0.131)\end{array}$ & $\begin{array}{c}0.027 \\
(-0.049,0.112)\end{array}$ \\
\hline Parental cognition & $\begin{array}{c}0.356 \\
(0.137,0.557)\end{array}$ & $\begin{array}{c}0.238 \\
(0.025,0.406)\end{array}$ & $\begin{array}{c}0.959 \\
(0.860,1.064)\end{array}$ & $\begin{array}{c}0.788 \\
(0.664,0.949)\end{array}$ & $\begin{array}{c}0.258 \\
(0.044,0.470)\end{array}$ & $\begin{array}{c}-0.418 \\
(-0.723,-0.114)\end{array}$ & $\begin{array}{c}1.054 \\
(0.930,1.208)\end{array}$ & $\begin{array}{c}0.713 \\
(0.552,0.902)\end{array}$ \\
\hline Parents' SE skills & $\begin{array}{c}0.367 \\
(0.199,0.541)\end{array}$ & $\begin{array}{c}0.430 \\
(0.249,0.600)\end{array}$ & $\begin{array}{c}-0.033 \\
(-0.121,0.050)\end{array}$ & $\begin{array}{c}-0.050 \\
(-0.164,0.052)\end{array}$ & $\begin{array}{c}0.283 \\
(0.081,0.520)\end{array}$ & $\begin{array}{c}0.050 \\
(-0.180,0.310)\end{array}$ & $\begin{array}{c}0.014 \\
(-0.074,0.100)\end{array}$ & $\begin{array}{c}-0.069 \\
(-0.180,0.029)\end{array}$ \\
\hline Parental health & $\begin{array}{c}0.107 \\
(0.005,0.286)\end{array}$ & $\begin{array}{c}0.015 \\
(-0.089,0.229)\end{array}$ & $\begin{array}{c}-0.040 \\
(-0.122,0.030)\end{array}$ & $\begin{array}{c}0.046 \\
(-0.045,0.155)\end{array}$ & $\begin{array}{c}0.054 \\
(-0.098,0.216)\end{array}$ & $\begin{array}{c}-0.219 \\
(-0.458,-0.019)\end{array}$ & $\begin{array}{c}-0.021 \\
(-0.098,0.064)\end{array}$ & $\begin{array}{c}0.045 \\
(-0.043,0.149)\end{array}$ \\
\hline Substitutability & $\begin{array}{c}0.589 \\
(-0.459,0.945)\end{array}$ & $\begin{array}{c}-0.111 \\
(-0.248,0.640)\end{array}$ & $\begin{array}{c}0.074 \\
(-0.122,0.547)\end{array}$ & $\begin{array}{c}-0.365 \\
(-0.530,0.222)\end{array}$ & $\begin{array}{c}0.448 \\
(-0.400,0.780)\end{array}$ & $\begin{array}{c}-0.098 \\
(-0.274,0.044)\end{array}$ & $\begin{array}{c}0.279 \\
(-0.028,0.614)\end{array}$ & $\begin{array}{c}-0.306 \\
(-0.472,0.193)\end{array}$ \\
\hline Investment $\mathrm{r}$ & & & & & $\begin{array}{c}-0.267 \\
(-0.653,0.081)\end{array}$ & $\begin{array}{c}-1.592 \\
(-1.956,-1.174) \\
\end{array}$ & $\begin{array}{c}0.220 \\
(0.040,0.409) \\
\end{array}$ & $\begin{array}{c}-0.129 \\
(-0.300,0.042) \\
\end{array}$ \\
\hline
\end{tabular}

Note: $90 \%$ bootstrapped confidence interval in parenthesis. 100 replications. 
As seen so far, there are two features that describe the changes in the production of skills associated with the exposure of ChCC since gestation. First, we observe a consistent increment in the share of parental investment, which may imply a rise in the return of that variable, measured by the average value of its marginal product. Second, we detect a small decrease in the substitutability parameter, that could translate into a change the elasticity of substitution of the production functions. Table 3.12 shows the pre-post-ChCC differences in the average marginal product of investment and the elasticity of substitution. Notice that in spite of the increase of the investment share, the average marginal product of investment increased significantly only for cognitive and socio-emotional skills of children aged 18 to 24 months. Further, none of the reductions in the elasticity of substitution is statistically significant.

Considering the results of table 3.7 and the last results, we can conclude that $\mathrm{ChCC}$ exposure affected the age groups differently. For the younger age group, $\mathrm{ChCC}$ is associated with both a positive change in the quantity of investment and its productivity, with statistically significant differences in socio-emotional and cognitive skills. On the other hand,for the older age group, we observe a positive difference in socio-emotional skills and an increase in the quantity of investment but with no difference in the productivity of investment.

Table 3.12: Differences in production functions parameters

\begin{tabular}{lcccc}
\hline \hline & \multicolumn{2}{c}{ Investment Marg. Product } & \multicolumn{2}{c}{ Elasticity of substitution } \\
& Age 18-23 months & Age 36-47 months & Age 18-23 months & Age 36-47 months \\
& $(1)$ & $(2)$ & $(3)$ & $(4)$ \\
\hline External S.E. skills & 0.367 & 0.370 & 0.093 & -0.727 \\
& $(-0.083,0.765)$ & $(-0.043,0.620)$ & $(-1.075,2.150)$ & $(-1.185,0.148)$ \\
Internal S.E. skills & 0.355 & 0.154 & 0.038 & -0.463 \\
& $(0.069,0.591)$ & $(-0.027,0.260)$ & $(-0.665,0.732)$ & $(-0.601,0.321)$ \\
Cognition & 2.409 & 0.295 & -0.900 & -0.622 \\
& $(1.499,3.368)$ & $(0.142,0.410)$ & $(-1.699,0.260)$ & $(-1.522,0.103)$ \\
Health & -0.294 & 0.061 & -0.119 & -0.249 \\
& $(-0.675,0.029)$ & $(-0.118,0.284)$ & $(-0.348,0.298)$ & $(-0.412,0.051)$ \\
\hline \hline
\end{tabular}

Note: $90 \%$ bootstrapped confidence interval in parenthesis. 100 replications. 


\subsection{3}

\section{Model fit and simulation exercises}

We will now asses whether the model can explain observed differences in terms of latent skills between pre-ChCC and post-ChCC cohorts. We compare cohort differences in abilities as shown in our data and as predicted by the production function. Since these latent variables are also estimated we compare confidence intervals of our latent variables estimates and our model estimates. We check that the confidence intervals overlap for internal socio-emotional skills and cognition. For these variables our model is able to satisfactorily predict observed differences between cohorts. The same is not true for external socio-emotional skills, for which our model predicts only the sign of the difference but underestimates its magnitude. The parental socioemotional abilities are measured using a personality test that does not measure aggresive behavior and attentional problems, the components of externalising score. Hence, we cannot predict the variation in externalising abilities as well as in other latent traits.

Table 3.13: Observed and predicted value of children abilities - Age 18-23 months

\begin{tabular}{lcccc}
\hline \hline & \multicolumn{2}{c}{ Age 18-23 months } & \multicolumn{2}{c}{ Age 36-47 months } \\
& Observed & Predicted & Observed & Predicted \\
& $(1)$ & $(2)$ & $(3)$ & $(4)$ \\
\hline External S.E. skills & 0.806 & 0.376 & 0.856 & 0.431 \\
& $(0.603,1.031)$ & $(0.262,0.543)$ & $(0.715,0.995)$ & $(0.342,0.503)$ \\
Internal S.E. skills & 0.303 & 0.252 & 0.252 & 0.232 \\
& $(0.247,0.392)$ & $(0.202,0.331)$ & $(0.225,0.319)$ & $(0.199,0.277)$ \\
Cognition & 0.910 & 1.012 & -0.310 & -0.185 \\
& $(0.818,1.113)$ & $(0.901,1.113)$ & $(-0.443,-0.174)$ & $(-0.242,-0.123)$ \\
\hline \hline
\end{tabular}

Note: Bootstrapped confidence interval in brackets. 100 replications.

As ChCC contemplates a range of actions targeted at vulnerable children and families it is a natural step to analyse whether differences in child abilities associated with $\mathrm{ChCC}$ depend on family characteristics. We plot predicted differences between post-ChCC and pre-ChCC cohorts against deciles of parental cognition in figure 3.3.

For the 18-23 months age group, families with high level of cognition appear to have benefited the least from ChCC. In this group, the highest impacts are found for families in the middle of the distribution when considering effects on a child's socio-emotional abilities and for families at bottom of the distribution when considering impacts on a child's cognitive abilities. The story reverses once we look at the children of 36-47 months of age: the programme's effects appears to increase with parental cognition ${ }^{22}$.

\footnotetext{
${ }^{22}$ Here the exception is child's cognition for which the programme is associated with
} 
Figure 3.3: ChCC predicted effect along parental cognition distribution
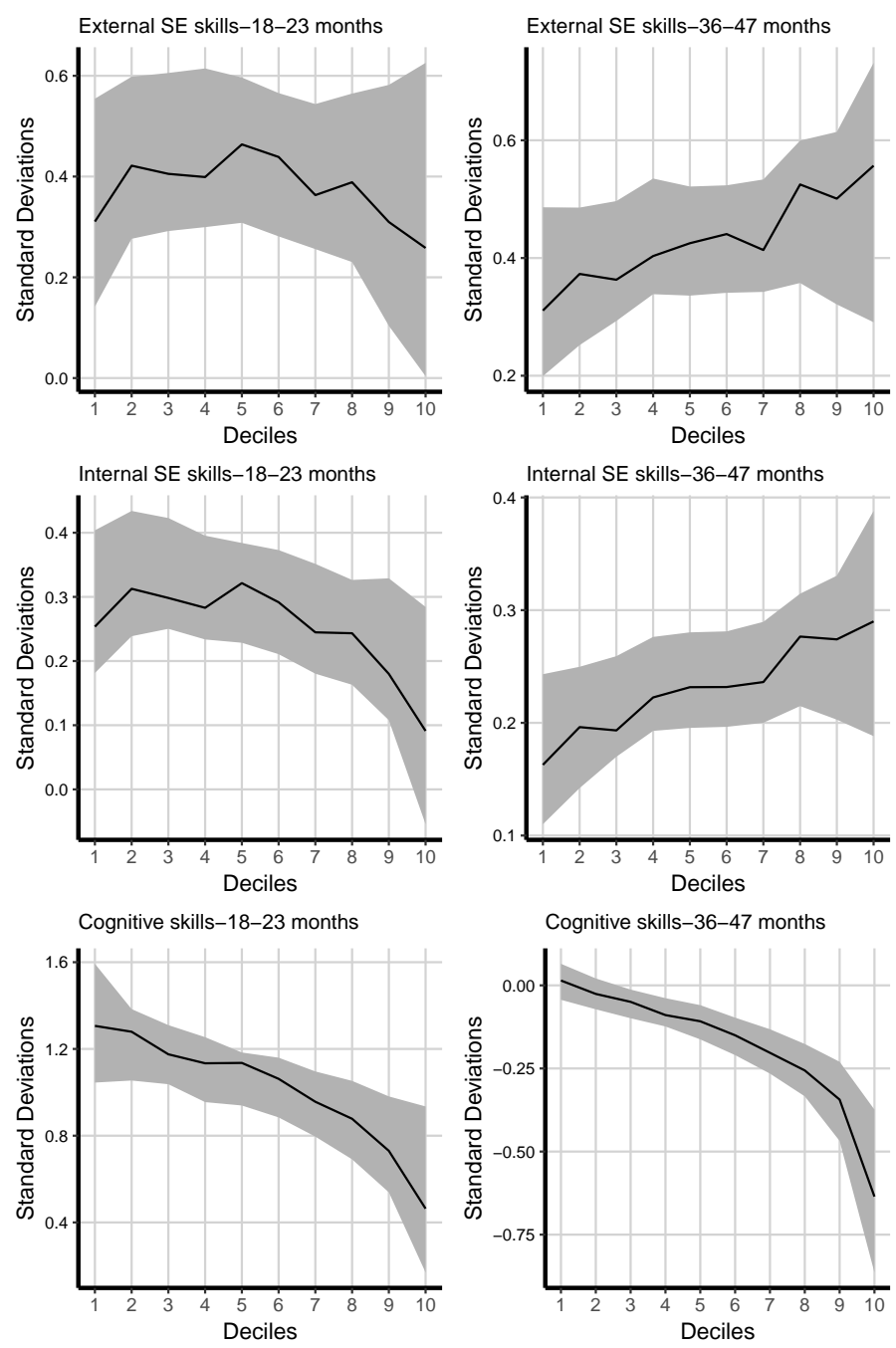

Source: Own elaboration based on production function results

As we have shown before, the technology of skill production and the quantity of inputs - essentially the investment level - change after the implementation of ChCC. We attempt to separate the part of ChCC effect associated with changes in the input levels from the total effect of $\mathrm{ChCC}$, which also includes changes in the technology of skill production. In order to do that, we estimate differences between the pre and post $\mathrm{ChCC}$ cohorts fixing the production function parameters at the pre-ChCC levels. We call this statistic the Quantity effect. The results are in Table 3.14. Changes in the technology of production function explains between $80 \%-40 \%$ of the average effect of ChCC on socio-emotional abilities. For cognitive abilities, in age 18-23 months all the effect appears from differences in technology of production while for the 36-47 months age group all the negative impact also arises almost exclusively due to changes in technology.

negative effects and these effects are less negative for families with lowest levels of cognition 
Table 3.14: ChCC effect on children abilities with and without a change in production function

\begin{tabular}{lcccc}
\hline \hline & \multicolumn{2}{c}{ Age 18-23 months } & \multicolumn{2}{c}{ Age 36-47 months } \\
& Total effect & Quantity effect & Total effect & Quantity effect \\
& $(1)$ & $(2)$ & $(3)$ & $(4)$ \\
\hline External S.E. skills & 0.376 & 0.098 & 0.431 & 0.075 \\
& $(0.262,0.543)$ & $(0.023,0.227)$ & $(0.342,0.503)$ & $(0.016,0.143)$ \\
Internal S.E. skills & 0.252 & 0.085 & 0.232 & 0.134 \\
& $(0.202,0.331)$ & $(0.029,0.172)$ & $(0.199,0.277)$ & $(0.080,0.171)$ \\
Cognition & 1.012 & 0.059 & -0.185 & 0.003 \\
& $(0.901,1.113)$ & $(-0.018,0.151)$ & $(-0.242,-0.123)$ & $(-0.060,0.064)$ \\
\hline \hline
\end{tabular}

Note: Bootstrapped confidence interval in brackets. 100 replications.

Figure 3.4 shows ratio of quatity to total effect, as defined above per decile of parental cognition. The patterns for the younger age group shows that the percentage of total explained by level of parental investment decreases with parental ability decile. For those in the lower ability deciles the policy affected levels of investments while for those at the top of the ability decile the policy appears to have affected only the productivity of that investment. For the older age group we are not able to identify a clear pattern.

\section{6}

\section{conclusion}

This article offers a structural assessment of the national policy Chile Crece Contigo. We estimate a production function of children abilities and health for cohorts before and after the national expansion of ChCC. Our methodology allows us to separate the effects between changes in the magnitude of latent variables and changes in the parameters of the production function. The former are associated with changes in parental investment and child abilities while the latter is associated with changes in the productivity of inputs in our production function.

We find that families exposed to ChCC since gestation are characterised by higher levels of parent-child interaction and children with higher levels of socio-emotional abilities with an ambiguous result for children's cognitive abilities. In terms of productivity, we find gains in the productivity of investment associated with ChCC only for our young age groups. The policy emphasises the reduction of inequalities in the development of early-childhood within Chile by devising specific actions for vulnerable children and their families. Our results suggest that $\mathrm{ChCC}$ had its intended effects of higher impacts on vulnerable populations only for children up to two years old. For children of 3-4 years of age we find evidence of the opposite, least vulnerable families appear to benefit most from the policy. 
Figure 3.4: Proportion of ChCC quantity effect along parental cognition distribution
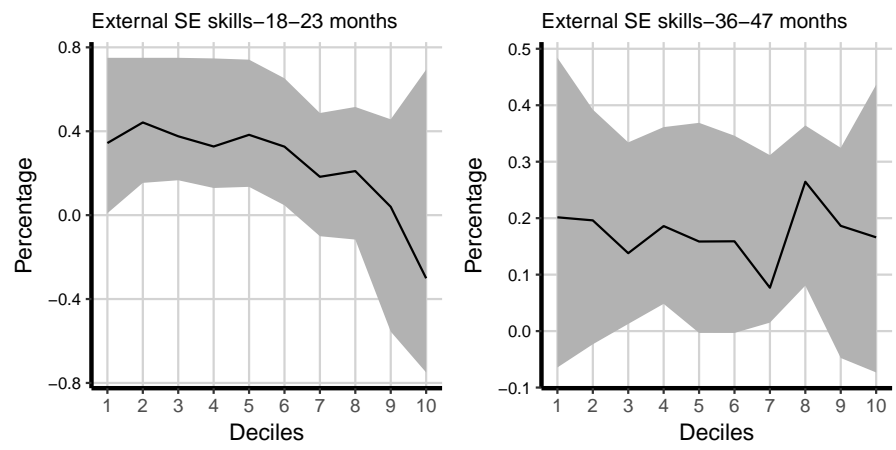

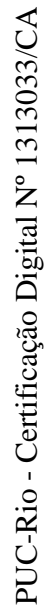
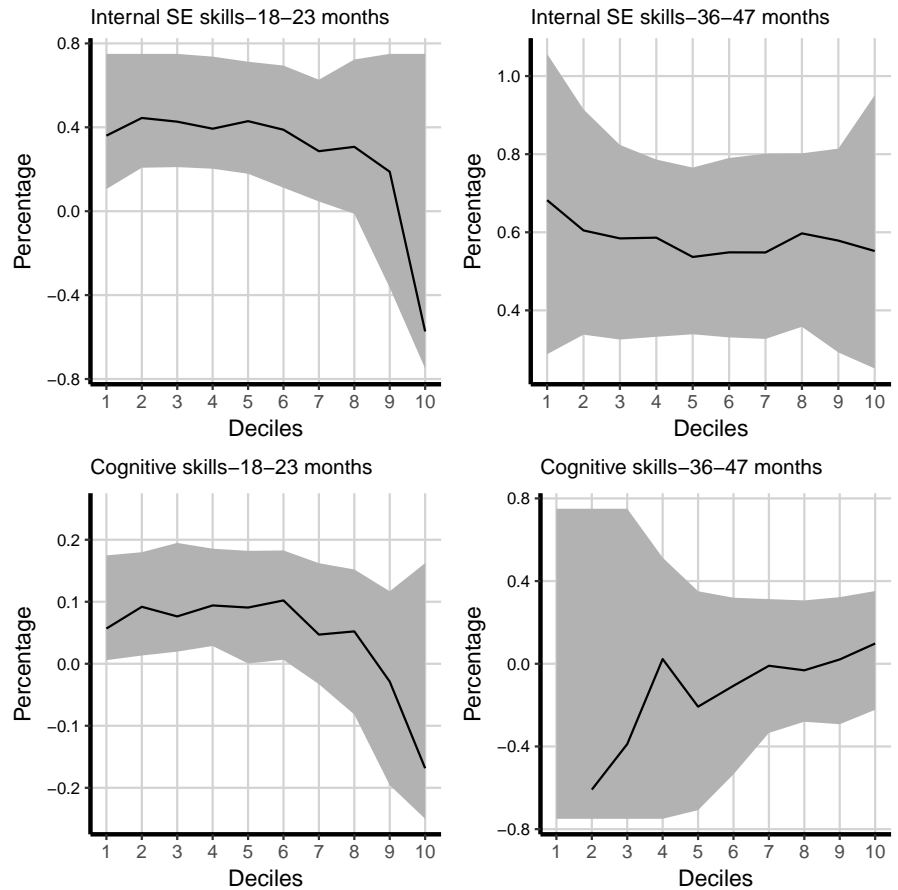

Source: Own elaboration based on production function results 


\section{Bibliography}

[1] AGUIAR PALMA, M.; ROMAN EYZAGUIRRE, S.. An structural assessment of chile crece contigo. Unpublished manuscript, 2017.

[2] FERNÁNDEZ, R.. Does culture matter? Technical report, National Bureau of Economic Research, 2010.

[3] ALESINA, A.; GIULIANO, P.. Culture and institutions. Journal of Economic Literature, 53(4):898-944, 2015.

[4] CHRISTOPOULOU, R.; LILLARD, D. R.. Is smoking behavior culturally determined? evidence from british immigrants. Journal of economic behavior \& organization, 110:78-90, 2015.

[5] ATKIN, D.. The caloric costs of culture: Evidence from indian migrants. The American Economic Review, 106(4):1144-1181, 2016.

[6] SINGH, G. K.; KOGAN, M. D. ; DEE, D. L.. Nativity/immigrant status, race/ethnicity, and socioeconomic determinants of breastfeeding initiation and duration in the united states, 2003. Pediatrics, 119(Supplement 1):S38-S46, 2007.

[7] MEREWOOD, A.; BROOKS, D.; BAUCHNER, H.; MACAULEY, L. ; MEHTA, S. D.. Maternal birthplace and breastfeeding initiation among term and preterm infants: a statewide assessment for massachusetts. Pediatrics, 118(4):e1048-e1054, 2006.

[8] KIMBRO, R. T.; LYNCH, S. M. ; MCLANAHAN, S.. The influence of acculturation on breastfeeding initiation and duration for mexican-americans. Population Research and Policy Review, 27(2):183199, 2008.

[9] GRIFFITHS, L. J.; TATE, A. R.; DEZATEUX, C.; GROUP, M. C. S. C. H. ; OTHERS. The contribution of parental and community ethnicity to breastfeeding practices: evidence from the millennium cohort study. International Journal of Epidemiology, 34(6):1378-1386, 2005. 
[10] LEE, H. J.; ElO, I. T.; MCCOlluM, K. F. ; CULHANE, J. F.. Racial/ethnic differences in breastfeeding initiation and duration among low-income inner-city mothers. Social science quarterly, 90(5):1251-1271, 2009.

[11] BRICK, A.; NOLAN, A.. Maternal country of birth differences in breastfeeding at hospital discharge in ireland. The Economic and Social Review, 45(4, Winter):455-484, 2014.

[12] MCKINNEY, C. O.; HAHN-HOLBROOK, J.; CHASE-LANSDALE, P. L.; RAMEY, S. L.; KROHN, J.; REED-VANCE, M.; RAJU, T. N.; SHALOWITZ, M. U. ; OTHERS. Racial and ethnic differences in breastfeeding. Pediatrics, 138(2):e20152388, 2016.

[13] BARANOWSKI, T.; BEE, D. E.; RASSIN, D. K.; RICHARDSON, C. J.; BROWN, J. P.; GUENTHER, N. ; NADER, P. R.. Social support, social influence, ethnicity and the breastfeeding decision. Social science \& medicine, 17(21):1599-1611, 1983.

[14] HOHL, S.; THOMPSON, B.; ESCAREÑO, M. ; DUGGAN, C.. Cultural norms in conflict: Breastfeeding among hispanic immigrants in rural washington state. Maternal and child health journal, p. 1-9, 2016.

[15] GALLEGOS, D.; VICCA, N. ; STREINER, S.. Breastfeeding beliefs and practices of african women living in brisbane and perth, australia. Maternal \& child nutrition, 11(4):727-736, 2015.

[16] NOLAN, A.; LAYTE, R.. The 'healthy immigrant effect': breastfeeding behaviour in ireland. The European Journal of Public Health, p. cku177, 2014.

[17] VANDERLINDEN, K.; LEVECQUE, K. ; VAN ROSSEM, R.. Breastfeeding or bottled milk? poverty and feeding choices in the native and immigrant population in belgium. Journal of Immigrant and Minority Health, 17(2):319-324, 2015.

[18] DENNIS, C.-L.. Breastfeeding initiation and duration: A 19902000 literature review. Journal of Obstetric, Gynecologic, \& Neonatal Nursing, 31(1):12-32, 2002.

[19] LEÓN-CAVA, N.; LUTTER, C.; ROSS, J. ; MARTIN, L.. Quantifying the benefits of breastfeeding: a summary of the evidence. Pan American Health Organization, Washington DC, 2002. 
[20] HORTA, B. L.; VICTORA, C. G.. Long-term effects of breastfeeding: A systematic review. World Health Organization, 2013.

[21] HORTA, B. L.; VICTORA, C. G.. Short-term effects of breastfeeding: A systematic review on the benefits of breastfeeding on diarrhoea and pneumonia mortality. World Health Organization, 2013.

[22] FEARON, J. D.. Ethnic and cultural diversity by country. Journal of Economic Growth, 8(2):195-222, 2003.

[23] LJUNGE, M.. Social capital and health: Evidence that ancestral trust promotes health among children of immigrants. Economics \& Human Biology, 15:165-186, 2014.

[24] AKERLOF, G. A.; KRANTON, R. E.. Economics and identity. The Quarterly Journal of Economics, 115(3):715-753, 2000.

[25] BISIN, A.; PATACCHINI, E.; VERDIER, T. ; ZENOU, Y.. Formation and persistence of oppositional identities. European Economic Review, 55(8):1046-1071, 2011.

[26] BISIN, A.; VERDIER, T.. The economics of cultural transmission and socialization. Handbook of Social Economics, p. nc, 2010.

[27] BISIN, A.; PATACCHINI, E.; VERDIER, T. ; ZENOU, Y.. Bend it like beckham: Ethnic identity and integration. European Economic Review, 2016.

[28] ABRAMITZKY, R.; BOUSTAN, L. P. ; ERIKSSON, K.. Cultural assimilation during the age of mass migration. Working Paper 22381, National Bureau of Economic Research, July 2016.

[29] del Cid Lucero, V. M., editor. Antecedentes, situación actual y perspectivas de la salud intercultural en América Latina. URACCAN (Universidad de las Regiones Autónomas de la Costa Caribe Nicaragüense), 2008.

[30] UNICEF; FUNPROEIB ANDES. Atlas sociolingüístico de pueblos indígenas en América Latina. FUNPROEIB Andes, 2009.

[31] HENDERSON, P. V.. The course of Andean history. UNM Press, 2013. 
[32] LOCKHART, J.; SCHWARTZ, S. B.. Early Latin America: A History of Colonial Spanish America and Brazil, volumen 46. Cambridge University Press, 1983.

[33] ABERCROMBIE, T. A.. The politics of sacrifice: an Aymara cosmology in action. PhD thesis, University of Chicago, 1986.

[34] GRIESHABER, E. P.. Survival of indian communities in nineteenth-century bolivia: A regional comparison. Journal of Latin American Studies, 12(02):223-269, 1980.

[35] ALBÓ, X.. Aymaras entre bolivia, perú y chile. Estudios Atacameños. Arqueología y antropología surandinas, (19):43-74, 2000.

[36] INEI. Peru: Migracion Interna Reciente y el Sistema de Ciudades 2001-2007. PRINLEY SRL, 2011.

[37] EVIA, J. L.; URQUIOLA, M. S.; ANDERSEN, L.; ANTELO, E. ; NINA, O.. Geography and development in bolivia: Migration, urban and industrial concentration, welfare, and convergence: 1950-1992. 1999.

[38] THORVALDSEN, G.. Was there a european breastfeeding pattern? The History of the Family, 13(3):283-295, 2008.

[39] SPANISH PEDIATRICS ASSOCIATION. Lactancia materna: guía para profesionales, 2004.

[40] BernabeU-MeSTRE, J.. Problèmes de santé et causes de décès infantiles en espagne, 1900-1935. In: ANNALES DE DÉMOGRAPHIE HISTORIQUE, volumen 1994, p. 61-77. Persée-Portail des revues scientifiques en SHS, 1994.

[41] CAMINO, L.. Lactancia: una práctica que trasciende los tiempos. Rev. peru. epidemiol.(Online), 8(2):33-42, 1995.

[42] PARRAGA, I. M.. Dietary beliefs, nutritional patterns and nutritional status of urban Aymara women and children. PhD thesis, Case Western Reserve University, 1992.

[43] REAL ACADEMIA ESPAÑOLA. Diccionario de la lengua española. 2014. 
[44] AJACOPA, T. L.; CAZAZOLA, E.; PAIRUMANI, F. L.; MARTÍNEZ, P. P. ; PAZ-BOLIVIA, L.. Diccionario bilingüe iskay simipi yuyayk'ancha. La Paz, 2007.

[45] YAPU, M.. Primera infancia: experiencias y políticas públicas en Bolivia: aporte a la educación actual. 2010.

[46] MOORE, E. R.; ANDERSON, G. C. ; BERGMAN, N.. Early skin-to-skin contact for mothers and their healthy newborn infants. Cochrane Database of Systematic Reviews, 2012.

[47] BAKER, M.; MILLIGAN, K.. Maternal employment, breastfeeding, and health: Evidence from maternity leave mandates. Journal of health economics, 27(4):871-887, 2008.

[48] MANDAL, B.; ROE, B. E. ; FEIN, S. B.. Work and breastfeeding decisions are jointly determined for higher socioeconomic status us mothers. Review of Economics of the Household, 12(2):237-257, 2014.

[49] HUANG, R.; YANG, M.. Paid maternity leave and breastfeeding practice before and after california's implementation of the nation's first paid family leave program. Economics \& Human Biology, 16:45-59, 2015.

[50] GRUMMER-STRAWN, L. M.. The effect of changes in population characteristics on breastfeeding trends in fifteen developing countries. International Journal of Epidemiology, 25(1):94-102, 1996.

[51] JAYACHANDRAN, S.; KUZIEMKO, I.. Why do mothers breastfeed girls less than boys? evidence and implications for child health in india. The Quarterly Journal of Economics, 126(3):1485-1538, 2011.

[52] ALTAMIRANO, T.. Migración y estrategias de supervivencia de origen rural entre los campesinos de la ciudad. Anthropologica, 1(1):127-158, 1983.

[53] FERNANDEZ, R.; FOGLI, A.. Culture: An empirical investigation of beliefs, work, and fertility. American Economic Journal: Macroeconomics, 1(1):146-177, 2009.

[54] CURRIE, J.. Healthy, wealthy, and wise: Socioeconomic status, poor health in childhood, and human capital development. Journal of Economic Literature, 47(1):87-122, 2009. 
[55] GUXENS, M.; MENDEZ, M. A.; MOLTÓ-PUIGMARTÍ, C.; JULVEZ, J.; GARCÍA-ESTEBAN, R.; FORNS, J.; FERRER, M.; VRIJHEID, M.; LÓPEZSABATER, M. C. ; SUNYER, J.. Breastfeeding, long-chain polyunsaturated fatty acids in colostrum, and infant mental development. Pediatrics, 128(4):e880-e889, 2011.

[56] VICTORA, C. G.; HORTA, B. L.; DE MOLA, C. L.; QUEVEDO, L.; PINHEIRO, R. T.; GIGANTE, D. P.; GONÇALVES, H. ; BARROS, F. C.. Association between breastfeeding and intelligence, educational attainment, and income at 30 years of age: a prospective birth cohort study from brazil. The Lancet Global Health, 3(4):e199-e205, 2015.

[57] BISIN, A.; VERDIER, T.. The economics of cultural transmission and the dynamics of preferences. Journal of Economic theory, 97(2):298-319, 2001.

[58] LEE, S.; KELLEHER, S. L.. Biological underpinnings of breastfeeding challenges: the role of genetics, diet, and environment on lactation physiology. American Journal of Physiology - Endocrinology and Metabolism, 311(2):E405-E422, 2016.

[59] MOSSBRUCKER, H.. Amerindian migration in peru and mexico. 1997.

[60] PINO, P. D.; DEL PINO, P.. Repensar la desnutrición: infancia, alimentación y cultura en Ayacucho, Perú. Número 612.3 362.19639. 2012.

[61] ATTANASIO, O. P.. The determinants of human capital formation during the early years of life: Theory, measurement, and policies. Journal of the European Economic Association, 13(6):949-997, 2015.

[62] CUNHA, F.; HECKMAN, J. J.; LOCHNER, L. ; MASTEROV, D. V.. Interpreting the evidence on life cycle skill formation. Handbook of the Economics of Education, 1:697-812, 2006.

[63] HANNON, P.. Developmental neuroscience: implications for early childhood intervention and education. Current Paediatrics, 13(1):58-63, 2003.

[64] KNUDSEN, E. I.. Sensitive periods in the development of the brain and behavior. Journal of cognitive neuroscience, 16(8):1412-1425, 2004. 
[65] KNUDSEN, E. I.; HECKMAN, J. J.; CAMERON, J. L. ; SHONKOFF, J. P.. Economic, neurobiological, and behavioral perspectives on building america's future workforce. Proceedings of the National Academy of Sciences, 103(27):10155-10162, 2006.

[66] NEWPORT, E.. Language Development, Critical Periods in. John Wiley \& Sons, Ltd, 2006.

[67] DOYLE, O.; HARMON, C. P.; HECKMAN, J. J. ; TREMBLAY, R. E.. Investing in early human development: timing and economic efficiency. Economics \& Human Biology, 7(1):1-6, 2009.

[68] ALMOND, D.; CURRIE, J.. Killing me softly: The fetal origins hypothesis. The Journal of Economic Perspectives, 25(3):153-172, 2011.

[69] OLDS, D. L.. Prenatal and infancy home visiting by nurses: From randomized trials to community replication. Prevention Science, 3(3):153-172, 2002.

[70] HOWARD, K. S.; BROOKS-GUNN, J.. The role of home-visiting programs in preventing child abuse and neglect. The future of Children, 19(2):119-146, 2009.

[71] DOYLE, O.; HARMON, C.; HECKMAN, J. J.; LOGUE, C. ; MOON, S. H.. Early skill formation and the efficiency of parental investment: A randomized controlled trial of home visiting. Labour Economics, 45:40 - 58, 2017. Field experiments in labor economics and social policies.

[72] BEDREGAL, P.. Chile crece contigo: el desafío de la protección social a la infancia. Report, Facultad de Medicina de la Pontifica Universidad Católica de Chile, November 2013.

[73] ASESORÍAS PARA EL DESARROLLO. Informe final de la evaluación de impacto del sistema de protección integral a la infancia (chile crece contigo, ccc). Articulos de la Dirección de Presupuesto Gobierno de Chile, 2013.

[74] MINISTERIO DE PLANIFICACION. Ley 20379 crea el sistema intersectorial de protecciǿn social e institucionaliza el subsistema de protecciǿn integral a la infancia "chile crece contigo", 2009.

[75] SILVA, V.; MOLINA, H.. Cuatro años creciendo juntos: memoria de la instalación del sistema de protección integral a la infancia Chile Crece Contigo 2006-2010. Santiago: MIDEPLAN., 2010. 
[76] Bedregal, P.; TORRES, A. ; CARVAllO, C.. Chile crece contigo: el desafío de la protección social a la infancia. Working paper, UNDP Chile, December 2014.

[77] STRAIN, H.. Norma Tecnica para la supervision de niños y niñas de 0 a 9 años en la Atencion Primaria de Salud. Ministerio de Salud Chile, 2014.

[78] MORAGA, C.. Orientaciones tecnicas visita domiciliaria integral para el desarrollo biopsicosocial de la infancia. Technical report, Ministerio de Salud Chile, 2009.

[79] HERRERA, R.; LARRAÑAGA, O. ; TELIAS, A.. La ficha de protección social. Documento de Trabajo, 3, 2010.

[80] BEHRMAN, J.; BRAVO, D. ; URZÚA, S.. Encuesta longitudinal de la primera infancia: Aspectos metodológicos y primeros resultados. Report, Departamento de Economia Universidad de Chile, December 2010.

[81] ACHENBACH, T. M.. The classification of children's psychiatric symptoms: A factor-analytic study. Psychological Monographs: general and applied, 80(7):1, 1966.

[82] HUAQING QI, C.; KAISER, A. P.. Behavior problems of preschool children from low-income families: Review of the literature. Topics in early childhood special education, 23(4):188-216, 2003.

[83] ACHENBACH, T. M.; EDELBROCK, C. ; HOWELL, C. T.. Empirically based assessment of the behavioral/emotional problems of 2-and 3-year-old children. Journal of abnormal child psychology, 15(4):629-650, 1987.

[84] THOMPSON, R. A.. Early attachment and later development: Familiar questions, new answers. 2008.

[85] BARKER, E. D.; JAFFEE, S. R.; UHER, R. ; MAUGHAN, B.. The contribution of prenatal and postnatal maternal anxiety and depression to child maladjustment. Depression and anxiety, 28(8):696-702, 2011.

[86] WEIKART, D. P.; OTHERS. Longitudinal results of the ypsilanti perry preschool project. final report. volume ii of 2 volumes. 1970. 
[87] HECKMAN, J. J.; MOON, S. H.; PINTO, R.; SAVELYEV, P. A. ; YAVITZ, A.. The rate of return to the highscope perry preschool program. Journal of public Economics, 94(1):114-128, 2010.

[88] CAMPBElL, F. A.; RAMEY, C. T.; PUngEllo, E.; SPARLING, J. ; MILLER-JOHNSON, S.. Early childhood education: Young adult outcomes from the abecedarian project. Applied developmental science, 6(1):42-57, 2002.

[89] MALUCCIO, J. A.; HODDINOTT, J.; BEHRMAN, J. R.; MARTORELL, R.; QUISUMBING, A. R. ; STEIN, A. D.. The impact of improving nutrition during early childhood on education among guatemalan adults. The Economic Journal, 119(537):734-763, 2009.

[90] WALKER, S. P.; CHANG, S. M.; POWELL, C. A. ; GRANTHAMMCGREGOR, S. M.. Effects of early childhood psychosocial stimulation and nutritional supplementation on cognition and education in growth-stunted jamaican children: prospective cohort study. The lancet, 366(9499):1804-1807, 2005.

[91] GLOVER, V.. Maternal depression, anxiety and stress during pregnancy and child outcome; what needs to be done. Best practice \& research Clinical obstetrics \& gynaecology, 28(1):25-35, 2014.

[92] SCHULZ, L. C.. The dutch hunger winter and the developmental origins of health and disease. Proceedings of the National Academy of Sciences, 107(39):16757-16758, 2010.

[93] SCHOLTE, R. S.; VAN DEN BERG, G. J. ; LINDEBOOM, M.. Longrun effects of gestation during the dutch hunger winter famine on labor market and hospitalization outcomes. Journal of health economics, 39:17-30, 2015.

[95] CUNHA, F.; HECKMAN, J. J. ; SCHENNACH, S. M.. Estimating the technology of cognitive and noncognitive skill formation. Econometrica, 78(3):883-931, 2010.

[96] ATTANASIO, O. P.; FERNÁNDEZ, C.; FITZSIMONS, E. O.; GRANTHAMMCGREGOR, S. M.; MEGHIR, C. ; RUBIO-CODINA, M.. Using the infrastructure of a conditional cash transfer program to deliver a scalable integrated early child development program in colombia: cluster randomized controlled trial. BMJ, 349:g5785, 2014. 
[97] ATTANASIO, O.; CATTAN, S.; FITZSIMONS, E.; MEGHIR, C. ; RUBIOCODINA, M.. Estimating the production function for human capital: Results from a randomized control trial in colombia. Technical report, National Bureau of Economic Research, 2015.

[98] ATTANASIO, O.; MEGHIR, C. ; NIX, E.. Human capital development and parental investment in india. Technical report, National Bureau of Economic Research, 2015.

[99] WOOLDRIDGE, J. M.. Econometric analysis of cross section and panel data. MIT press, 2010.

[100] WILlCUTT, E. G.; DOYLE, A. E.; NIGG, J. T.; FARAONE, S. V. ; PENNINGTON, B. F.. Validity of the executive function theory of attention-deficit/hyperactivity disorder: a meta-analytic review. Biological psychiatry, 57(11):1336-1346, 2005.

[101] FORD, S.; FARAH, M. S.; SHERA, D. M. ; HURT, H.. Neurocognitive correlates of problem behavior in environmentally at-risk adolescents. Journal of Developmental \& Behavioral Pediatrics, 28(5):376385, 2007.

[102] ANDERSON, P.. Assessment and development of executive function (ef) during childhood. Child neuropsychology, 8(2):71-82, 2002.

[103] LIU, J.. Childhood externalizing behavior: theory and implications. Journal of child and adolescent psychiatric nursing, 17(3):93-103, 2004.

[104] BERNAL, R.; ATTANASIO, O.; PEÑA, X. ; VERA-HERNÁNDEZ, M.. Efectos de la Transición de Educación Inicial Comunitaria a Atención en Centros de Desarrollo Infantil en Colombia. DOCUMENTOS CEDE 014067, UNIVERSIDAD DE LOS ANDES-CEDE, Nov. 2015.

[105] WEILAND, C.; YOSHIKAWA, H.. Impacts of a prekindergarten program on children's mathematics, language, literacy, executive function, and emotional skills. Child Development, 84(6):2112-2130, 2013.

[106] HECKMAN, J. J.. Role of income and family influence on child outcomes. Annals of the New York Academy of Sciences, 1136(1):307323, 2008. 
[107] MCLACHLAN, G.; PEEL, D.. Finite mixture models. John Wiley \& Sons, 2004.

[108] ATTANASIO, O.; MEGHIR, C.; NIX, E. ; SALVATI, F.. Human capital growth and poverty: Evidence from ethiopia and peru. Review of Economic Dynamics, 25:234-259, 2017.

[109] BAI, J.. Estimation of a change point in multiple regression models. The review of economics and statistics, 79(4):551-563, 1997.

[110] PIEHL, A. M.; COOPER, S. J.; BRAGA, A. A. ; KENNEDY, D. M.. Testing for structural breaks in the evaluation of programs. The Review of Economics and Statistics, 85(3):550-558, 2003. 


\section{Chapter 2 - Additional results}

\section{A.1 \\ Chile Crece Contigo}

The following table shows statistics of ChCC activities among beneficiaries in the public health system. The activities with the highest coverage are educational sessions.

Table A.1: ChCC Statistics

\begin{tabular}{lccccc}
\hline \hline & 2008 & 2009 & 2010 & 2011 & 2012 \\
\hline $\begin{array}{l}\text { Pregnant women with psycho-social evaluation } \\
\text { (in percentage) }\end{array}$ & & 92.0 & 88.3 & 96.7 & 97.1 \\
$\begin{array}{l}\text { Pregnant women with psycho-social risk (in } \\
\text { percentage) }\end{array}$ & 28.1 & 35.9 & 34.2 & 38.1 & 38.2 \\
$\begin{array}{l}\text { Home visits per pregnant women with psycho- } \\
\text { social risks }\end{array}$ & 0.9 & 0.9 & 1.1 & 1.1 & 1.2 \\
$\begin{array}{l}\text { Participants of group educational sessions on } \\
\text { pregnancy topics per pregnant women }\end{array}$ & 0.7 & 0.9 & 1.2 & 1.1 & 1.3 \\
\hline $\begin{array}{l}\text { Children under two with psychomotor evalua- } \\
\text { tion (in percentage) }\end{array}$ & 79.5 & 80.7 & 87.0 & 88.8 \\
$\begin{array}{l}\text { Children aged 24 to 47 months with psychomo- } \\
\text { tor evaluation (in percentage) }\end{array}$ & & 32.0 & 28.8 & 31.4 & 33.0 \\
$\begin{array}{l}\text { Evaluated children with developmental deficits } \\
\text { under treatment (in percentage) }\end{array}$ & 6.4 & 6.4 & 6.6 & 6.3 & 5.7 \\
$\begin{array}{l}\text { Home visits per children with developmental } \\
\text { deficits }\end{array}$ & 0.3 & 0.8 & 1.1 & 1.3 & 1.7 \\
$\begin{array}{l}\text { Participants of group educational sessions on } \\
\text { parenting per children under six }\end{array}$ & 0.3 & 0.3 & 0.4 & 0.4 & 0.4 \\
\hline \hline
\end{tabular}

\section{A.1.1}

\section{Regional variation in ChCC expansion date}

The implementation of $\mathrm{ChCC}$ varied regionally. The programme is implemented by various ministries, its pilot cohort was done at district level, and regional administrative and implementation capacity varies. Thus it is difficult to determine when the entire population was serviced by $\mathrm{ChCC}$ in each region. The implementation of the $\mathrm{ChCC}$ happened first in districts with better infrastructure and maternity centre management capacities(75). Also, the availability of non-physician professionals, such as psychologists and social workers, conditioned the implementation of the policy(72). If we were to compare using these differences our results would be subject to bias coming from 
the moment the policy was implemented in each region. Figure A.1 depicts the differences in the moment of expansion of the policy by region.

Figure A.1: Number of first psycho-motor evaluations to children less than five in the public health system, by region
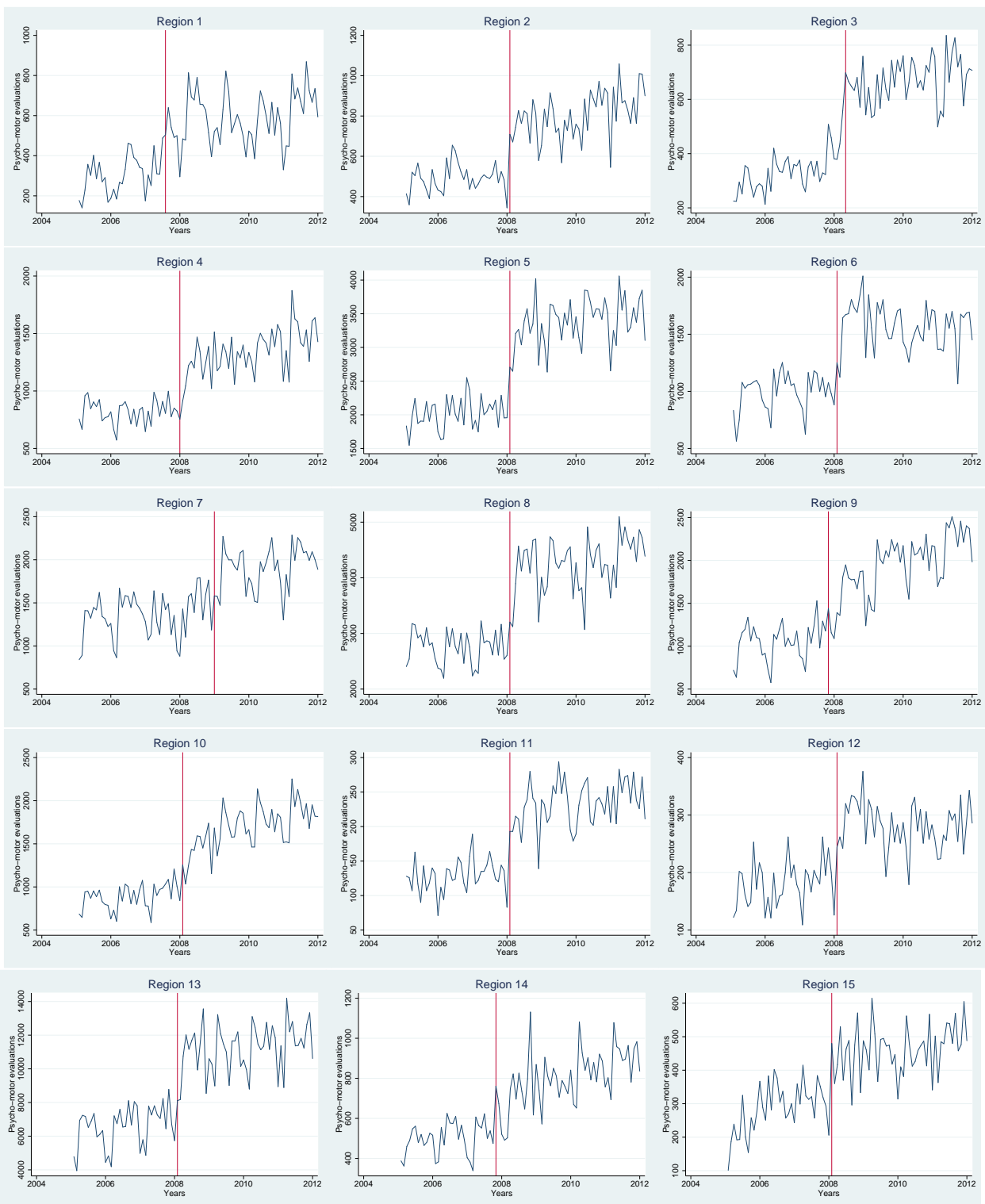

Source: DEIS Chile

Since the date when ChCC expanded is uncertain, we estimate the date of ChCC expansion by region using the health statistics time series. In order to determine the most likely moment when ChCC started by region, we test the existence of a structural break between 2007 and 2009 in the DEIS series, following the methodology detailed in (110). First we regress our programme activity variable on a time in months, controls and error term. The specification is as below.

$$
h_{t}=\alpha+\delta S_{t}+\beta_{1} t+\beta_{2} x_{t}+d_{t}+\epsilon_{t}
$$


where $h_{t}$ is the number of psycho-motor evaluations or the number of home visits, $d_{t}$ are monthly dummies, $S_{t}$ is the point of structural break, $t$ is time (in months), and $\epsilon_{t}$ is an error term.

Given a trend-stationary time-series, we test a null hypothesis that the time parameters do not change, using the Wald statistic.

$$
\begin{gathered}
H_{0}: \delta=0 \forall t \\
H_{0}: \delta \neq 0 \forall t \geq t_{0}
\end{gathered}
$$

where $t_{0}$, the moment of the structural break is unknown. We start by defining the period of possible break-point as the period between March 2007 till December 2008, this is because this cover the beginning of the ChCC pilot in June 2007 and an expansion period for the programme. Within this time window we calculate the Wald statistic for every month for every region in Chile. We choose the period which has the highest Wald statistic as our breakperiod. Our statistic of interest is hence the sup Wald.

The intuition behind our analysis is simple. The sup Wald gives the month for which our time-series are most likely to have changed. We then compare our sup Wald statistic to asymptotic critical values for the maximum Wald statistic as tabuled by Andrews (1993).

The results show evidence of a structural break in almost all regions. Figure A.2 synthesises these results by showing the sup Wald statistic, the break date for each region, and the critical value of Andrews' test (horizontal line). Notice that the maximum Wald statistic surpasses the critical value in all but one region for the psycho-motor evaluations and the home visits time series. Further in approximately $75 \%$ of regions the maximum is reached by February/2008.

We now have estimated the date of start of implementation of ChCC in each region. But we also need to take the variance of the estimated break-date into account when evaluating the effects of the programme. So, we estimate the confidence interval for our parameter of interest- the estimated break date per region- as in Bai(109) ${ }^{1}$.

Bai assumes that error term in (A-1) and the break-point variables are strictly stationary and derives the analytical density function and the

${ }^{1}$ Bai solves the following problem in order to find the break-date point.

$$
\hat{B}_{r}=\operatorname{argmin} \frac{1}{T} \sum_{t=1}^{T} \hat{\epsilon}_{r t}^{2}\left(B_{r t}\right)
$$

where $\hat{\epsilon}_{r t}^{2}\left(B_{r t}\right)$ are the predicted residuals of equation (A-1) when $B_{r t}$ is the breakpoint. This problem is equivalent to solving for break-date as in Andrews (1993) 
Figure A.2: Regional variation on the date of ChCC expansion

\section{Psycho-motors evaluations}

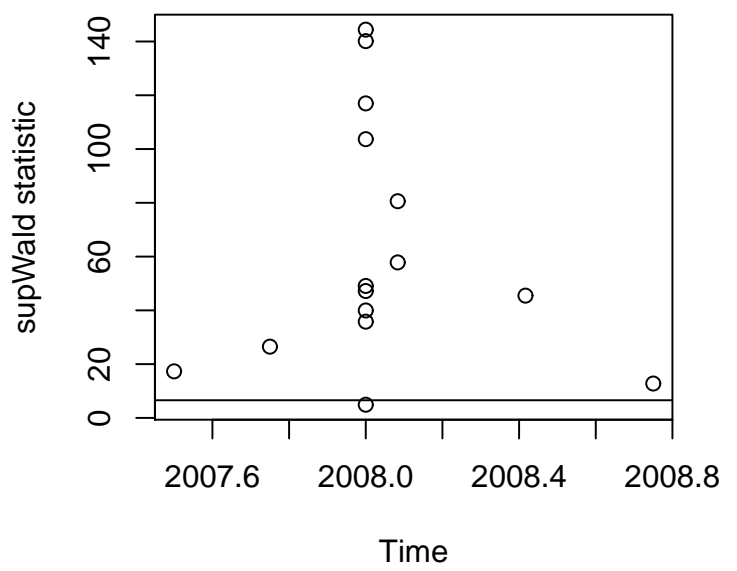

cumulative distribution function of the break point parameter ${ }^{2}$. We use the distributions to construct the confidence intervals at $95 \%$ level to be taken into account in our second stage estimations.

Table A.2 shows the confidence intervals of the regional break-points according to psycho-motor evaluation series.

Table A.2: Moment of ChCC expansion according to psycho-motor evaluation series

\begin{tabular}{lc}
\hline \hline & Break date confidence interval (in years) \\
\hline tarapaca & $2,007.917(2,007.833,2,008.000)$ \\
antofagasta & $2,007.833(2,007.417,2,008.250)$ \\
atacama & $2,007.333(2,000.833,2,013.833)$ \\
coquimbo & $2,007.167(2,006.917,2,007.417)$ \\
valparaiso & $2,008.667(2,008.417,2,008.917)$ \\
ohiggins & $2,008.083(2,007.750,2,008.417)$ \\
maule & $2,007.250(2,006.583,2,007.917)$ \\
biobio & $2,007.833(2,007.417,2,008.250)$ \\
la araucania & $2,008.167(2,008.000,2,008.333)$ \\
los lagos & $2,008.500(2,008.167,2,008.833)$ \\
aysen & $2,007.833(2,007.583,2,008.083)$ \\
magallanes & $2,008.000(2,007.750,2,008.250)$ \\
metropolitana de santiago & $2,008.250(2,008.083,2,008.417)$ \\
los rios & $2,008.000(2,007.750,2,008.250)$ \\
arica y parinacota & $2,007.167(2,006.500,2,007.833)$ \\
\hline \hline
\end{tabular}

Note: All specifications include seasonal dummies, population under five and trend.

\footnotetext{
${ }^{2}$ In ?? we tested for a unit root, using Zivot \& Andrews (2003) test. and we find that the process is stationary which is in line with the assumptions outline in Bai (109)
} 
B

\section{Chapter 3 - Additional results}

Table B.1: Sample size

\begin{tabular}{lcccc}
\hline \hline & \multicolumn{2}{c}{$18-23$ months } & \multicolumn{2}{c}{$36-47$ months } \\
Year of interview & pre-ChCC & post-ChCC & pre-ChCC & post-ChCC \\
\hline 2010 & 904 & 469 & 2638 & 0 \\
2012 & 0 & 437 & 451 & 2066 \\
\hline \hline
\end{tabular}

Table B.2: 2010 Descriptive Statistics - Socio-demographic characteristics

\begin{tabular}{lccc}
\hline \hline & \multicolumn{3}{c}{$18-23$ months } \\
\cline { 2 - 4 } & pre-ChCC & post-ChCC & P-val \\
\hline Working memory & 0.02 & -0.05 & 0.21 \\
Vocabulary & 0.07 & 0.15 & 0.18 \\
Mother education & 10.56 & 10.62 & 0.81 \\
Father education & 10.55 & 10.76 & 0.28 \\
Height & -0.01 & -0.00 & 0.90 \\
Weight & -0.09 & -0.15 & 0.43 \\
Gestation in weeks & 0.02 & 0.09 & 0.11 \\
Birth height & -0.06 & 0.00 & 0.25 \\
Birth weight & 0.02 & -0.04 & 0.35 \\
Sex of the child & 0.50 & 0.49 & 0.86 \\
Main caregiver's age & 27.55 & 27.61 & 0.81 \\
Minors $<7$ & 1.43 & 1.45 & 0.65 \\
Minors $>7$ & 0.78 & 0.77 & 0.95 \\
Parents live together & 0.62 & 0.64 & 0.74 \\
Per capita income & 11.10 & 11.06 & 0.41 \\
\hline Observations & 904 & 469 & 1300 \\
\hline \hline
\end{tabular}

Source: ELPI 2010 
Table B.3: 2012 Descriptive Statistics - Socio-demographic characteristics

\begin{tabular}{lccc}
\hline \hline & \multicolumn{3}{c}{$36-47$ months } \\
\cline { 2 - 4 } & pre-ChCC & post-ChCC & P-val \\
\hline Working memory & 0.10 & -0.01 & 0.11 \\
Vocabulary & 0.05 & 0.05 & 0.99 \\
Mother education & 11.10 & 11.01 & 0.55 \\
Father education & 11.07 & 10.89 & 0.29 \\
Height & -0.01 & 0.01 & 0.75 \\
Weight & 0.09 & 0.05 & 0.44 \\
Gestation in weeks & -0.01 & 0.00 & 0.77 \\
Birth height & -0.05 & -0.05 & 0.99 \\
Birth weight & -0.01 & -0.03 & 0.83 \\
Sex of the child & 0.51 & 0.51 & 0.93 \\
Main caregiver's age & 29.56 & 29.64 & 0.83 \\
Minors < 7 & 1.43 & 1.41 & 0.50 \\
Minors $>7$ & 0.78 & 0.77 & 0.85 \\
Parents live together & 0.63 & 0.64 & 0.66 \\
Per capita income & 11.30 & 11.32 & 0.57 \\
\hline Observations & 451 & 2066 & 2269 \\
\hline \hline Source: ELPI 2012 & &
\end{tabular}


Figure B.1: Distribution of latent variables - Age 18-23 months
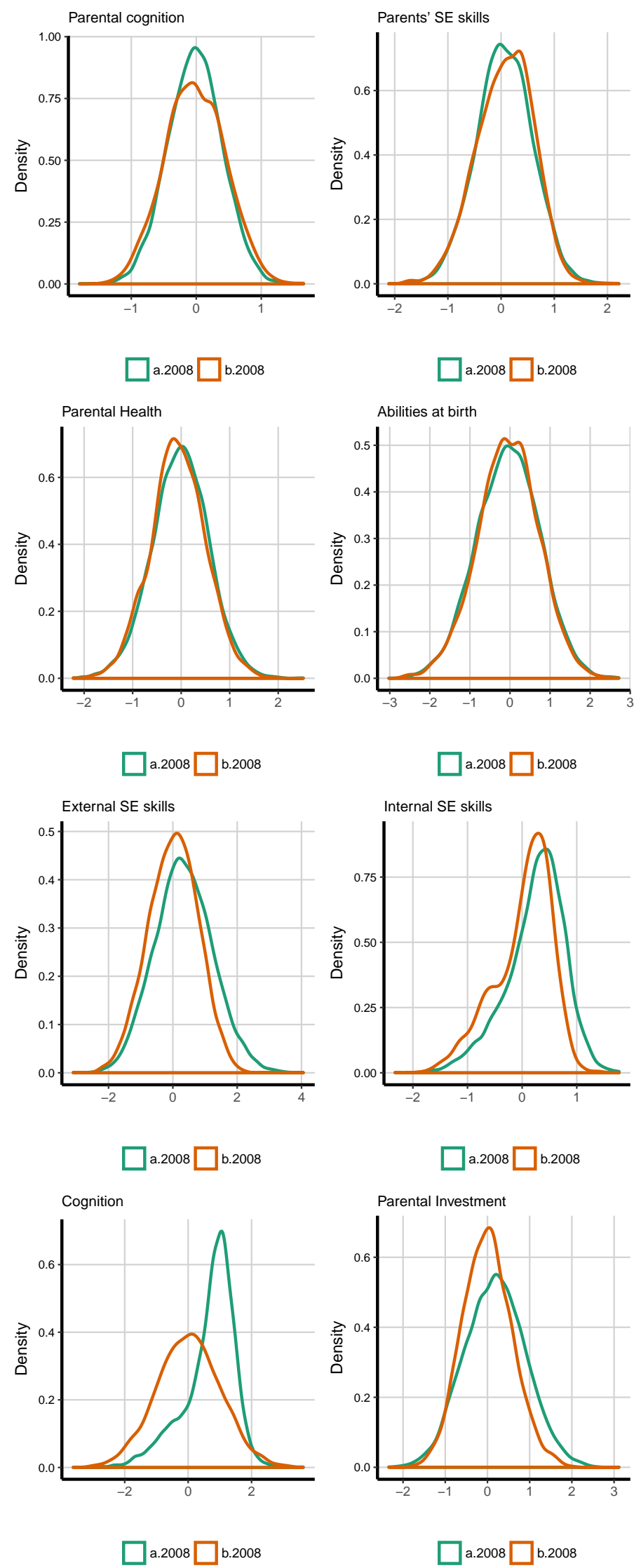
Figure B.2: Distribution of latent variables - Age 36-47 months
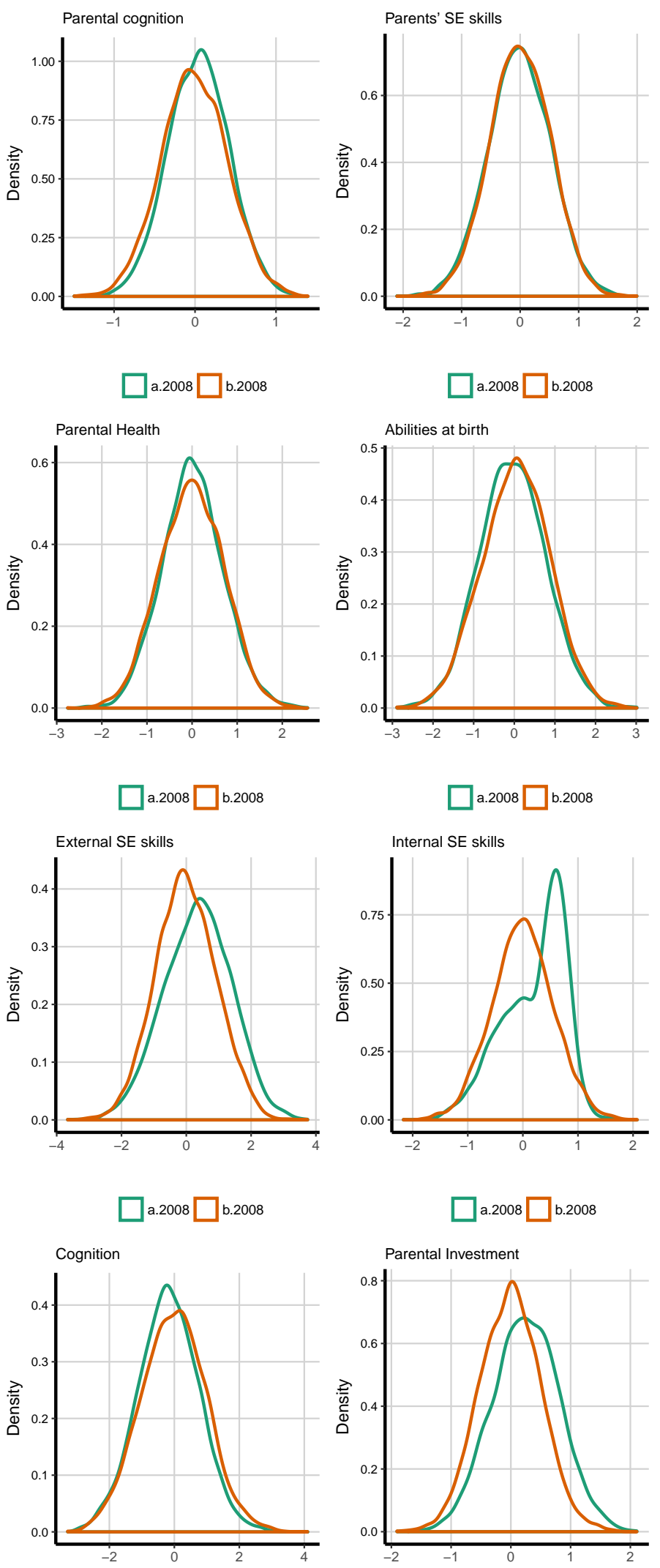

$\square$ a.2008 $\square$ b.2008

$\square$ a.2008 $\square$ b.2008 